Chapman University

Chapman University Digital Commons

Education (PhD) Dissertations

Dissertations and Theses

Summer 8-2020

\title{
Developing Trust in a Cross-Functional Workgroup: Assessing the Effectiveness of a Communication Intervention
}

Scott De Long

Chapman University, delon108@mail.chapman.edu

Follow this and additional works at: https://digitalcommons.chapman.edu/education_dissertations

Part of the Educational Assessment, Evaluation, and Research Commons

\section{Recommended Citation}

De Long, R. S. (2020). Developing trust in a cross-functional workgroup: Assessing the effectiveness of a communication intervention [Doctoral dissertation, Chapman University]. Chapman University Digital Commons. https://doi.org/10.36837/chapman.000193

This Dissertation is brought to you for free and open access by the Dissertations and Theses at Chapman University Digital Commons. It has been accepted for inclusion in Education (PhD) Dissertations by an authorized administrator of Chapman University Digital Commons. For more information, please contact laughtin@chapman.edu. 
Developing Trust in a Cross-Functional Workgroup:

Assessing the Effectiveness of a Communication Intervention

A Dissertation by
R. Scott De Long

Chapman University

Orange, CA

Attallah College of Educational Studies

Submitted in partial fulfillment of the requirements for the degree of

Doctor of Philosophy in Education

August 2020

Committee in charge:

Whitney McIntyre Miller, Ph.D., Chair

Randy Busse, Ph.D.

Dawn Hunter, Ph.D.

Barbara Bucklin, Ph.D. 
The dissertation of R. Scott De Long is approved.
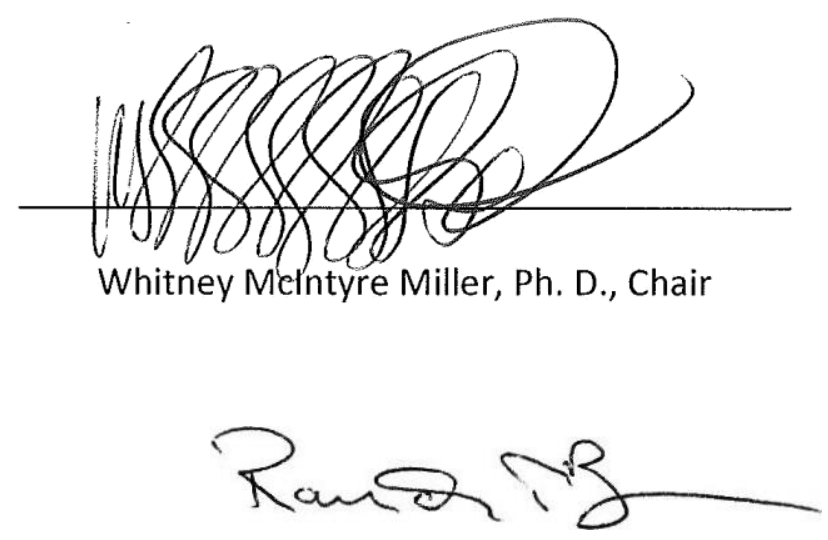

Randy Busse, Ph. D.

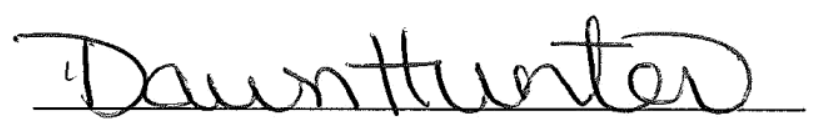

Dawn Hunter, Ph. D.

Bubina R.Buchi

Barbara Bucklin, Ph. D.

July 2020 
Developing Trust in a Cross-Functional Workgroup:

Assessing the Effectiveness of a Communication Intervention

Copyright (C) 2020

by R. Scott De Long 


\section{ACKNOWLEDGMENTS}

I would like to acknowledge my doctoral dissertation committee. They all have been instrumental in this final product, offering both insight and critique throughout the process. They have been willing to offer their expertise, counsel, and support. This committee was selected because of the impact they have made on me in my educational journey, which has translated into my professional career and my personal life.

To Dr. Whitney McIntyre Miller, your pursuit of knowledge is impressive, but more importantly, the dedication you have shown to students in both the master's and doctoral program is inspirational. You continually push me to learn and grow. Your subtle style of challenging me has led me in directions I was not sure I belonged. I have always appreciated the time you spent allowing me to vent frustrations and also see situations from a different perspective. I have taken some of these skills and incorporated them into my own work, and I have become a better person for it. More than anything, I can honestly say, without you and Dawn Hunter, I would not have returned to this program after some of the difficulties I had that initially led me to quit. It was you who convinced me to take a leave of absence rather than drop out of the program, which helped facilitate my return. I am grateful for the time I have spent with you.

To Dr. Dawn Hunter, I owe you so much respect and appreciation for helping me return to the doctoral program. Your presence and patience allowed me to believe that reengaging with the university would provide me with the opportunity to enable others to see from a different perspective. You have a gentle and loving soul that compliments your insistence on excellence, and this has guided me through my studies. You, too, have influenced my work and provided me with mentorship on how to conduct my life and achieve my personal goals. 
To Dr. Randy Busse, thank you for all you have done to influence my learning. I was impressed with you from the first day of the first class I took in the master's program. Your ability to see past dogma and doctrine has led me to look at issues with greater breadth and depth than I would have without knowing you. I have appreciated your direct and straightforward style, which is coupled with a free spirit and a unique set of traits I have admired and, at times, tried to emulate. Your guidance through the quantitative section of this dissertation has been invaluable, but it is your spirit that has been most influential in my life.

To Dr. Barbara Bucklin, I want to thank you for your willingness to participate in this journey as well. I learned so much by working with you in the private sector, and your analytical approach to problem solving and program building supported all of my efforts to implement change in the organization. Your positive critique and the advice you provided have been right on target — and so valuable. I am grateful for all you have taught me, and I sincerely appreciate the time and effort you have put into my dissertation process.

I would also like to acknowledge others who have provided support and guidance along the way. Lisa Boskovich, a member of my cohort, has been supportive throughout our time together in the doctorate program. Lisa also assisted as the outside observer for both participant groups, providing me with checks and balances, which was a beneficial reminder of the importance to reduce any potential bias. John Miller, a work associate, has been there, too, and allowed me to vent frustrations I have had during this journey, which has been more helpful than he will ever know. Ryan Mann, another work associate, is also a doctoral candidate at Walden University in forensic psychology and was always available to check my assumptions and provide support during the quantitative data analysis portion of my study. 
I would like to send a special thank you to Dr. Penny Bryan: Without you taking a leap of faith, I would never have started this journey at Chapman. Dr. Bryan spent time with me during the initial interview for the master's program, invited me to sit in a class, and was genuinely supportive. I am a nontraditional student and came from a philosophical background so different from hers and that of the program, and it had to be a difficult decision for her even to allow me into her world. As time went by, she opened my eyes and my heart to a process of leadership that was foreign to me. This has softened my approach in almost every part of my life, and I am genuinely appreciative.

I would also like to thank others in the Attallah College of Educational Studies. Several of the faculty members were presented with challenges from me in the classroom. At times they were tough, holding to the high standards expected in academia, but they were always fair, open, and willing to engage. Special recognition needs to be made to Dr. Kris DePedro and Dr. Don Cardinal, both of whom went out of their way to allow me time to reengage in their classes after an abrupt departure. I would also like to acknowledge other professors who provided me with the opportunity to push through some challenging courses, including Dr. Keith Howard, Dr. Kelly Kennedy, and Dr. Michael Haas. Thank you all.

There are others in the Chapman University community I would like to thank as well. One of those is Dr. Lisa Sparks, who allowed me the opportunity to get into the classroom in front of some wonderful young people and teach two different communication courses for an entire year. Much of what I learned working with these students, which included some very critical feedback, has informed my style of working with the business community. It was being involved in the Leatherby Center for Entrepreneurial Studies where I first engaged with the university. I would like to thank the former director, Dr. Richard Sudek, who is now at the 
University of California, Irvine, and the two directors who followed him, Dr. Gene Alexander and Dr. Shan Steinbach, for allowing me the opportunity to become involved, as a teacher's aid, a guest speaker in several classrooms, a mentor to student teams, an instructor, and a member of Dr. Steinbach's Board of Challengers.

Lastly, I would like to thank my beautiful wife, Cheryl De Long. While you never really understood why I wanted to go back to school at my age, you have always provided me with support, the time, and the resources to complete this program. Without your support, I would never have earned this degree. Thank you for the sacrifices you have made along the way.

Thank you all, as well as the unnamed individuals, within and outside of my cohort, who allowed me to exchange ideas, debate, and sometimes even argue. The past 6 years have been instrumental in my journey on becoming the man I so want to be. This experience has been challenging and a blessing. 


\begin{abstract}
Developing Trust in a Cross-Functional Workgroup:

Assessing the Effectiveness of a Communication Intervention
\end{abstract}

by R. Scott De Long

Business organizations increasingly understand the benefits of forming cross-functional teams, which include collaborative efforts on new initiatives and solving for current issues in the organization. Putting together a group of people from different disciplines, however, is not enough to obtain the results businesses are looking to achieve. To be effective, groups must form into a team. There are two distinct differences between a group and a team. To build a team, a group must coalesce around a unifying mission, understanding, and agreement on the purpose of the team and what they need to accomplish to be successful. The second qualifying factor in the formation of a team is members of the group must trust each other. I created an intervention based on developing communication techniques in a small group to build trust in a crossfunctional workgroup. The purpose of this study was to (a) examine the potential effectiveness of an intervention I created using specifically designed communication techniques to build trust in a cross-functional workgroup, (b) determine which techniques were useful, and (c) assess where improvements could be made. What the study revealed is that a cross-functional workgroup can increase the level of trust group members have with each other and the group by enhanced communication training, including empathic listening and sharing experiences.

Keywords: trust, cross-functional workgroup, transformational leadership, humility, empathy, vulnerability 


\section{TABLE OF CONTENTS}

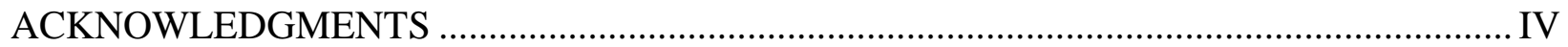

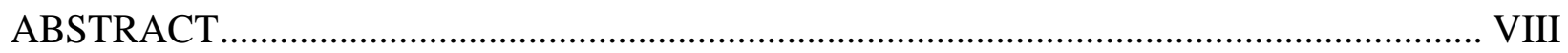

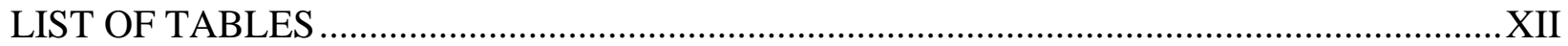

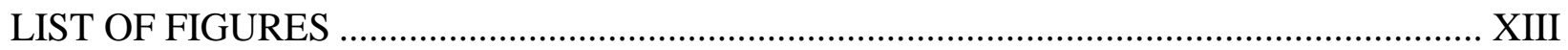

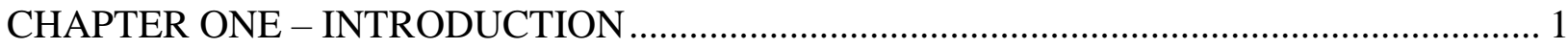

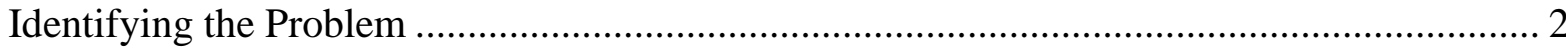

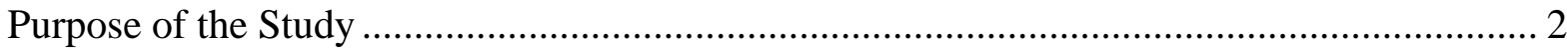

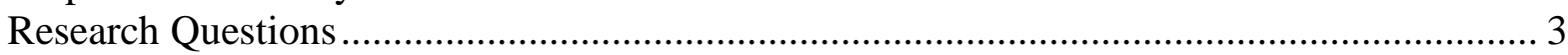

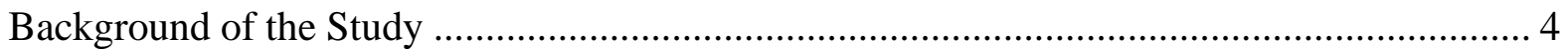

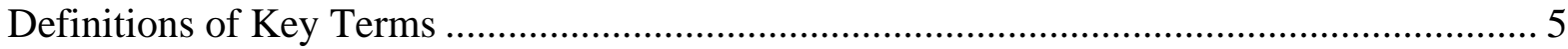

My Stance and Involvement in Personal Growth ................................................................. 7

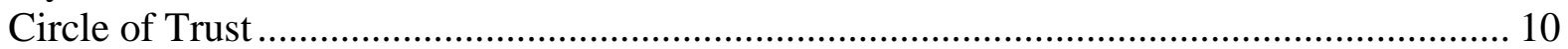

Developing a Process to Facilitate Building Trust ………................................................ 13

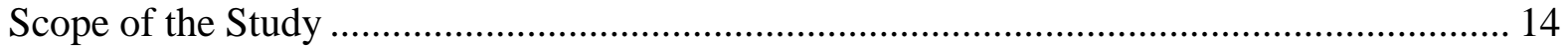

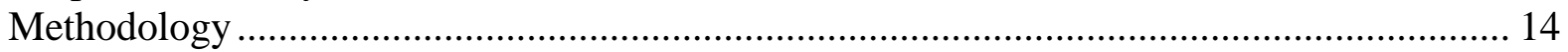

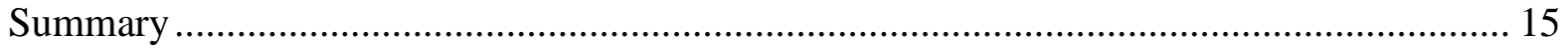

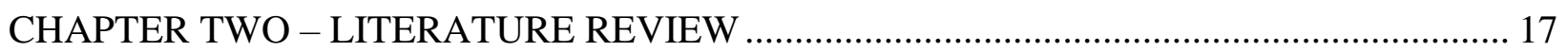

Theories of Leadership ................................................................................................ 17

Charismatic Leadership ....................................................................................... 17

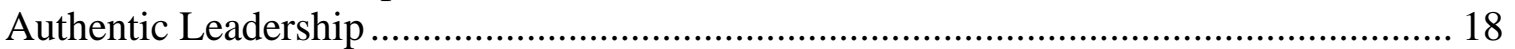

Transformational Leadership ................................................................................. 19

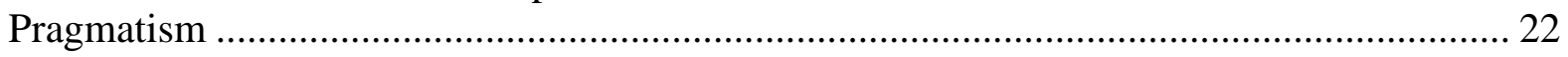

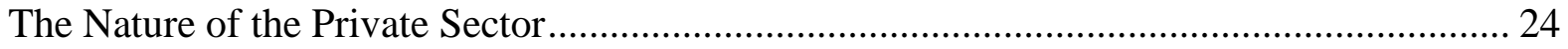

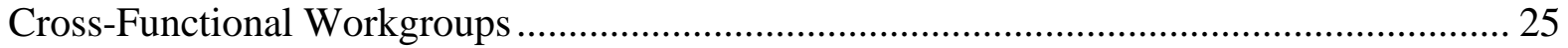

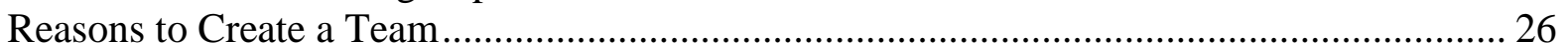

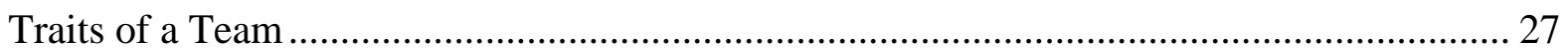

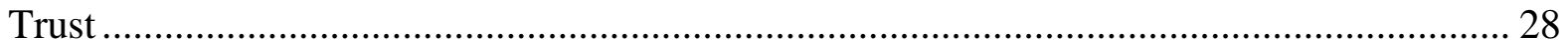

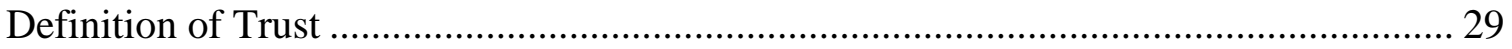

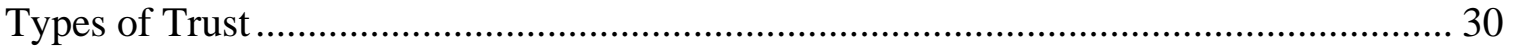

Crossover Between Cognitive and Affective Trust ......................................................... 33

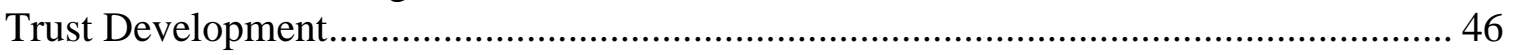

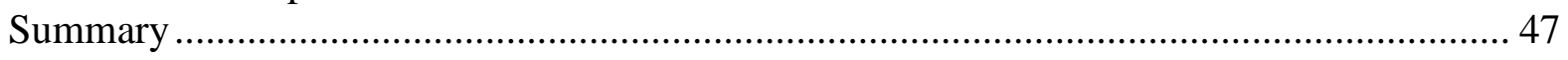

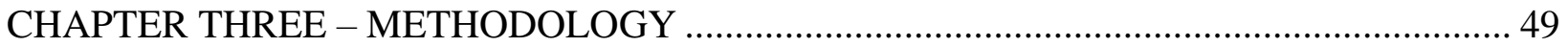

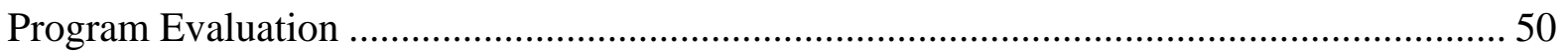

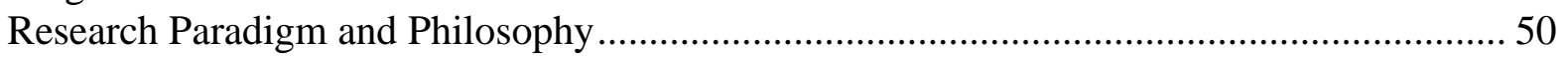

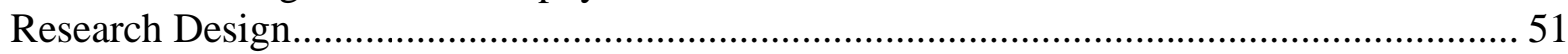

Research Design Process ............................................................................................... 54

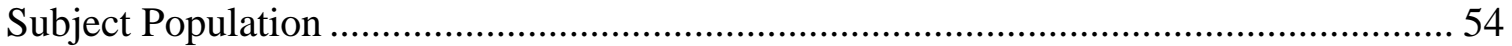

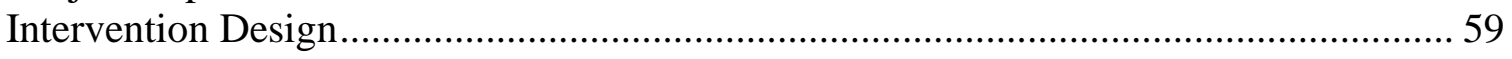




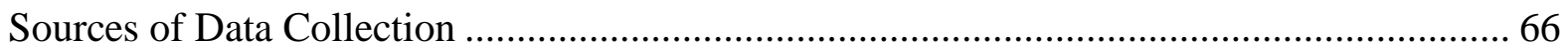

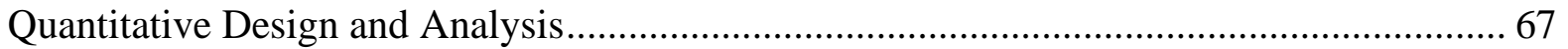

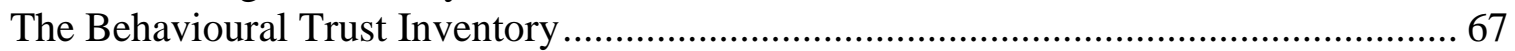

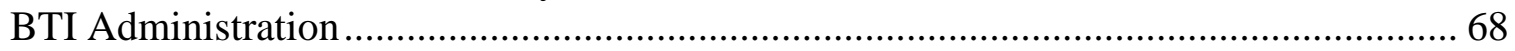

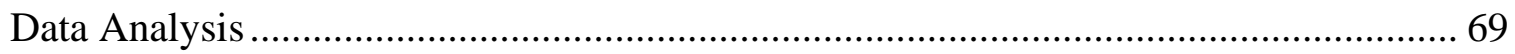

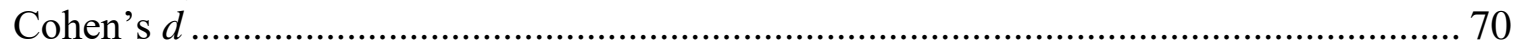

Participant Analysis ............................................................................................ 71

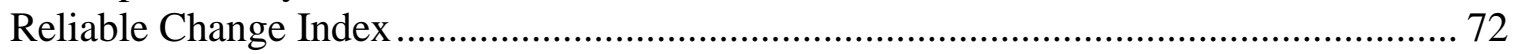

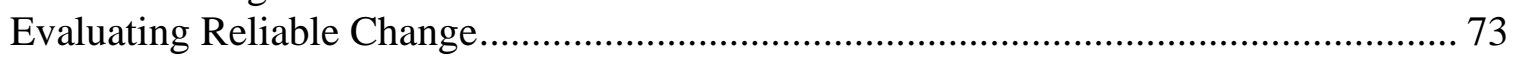

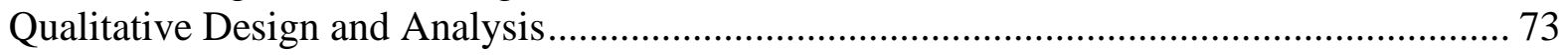

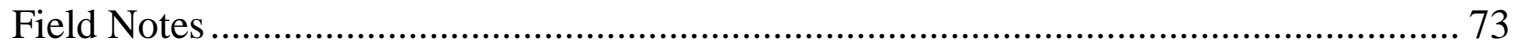

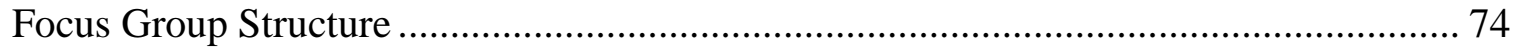

Development of Questions for the Focus Group ……………........................................ 76

Types of Focus Group Questions................................................................................ 78

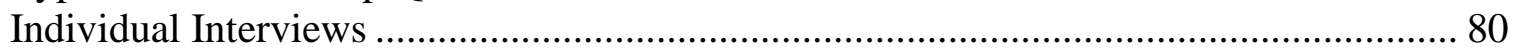

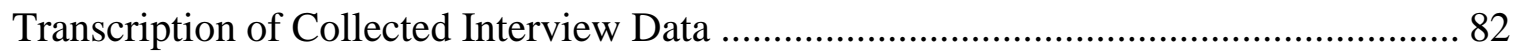

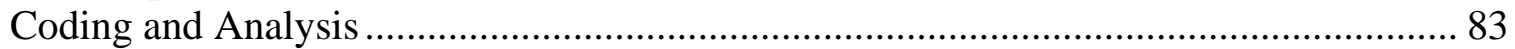

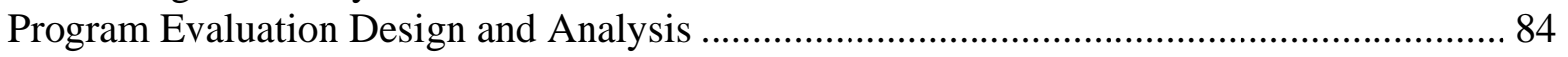

Postcourse Participant Survey ............................................................................... 84

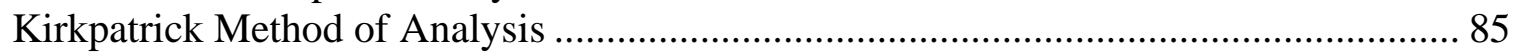

Approval to Conduct Research ....................................................................................... 86

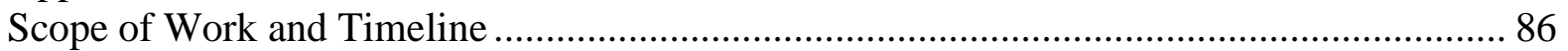

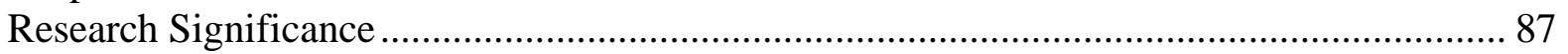

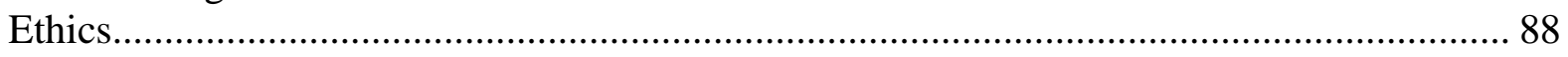

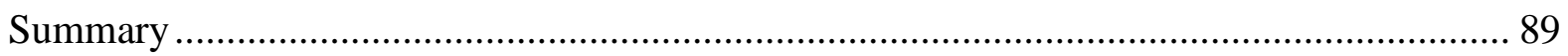

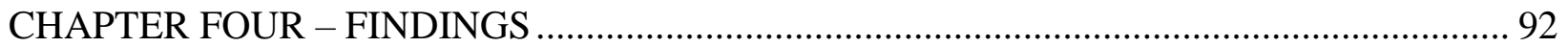

Quantitative Findings Related to the Primary Research Question........................................... 93

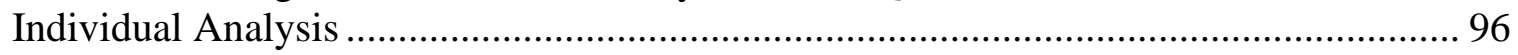

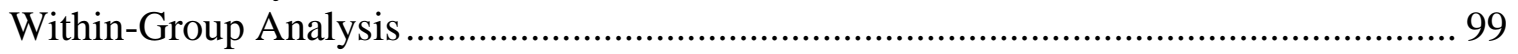

Between-Group Analysis ..................................................................................... 101

Summary of Quantitative Findings .......................................................................... 103

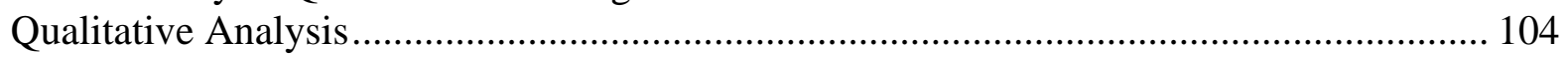

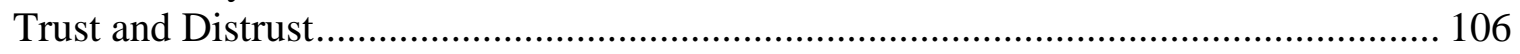

The Propensity to Trust and Its Effect on the Outcomes ................................................... 116

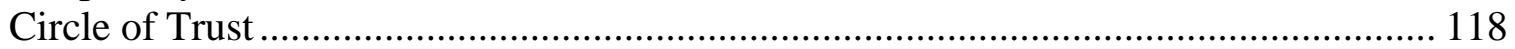

Secondary Research Questions ............................................................................. 121

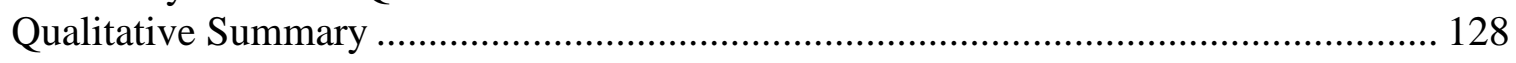

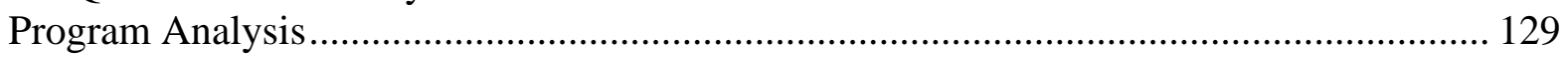

Clarity on the Value Proposition.............................................................................. 133

Techniques for Improving the Course ...................................................................... 134

Analyzing Positive Scores and Comments ……………........................................... 134

Concepts Addressed in the Course …………………............................................. 135

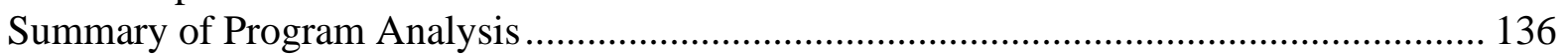

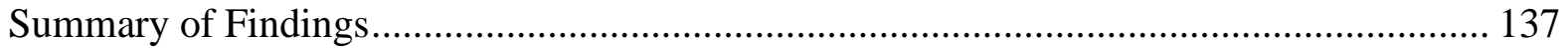




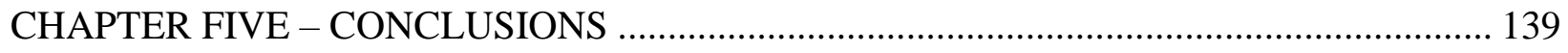

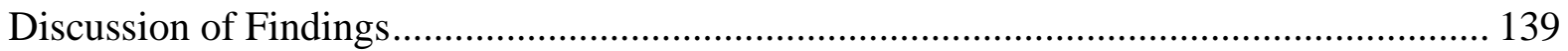

Primary Research Question.......................................................................... 140

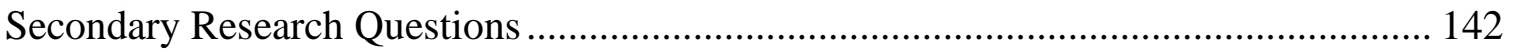

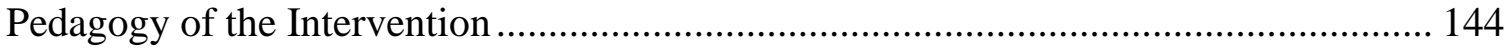

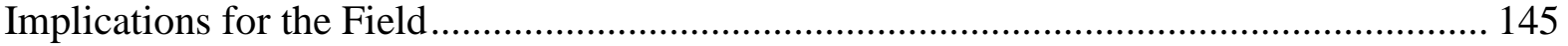

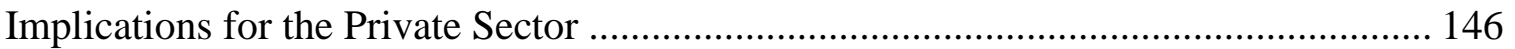

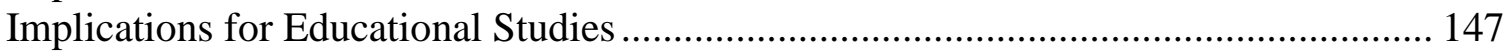

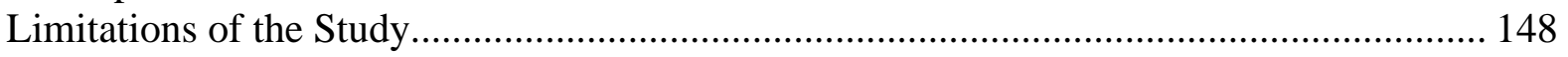

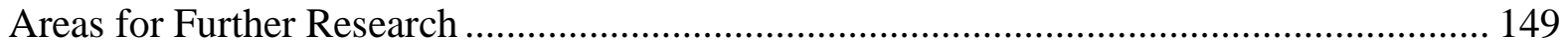

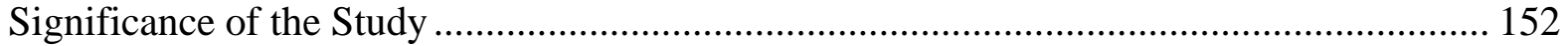

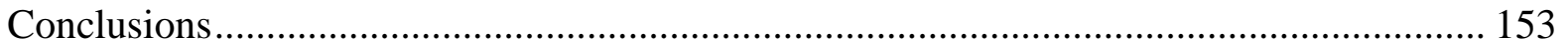

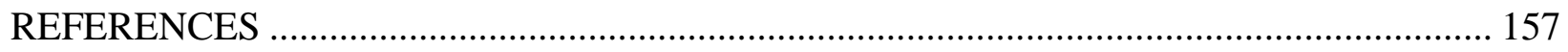

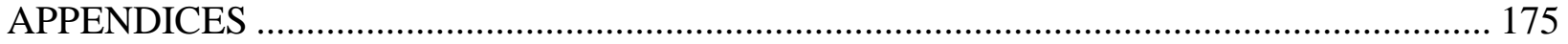




\section{LIST OF TABLES}

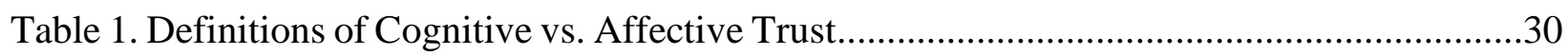

Table 2. Demographic Information of Participants..........................................................56

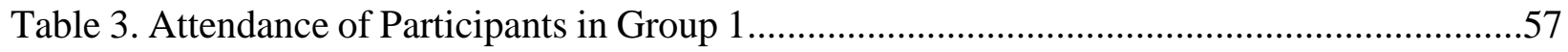

Table 4. Attendance of Participants in Group 2 ....................................................................57

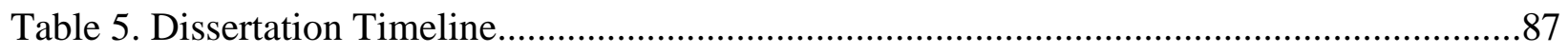

Table 6. Methods Used in the Research.................................................................... 91

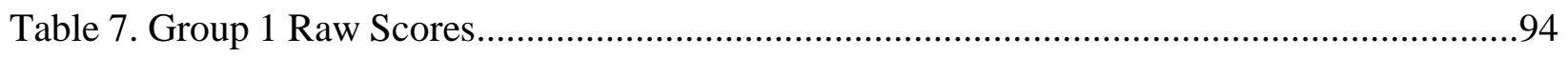

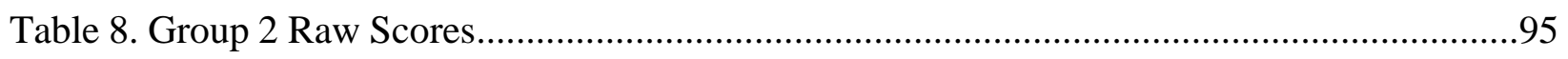

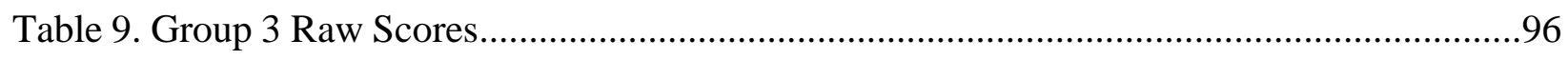

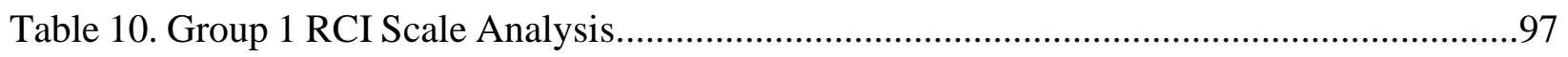

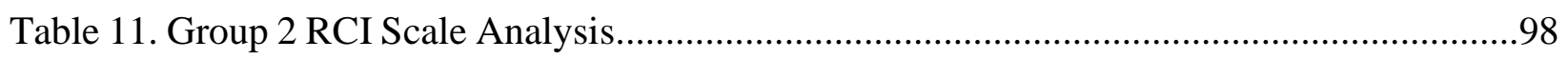

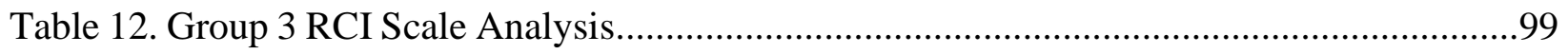

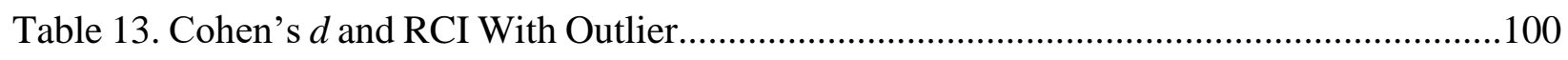

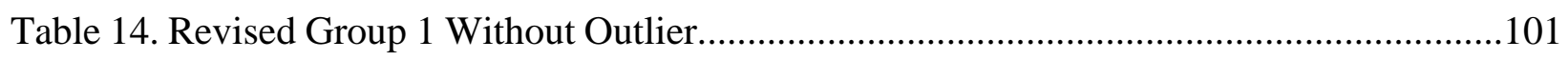

Table 15. Cohen's $d$ Between-Group Analysis................................................................102

Table 16. Cohen's $d$ Excluding Outlier From Group 1 ...................................................... 103

Table 17. Participant Groups’ Average Scores on Participant Satisfaction Survey....................130

Table 18. Individual Score Count From Participant Satisfaction Survey.................................131 


\section{LIST OF FIGURES}

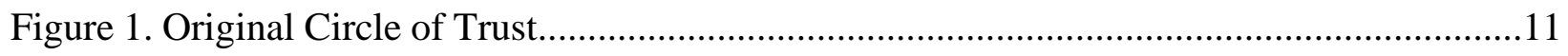

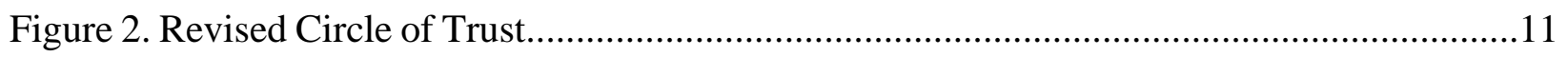

Figure 3. Circle of Trust and underlining values.......................................................... 12

Figure 4. Circle of Trust Through the Completed Cycle.......................................................13 


\section{CHAPTER ONE - INTRODUCTION}

Business organizations have been rapidly moving to the creation of cross-functional teams and workgroups (Cross, Rebele, \& Grant, 2016). Cross-functional teams are made up of stakeholders from different areas in the company and represent differing points of view; these stakeholders view problems from different angles when new propositions, systems, and products are considered (Hackman, 2002; Osterman, 1994).

There are multiple reasons for a business organization to form a cross-functional workgroup. One reason to build a cross-functional workgroup is to socialize new ideas between different departments in an organization (Salas, Sims, \& Burke, 2005). Cross-functional workgroups also create opportunities to solicit ideas from a diverse group to develop an efficient process for solving complex issues (Ehrhardt, Miller, Freeman, \& Hom, 2004; Osterman, 1994). In addition, creating cross-functional teams fosters dialogue, which promotes creativity (Love \& Roper, 2009). Creativity in a cross-functional team is developed through diverse thoughts and differing perspectives. The diversity of thought and sharing of those perspectives could potentially create synergy among the team, which often generates better ideas than any single member could on their own (McMahon, Ruggeri, Kammer, \& Katsikopoulos, 2016; Wolf, 2002). Additionally, the benefits of forming a cross-functional workgroup extend to solicitation of different perspectives from departments or work units to create a deep understanding of concepts the organization is considering (Salas et al., 2005). Understanding with and between departments can mitigate unintended consequences prior to a change in the organization (McMahon et al., 2016; Young \& Henquinet, 2000). 


\section{Identifying the Problem}

Forming cross-functional workgroups does not always provide the benefits listed in the previous section. There are potential obstacles in the formation of a team out of an ad-hoc workgroup, including disagreement on a unifying purpose and group members not bonding and trusting each other (Young-Hyman, 2017). Obtaining clarity and support for a unifying purpose is a crucial factor when a group is deemed ineffective (Young-Hyman, 2017). Members in an adhoc, cross-functional workgroup bring biases, motivations, and personality traits to the team (Davies, 1994). Further complicating the process is how the group is formed; existing power dynamics may create barriers (Keltner, Van Kleef, Chen, \& Kraus, 2008). Although these complications can be diminished, a group cannot properly function if members do not trust each other (Sangeetha \& Kumaran, 2018).

\section{Purpose of the Study}

The purpose of this study was to determine the effectiveness of an intervention program on building trust in interdepartmental groups in small business organizations. For this study, I used the U.S. Small Business Administration's (2019) standards to classify organizations as small businesses. The intervention was designed based on my experience working with crossfunctional groups in business and nonprofit organizations. The intervention was a 13-week classroom-style training program developed to teach participants crucial elements to facilitate communication and reduce the adverse effects of conflict. Additionally, the training program was designed to improve group communication while mitigating complications. For example, a finance department decision on budget restrictions potentially creates downstream consequences for the production department's ability to purchase raw materials, causing delays in delivery of a product and the customer to source a new supplier. Had the sales department been made aware of 
the need for budget restrictions that would affect customer orders, a group that involves every affected department could create a solution to solve the financial issues without affecting customer relationships. The hypothesis of this study was communication can lead to a deep understanding of participants' wants and needs. The primary purpose of increasing understanding between group members assists in conflict mitigation and improves collaboration between members. A secondary benefit of increasing understanding between group members is increasing the level of trust between group members, which is a necessary condition when building a team (Katzenbach \& Smith, 1992).

The intervention developed and tested in this study was confined to teaching communication techniques. These communication techniques were created to promote understanding between members and were intended to build trust between participants. The intervention was not designed to fully develop the transition from a group to a team. A critical component that allows for the transition from a group to a team is for the group to develop a unifying purpose. The intervention did, however, clear the pathway to the formation of a team by providing communication tools that allowed the group to develop trust among its members, which could improve the possibility of establishing a unifying purpose.

\section{Research Questions}

The study addressed the following research question: What effect, if any, will an intervention based on improving communication in a cross-functional workgroup have on the development of trust? The intervention focused on two areas specific to verbal communication. The first area was a process that facilitates empathic listening. The second area used a particular process of speaking or sharing of information termed Gestalt language protocol (GLP; Stathakis, 2013). These processes are discussed in Chapter 3. Both of these processes were instrumental in 
the instruction given during the intervention. Two additional research questions were designed to understand the role of empathic listening and GLP in the development of trust in a crossfunctional workgroup.

1. What role, if any, does empathic listening play in the development of trust in a crossfunctional workgroup?

2. What role, if any, does Gestalt language protocol play in the development of trust in a cross-functional workgroup?

Beyond answering the primary and secondary research questions, I explored areas of the course participants believed to be effective and areas they felt should be enhanced or eliminated. Another purpose of this inquiry was to identify areas for improvement in the program.

\section{Background of the Study}

Business leaders and scholars have noted the formation of silos is one of the significant issues facing workplace organizations (Boros, van Gorp, Cerdeon, \& Boote, 2017). These silos are typically divisions or departments saddled with departmental goals and budgets that conflict with the organization's mission (Wilmot \& Hocker, 2001). Next are just a couple of examples of where misalignment between departmental priorities may be present.

A typical goal of a sales department may be to secure more customers, which can conflict with the purpose of the credit department tasked with validating these customers have the ability to pay for the goods or services they purchase. Another example of a conflict between different functions would be between the human resources department, which is often charged with ensuring organizational morale, and goals of an operations group that aims to meet quantifiable metric goals. Similarly, a software development department may have breakthroughs that require 
faster computer processors; this goal could clash with the budget of the information technology department.

Conflicts frequently occur in business organizations. Individual people and departments make decisions in a vacuum and can cause management to force decisions on others that are typically not well received. These decisions can lead to conflicts that result in a multitude of negative feelings, including anger (Canary, Spitzberg, \& Semic, 1998), jealousy or envy

(Guerrero \& Andersen, 1998), and guilt (Baumeister, Stillwell, \& Heatherton, 1994). Wilmot and Hocker (2001) stated unresolved negative emotions could lead to a "us vs. them" mentality in an organization. This feeling can disrupt anticipated efficiencies or advantages, create competition for future resources, and pit one department against another. This adversarial relationship can harm the organization and its mission in the process.

While one benefit of a cross-functional team is the ability to create synergy through dialogue from people with diverse thought processes and opinions (Love \& Roper, 2009), another compelling reason to form a cross-functional team comes from an inverse look at the issue. Mitigating unintended consequences is another benefit realized with the creation of crossfunctional workgroups. The dialogue created in these workgroups helps the players to understand other departments' needs and limitations (Ayoko, Callan, \& Hartell, 2008).

\section{Definitions of Key Terms}

Several terms are critical to understanding the context of this research. Although this is not a comprehensive list, the list of terms and definitions offers an overview of the major themes of this study. Each term is discussed in greater detail in the literature review.

In this study, I use words many will find interchangeable, such as group and team. There is, however, a difference between these terms. According to Katzenbach and Smith (1992), 
business leaders and scholars recognize while all teams are a group, not all groups are a team. To Young-Hyman (2017), the most recognizable difference between these terms is a team is a group with a unifying purpose.

Trust is defined as the willingness to be vulnerable to the actions of others based on the expectation of a positive response (Mayer, Davis, \& Schoorman, 1995; Rousseau, Sitkin, Burt, \& Camerer, 1998).

The propensity to trust is a component of trust and is defined as an inherent willingness of a person to allow for trust in others without prior evidence; the other is worthy of trust. The propensity to trust may originate as a psychological trait in the trustee; it can also be learned through early childhood experiences (Couch \& Jones, 1997).

Trusting behaviors are another component of trust. Exhibiting trusting behavior means a trustor is willing to believe the trustee based on a commitment made by the trustee, which leaves the trustor in a vulnerable state (Huang \& Wilkinson, 2013).

A cross-functional workgroup is a group formed to solve a specific problem (Katzenbach \& Smith, 1992). Katzenbach and Smith (1992) identified three traits as crucial to forming crossfunctional groups: (a) technical or functional expertise, (b) problem-solving and decision-making skills, and (c) interpersonal skills.

Gestalt language protocol, or GLP, is a method of sharing from experience as opposed to telling others what to do or what they should do (Stathakis, 2013).

Transformational leadership is a leadership theory. In this theory, a leader works with teams to institute change (Bass, 1985). Individuals and their needs are considered in addition to intellectual stimulation for the individual and the organization (Bass, 1985; Burns, 1978). 


\section{My Stance and Involvement in Personal Growth}

I have been involved in the private sector since I entered the workforce in 1981. My career began in sales, and, over time, I assumed positions in sales management and general business management. During each step in my professional development, I learned how my individual goals contributed to departmental goals and realized the extent to which these goals sometimes opposed the company's goals. It was not just the battle for resources between people and departments that clearly were not in the best interest of the organization-competing for resources between departments without a broader understanding of how department goals aligned with the organization's goals created an adversarial relationship between departments and individuals in those departments.

Eventually, my experience in the business world led me to own and operate my own companies. This experience of owning my own company was much more impactful than leading other people's organizations. Running my own company brought these issues closer to home. While I had previously been responsible for the profitability of the organization, owning the company felt more personal. I would define success differently; to succeed, I would have to balance the bottom line with the impact of the work on the people who were helping build the organization. What became clear to me was the need to create an organizational culture of interdepartmental cooperation.

Cooperation benefited the organization in multiple ways. Collaboration between departments allowed individuals to work together to further the organization's mission and lead the process toward obtaining the vision. Cooperation between departments also affected morale in the workforce in positive ways. Positive morale translated into a more productive workplace and, I believe, happier employees. 
As I reached middle age, I became interested in more than just running a business. I decided to return to school and further my education. The concept of leadership is one I gravitated to more so than management. I enrolled in an executive leadership certificate program at the Haas School of Business at the University of California, Berkeley (Cal). The executive leadership program was an intense 160-hour course divided into a pair of 2-week, full-time sessions over 6 months. Business professors taught this program at both Cal and Stanford University, many of whom were also consultants for Fortune 500 companies. The content, structure, and interaction with my classmates in the executive leadership program ignited my thirst for knowledge.

In my search for additional higher education, I discovered the leadership program at Chapman University. Although I found it strange a leadership program was taught in the College of Education, rather than in a business school or political science program, I still enrolled in the Master of Leadership Development (MLD) program. The framework for leadership in education seemed diametrically opposed to what I had experienced in both the business world and in my Cal coursework.

I intended to quickly digest this information in the MLD program to meet the eligibility requirements so I could enroll in Chapman University's leadership studies doctoral program. However, the learning in the MLD program was much more impactful than I had imagined. The MLD program allowed me to see that leadership concepts can be viewed from different angles and that we can take different approaches to apply leadership. Leadership is not just a concept to be used in business or politics. Leadership can be developed in many functional areas and can be applied at many levels in an organization. 
My studies and experiences have led me to an approach consistent with transformational leadership theory. Transformational leadership was first introduced by Burns (1978), who conceptualized that organizations could be transformed by individuals supporting each other and the entire organization. Burns contrasted transformational leadership with what he termed transactional leadership and its system of rewards and punishments. To Burns, transactional leadership is a system that uses rewards and punishments to induce compliance from followers. Bass (1985) furthered the work of Burns and stated transformational leaders exhibit four main factors: (a) individual consideration, (b) intellectual stimulation, (c) inspiration, and (d) idealized influence.

My studies and my business experiences collided in such a way that I wanted to make an impact. I recognized the need for cross-functional teams and witnessed the struggle in developing ad-hoc groups into fully functioning teams. What I saw was that getting people with diverse opinions and motivations aligned with a unifying purpose was much harder than it seemed.

The difficulties or obstacles could be structural barriers, budgets, departmental priorities, and individual goals. What I discovered was profound, and although anecdotal, I found trust, or a lack thereof, is what keeps a group from coming together, establishing a common purpose, and becoming a team. My goal was to use my experiences in the private sector with the knowledge and skills I learned through the education process to create a training program to allow members of a group to establish trust. The program would be developed by focusing on my theory of the circle of trust (CoT), which I describe in the following section. The program would use the tenets of transformational leadership, keying in on empathy, vulnerability, humility, and reliability. 


\section{Circle of Trust}

The CoT is a theory in which trust can be formed between individuals and groups. It is based on existing theories of trust (Chua, Ingram, \& Morris, 2008; McAllister, 1995) and a combination of the types of trust — cognitive and affective trust - which are described in the literature review in Chapter 2. I first developed and described the model in an essay written during my master's program (De Long, 2014). In that essay, I explained the benefits of combining the forces of the social and private sectors with building cross-functional alliances with the capacity to tackle challenges far more significant than either group could manage alone. One of the fundamental premises of that essay was that distrust between these sectors was related to the motives each group brought to the table (Godfrey, 2005; Heap, 1998).

The CoT has gone through several iterations since I first introduced it in 2014. The CoT is based on a cycle that combines a desire to build trust in a relationship with specific communication techniques and consistent dependability. The initial version of the process started with respect (see Figure 1). This is not respect earned through great acts or deeds. The respect I described is a moral version. It is respect for basic humanity - a type of connection I believe every person deserves. The circle then moved to the concept Covey (2004) popularized: listening to understand. This concept alone would, as my theory suggested, build trust between parties. The final step in the original version was to share from past experience. This sharing indicates a level of vulnerability, allowing members to hear experiences rather than be told what to do. The cycle also explained how each trip through the CoT increases mutual trust (De Long, 2014). 


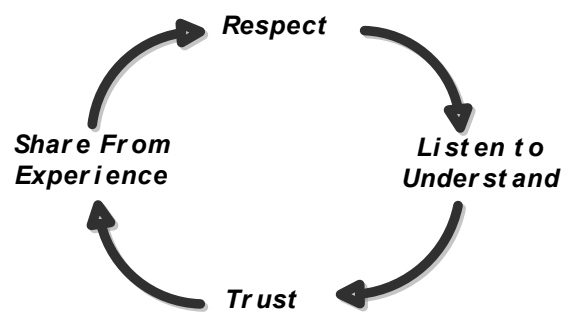

Figure 1. Original circle of trust.

Researchers have found the quickest way to erode trust is not being true to one's word (Haselhuhn, Scheitzer, Kray, \& Kennedy, 2017; Lewicki, 2006). The original CoT did not include a provision for dependability and was later amended to include a step described as deliver on the promise (Covey, 2004). Delivering on the promise encompasses being faithful to one's word; however, this statement also implies one would have the competency necessary to perform tasks implicit in the commitment. Therefore, the ability to perform a task and the integrity to deliver on one's commitment is essential to the concept of delivering on the promise.

In the first iteration, trust was removed as a parameter in the building of trust. While the simple act of listening to understand allows for some trust, I recognized trust is a construct that does take time to develop (Lewicki, 2006). In the first iteration, trust was an outcome rather than a process, so I added deliver on the promise as an action item, just as listening and sharing are action items in the cycle. The revised CoT is depicted in Figure 2.

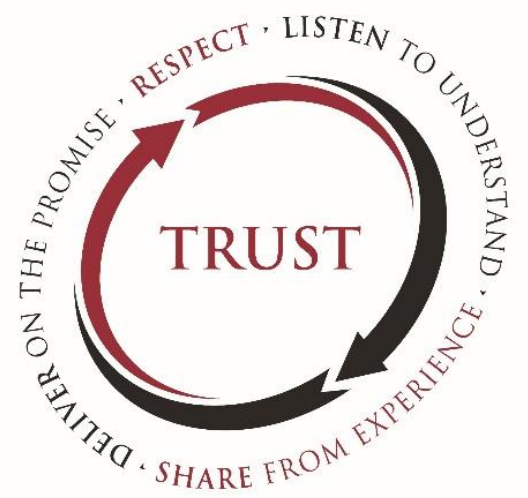

Figure 2. Revised circle of trust. 
The second iteration of the CoT (see Figure 3) was an attempt to add depth to each component. I paired each of the original concepts with terms I believed would resonate with individuals. Humility was associated with respect, as defined in my theory (Schein, 2013). Empathy was associated with listening to understand (Covey, 2004), vulnerability was associated with share from experience (Brown, 2010), and dependability was associated with deliver on the promise. These terms allow the observer to reflect on and experience emotions related to the actions described in the CoT.

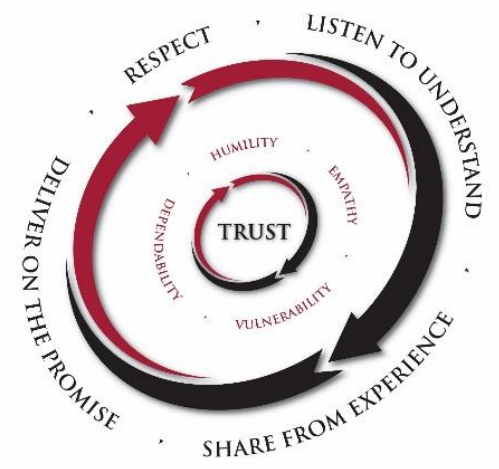

Figure 3. Circle of trust and underlining values.

The revised CoT was still deficient. This process is a cycle rather than a circle. Trust cannot be developed with one pass through the loop. The concepts needed refinement. The idea of respect being given rather than earned was difficult for the business community, which is the context of my work. Through experience working with groups in the business community, I revised the process to begin with intention rather than respect. Without the desire to trust, there would be no trust (Mayer et al., 1995; Rousseau et al., 1998). If the intention to develop a relationship is present between parties, and people work through the cycle, the next stage in the cycle is the recognition of the other's sincerity.

The cycle now starts with sincerity, and the outcome from this pass is the parties begin to develop the type of respect that is earned rather than granted. As this new level of respect is 
gained, continuing the process again allows for the formation of trust. Trust is a necessary component of building a healthy relationship. Finally, through this process of refinement, the next iteration of the CoT made sense to the business community I serve (see Figure 4).

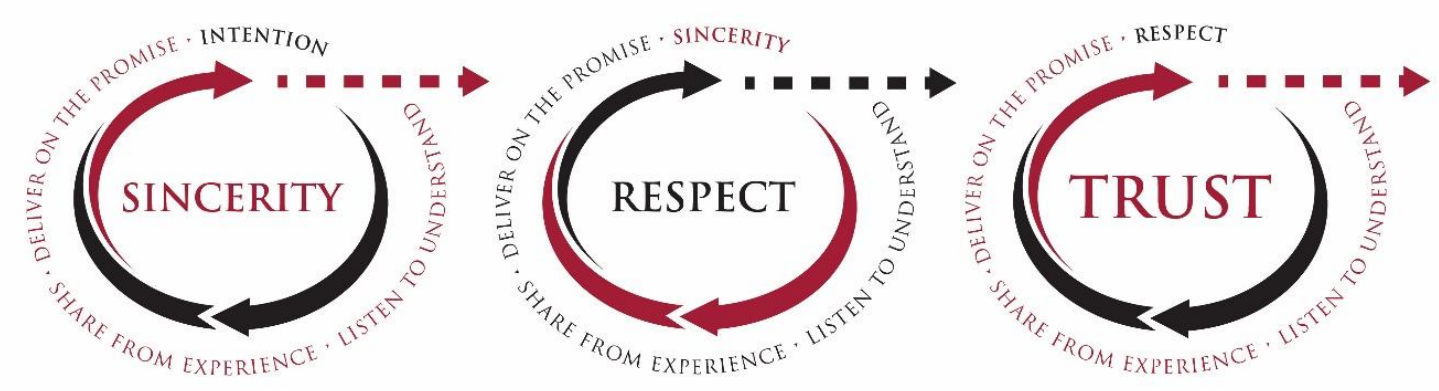

Figure 4. Circle of trust through the completed cycle.

\section{Developing a Process to Facilitate Building Trust}

The intervention I describe in this study is based on my theory that trust plays an integral role in the process of turning a cross-functional workgroup into a functional team. While building trust between people has been acknowledged as an essential component in a team, trust building has been viewed as a variable that takes time (Hill \& O'Hara, 2006; Vangen \& Huxum, 2003). There are few programs that have been developed and implemented that are devoted to building trust, and no programs have been explicitly geared toward cross-functional groups in business organizations. The intervention studied was developed primarily on concepts in the CoT.

The process of building trust takes time (Hill \& O'Hara, 2006). Building trust takes a combination of a willingness to trust, a belief the other possesses the competency required, and time to observe behaviors to ensure those behaviors are in alignment with one's view of what it would mean to trust (B. K. Choi, Moon, \& Nae, 2014). The process described in my intervention has multiple objectives, including teaching communication skills to participants and building 
trust in a cross-functional group. Communication skills taught in the intervention process are techniques participants can use in their daily lives to build trust beyond cross-functional groups.

\section{Scope of the Study}

The scope of this study was limited to small, for-profit business organizations. Two business organizations were selected to participate in an intervention designed to improve communication techniques. Both organizations were asked to provide 8 to 12 individuals from multiple departments to participate in the intervention coursework - a third business organization group of midlevel managers acted as the comparison group for the study.

\section{Methodology}

As I discuss in detail in Chapter 3, I used a mixed-method approach to perform this study. The mixed-method approach was a combination of two quantitative survey tools, qualitative focus groups, and individual qualitative interviews. This mixed-method approach was used to answer the research questions on trust development and the communication techniques used in training.

Quantitative analytics were performed with a previously validated survey tool called the Behavioural Trust Index (BTI; Gillespie, 2012). With the participant groups, I administered the pretest on the first day of the 13-week intervention, which I describe in greater detail in Chapter 3. The posttest was distributed as the last act of the last day of the course. Although the comparison group did not participate in the intervention, they were administered the pre- and post-test with the same 13-week gap as the participant groups. This comparison group served as a baseline to apply the statistics.

Two weeks after the last course session, I held a focus group discussion with both participant groups. Focus groups were used to gather rich data about the process and outcomes 
from participants' points of view (Krueger \& Casey, 2015). I also interviewed individual participants after the focus group sessions.

Criteria for participation in the individual interviews included (a) significant variances between pre- and post-test statistics and (b) undeniable passion exhibited during the course sessions and focus groups. The passion noted here was shown with visible body language and audible clues displayed by participants. I recorded observations in detailed field notes taken after each session. I conducted individual interviews with participants identified in the field notes and with those who had large variations between their pre- and post-test.

Additional qualitative data were recorded in the form of my field notes. The notes consisted of my observations of the class sessions and focus groups. These notes were my view, as the facilitator, of the climate of each session and participants' contextual observation.

\section{Summary}

The use of cross-functional groups in business organizations continues to increase (Cross et al., 2016; Love \& Roper, 2009). When successful, cross-functional groups, compared to individually assigned tasks, provide better outcomes and experience fewer unintended consequences (McMahon et al., 2016; Young \& Henquinet, 2000). Not all attempts at creating these groups are successful, and morale and work efficiency may suffer (Cross et al., 2016). One indicator in determining if a team will emerge is the level of trust present in members and the group. Therefore, a program to assist in trust development could benefit business organizations and assist in team formation (Sangeetha \& Kumaran, 2018).

One such process to address the deficiency of trust building in cross-functional team creation is the intervention under study in this research. This 13-week training course in communication techniques was analyzed to determine what effects it had on participants and 
groups. The intervention was pragmatic and included techniques associated with transformational leadership theory (Bass, 1990; Burns, 2003). 


\section{CHAPTER TWO - LITERATURE REVIEW}

The purpose of this study was to understand the effectiveness of building trust using a communication training program with cross-functional workgroups. The goal of the course was to train participants in a process that would enable them to communicate better with others who have different points of view. The review of the literature has been conducted to understand the essential concepts that frame this study.

Sections of the literature review include the theories of leadership used to create the Circle of Trust (CoT) detailed in the introduction. I also describe the components essential in the establishment of a team. Central to the formation of a team is the creation of trust in a group of individuals. The construct of trust is explored in four sections of this literature review: (a) components of trust, (b) characteristics inherent in trust, (c) conditions in which trust thrives, and (d) development of trust. In addition, the literature review will provide background for the specific teaching methods used during the intervention.

\section{Theories of Leadership}

Three intersecting theories inform scholarly understanding of leadership concepts and practices that have influenced my work with the CoT: (a) charismatic leadership, (b) authentic leadership, and (c) transformational leadership. The CoT and the communication intervention studied are based primarily on transformational leadership theory and practice. A review of charismatic and authentic leadership theories with their strengths and weaknesses frame the formation of transformational leadership and, thus, the CoT.

\section{Charismatic Leadership}

Downton (1973) coined the term charismatic leadership. Downton based this form of leadership on a leader's characteristics, notably charisma. Components of charisma include 
empathy, envisioning, and empowerment (J. Choi, 2006). Charisma is what draws followers to a leader and encourages confidence in that leader. Charisma also causes followers to want to perform for that leader (Downton, 1973).

Conger and Kanungo (1987) continued to use the term charismatic leadership and furthered Downton's (1973) explanation of what it means to be a charismatic leader. While acknowledging a charismatic leader possesses traits such as empathy, vision, and empowerment, which lead people to be inspired, the charismatic leader is also often saddled with negative attributes. These negative attributes include narcissism, a need for power, authoritarianism, and flawed vision (Conger \& Kanungo, 1987).

A charismatic leader seeks radical reform in an organization without necessarily considering consequences that may arise (Burns, 1978; Conger \& Kannugo, 1987). The charismatic leader's vision is transactional in nature (Burns, 1978). The charismatic leader is typically focused on short-term goals and getting the job done, as opposed to a transactional leader who has ethical considerations, including integrity, trustworthiness, and accountability (Burns, 1978). Another flaw in the charismatic leader is they often lack strategic planning (Meuser et al., 2016). It was these shortcomings that led George (2007) to develop an alternative to charismatic leadership: authentic leadership.

\section{Authentic Leadership}

Authentic leadership is based on the leader being true to themselves, understanding who they are, and living and leading through their values (George, 2007). This form of leadership has been described as an effective practice for achieving positive outcomes in organizations (George, 2007). The tenets of authentic leadership theory are (a) self-awareness, (b) balanced processing of information, (c) authentic behavior and acting, and (d) authentic relational orientation (Avolio 
\& Gardner, 2005). Authentic leaders understand their strengths and weaknesses and their moral values and beliefs, including self-confidence, reliability, and trustworthiness (Ilies, Morgenson, \& Nahrgang, 2005). George (2007) described authentic leadership as a process to develop connections with others, engendering trust.

Authentic leadership differs from charismatic leadership in several ways. Charismatic leaders do not employ the balanced processing of information nor the components of selfregulation authentic leaders possess (Avolio \& Gardner, 2005). Authentic leaders are concerned with follower self-awareness and development, which are not concerns of charismatic leaders (Avolio \& Gardner, 2005). Authentic leadership was developed based on potential defects in the transformational leader, which I explore in the following section.

\section{Transformational Leadership}

Transformational leadership requires leaders to inspire a shared vision and provide followers with tools and opportunities to realize the vision (Bass, 1985; Burns, 1978; Conger, \& Kanungo, 1985). Two essential conditions found in a transformational leader are (a) the ability to gain respect from followers and (b) the ability to gain trust from followers (Bass, 1990). The four fundamental tenets of transformational leadership are:

- An idealized influence that establishes high moral and ethical standards.

- Inspiration to provide followers with challenges and meaning and create the engagement to develop a shared vision.

- Intellectual stimulation provides the opportunity to generate creative ideas, learn, and grow.

- Consideration of each individual in the group (Bass, 1985). 
Burns (1978) contrasted a transactional leadership style with transactional leadership. Transactional leadership methods are described as "give-and-take leadership" (Burns, 1978, p. 23). To lead others, transactional leaders use charisma and motivate followers with rewards for positive behaviors and outcomes or, as Bass and Steidlmeier (1999) described, contingent reinforcement. Similarly, transactional leadership behaviors toward negative actions create the result of provoking punishment or fear of punishment in followers. Rather than empowering, this form of leadership is destructive to the leader-follower relationship. Transactional leadership is manipulative because it motivates followers with short-term victories at the cost of long-term vision and enrichment (Burns, 1978). Motivation is powerful, as it drives action; however, when motivational incentives are no longer present, the desired effect will also cease (J. Evans, 2009).

Transformational leaders combine the charisma of charismatic leaders (envisioning, energizing, enabling) with attributes of authentic leaders, including internal moral perspective, self-awareness, and balancing individual freedoms with public interest (Burns, 1978). This fusion of attributes suggests transformational leadership is not an extension of a charismatic theory of leadership. Instead, transforming leadership theory combines the charisma of charismatic leaders with the desire to uplift others to a higher level of morals and motivation (Burns, 1978). Burns (1978) recognized the importance of the ethics prescribed in transactional conduct; however, Burns described the transforming leader as one with a high moral vision, which Burns referred to as transforming values.

Bass (1985) enhanced Burns's (1978) transformational leadership by identifying transformational leadership as a distinct theory of leadership that can be measured based on impact on the followers. Transformational leadership is an approach leaders use to effect change in individuals and social systems, with the end goal to create more leaders. In this theory, 
motivation and its reliance on rewards and punishment evolved to be understood as the inspiration of followers (Bass, 1985). The motive of transformational leaders is to inspire followers to become more, do more, and create radical change for the benefit of the individual and the social system (Bass, 1985; J. Evans, 2009). The transformational leader uses specific techniques, allowing for this individualized consideration, including delegation, coaching, advising, and providing feedback with and to the follower (Bass, 1985; Burns, 2003). Individualized consideration is a process that treats individuals based on their needs through coaching and mentoring (Bass \& Steidlmeier, 1999).

Critics of transformational leadership have described a cult-like atmosphere, where a messiah-like leader, who has superhuman qualities, controls the flow of ideas through their insistence of a shared vision (Western, 2013). Western (2013) noted transformational leadership demands adherence to norms established by the dominant culture to provide individual rewards, and any dissent from followers to standards set by leadership is punished. Bass and Steidlmeier (1999) cited another flaw of transformational leadership: "In their efforts to accent the positive, they make inspiring appeals to maintain enthusiasm and morale of followers, they are inauthentic in transformational leadership" (p. 190). The transformational leader may publicly support a change inconsistent with their own beliefs (Bass \& Steidlmeier, 1999).

My rebuttal to Western's (2013) interpretation of what is meant by transformational leadership is it is a misrepresentation of the practice inherent in transformational organizations. Inspiring shared vision does not mean dictating that vision. Even as Bass and Steidlmeier (1999) criticized the pseudo-transformational leader, they also pointed out inspirational motivation provides opportunities to generate creative ideas. Inspiring shared vision does not mean the leader's views are the only ideas of value and that the leader creates the vision and expects others 
to adopt that vision; inspirational motivation creates opportunities for the group to cocreate the vision and learn and grow in that process (Bass \& Steidlmeier, 1999).

Although there is conflict among scholars' theories of leadership, much crossover exists. Many organizational leadership theories highlight the evolution of thought rather than revolution. Transformational leadership is an evolution and combination of charismatic and authentic leadership theories. Western's (2013) criticism of the transformational leader is tempered, as Western posited transformational leadership provides opportunities for leaders to function in many levels of an organization. Transformational leaders' emphasis on the empowerment of followers is consistent with a distributed leadership style, which Goleman (2000) described as the possibility of anyone in the organization leading. This distributed leadership style is compatible with transformational leadership theory and practices and contrasts with the charismatic leadership style, where the leader is the inspiration for the followers (Western, 2013). A transformational leadership style and distributed leadership style are inherent in the process developed in the CoT and the communication interventions used in this study.

\section{Pragmatism}

Pragmatism is a theory of practice for understanding, identifying, and solving problems (Legg \& Hookway, 2019). Pragmatism originated in the United States in the late 1800s (Legg \& Hookway, 2019). As cited by Luft (2004), pragmatism was first described by Charles Sanders Pierce, who described truth differently than other philosophers of the time. Other philosophers of the time believed judgment of what could be considered a truth must be suspended if there are multiple judgments on what may be true (Luft, 2004). In contrast to popular beliefs, Pierce viewed himself as a realist. Pierce's view contrasted with the rational beliefs of Cartesianism, a theoretical stance based on deductive reasoning. Pierce believed practical applications and 
consequences mattered more than the philosophical theory of a given subject. Pierce's pragmatic maxim dictated that the pragmatist sought purpose for items that were analyzed (Luft, 2004).

Pragmatism falls on a spectrum between positivism and constructionism. Positivism is an objective view of the world, a view that seeks existing truth. Constructionism, on the other hand, is a subjective position and seeks truth for individuals as they construct their world. Those who prescribe to a pragmatist belief balance objectivity and subjectivity to identify a practical solution that can be used both efficiently and effectively (Legg \& Hookway, 2019).

The pragmatist seeks knowledge of a process for improvement. The pragmatist wants to know when they are wrong and to identify errors to eliminate them (Legg \& Hookway, 2019). William James, a contemporary of Pierce, popularized pragmatism with teachings that ideas become valid when they work in concert with experiences (Legg \& Hookway, 2019). John Dewey, a pragmatist himself, challenged contemporary philosophers' views using theory as a source for criticism (Miller, 2014). Dewey was more interested in practical application and solving problems than discussing theory (Miller, 2014). Dewey employed a systematic process for solving problems:

1. Understand the problem by identifying its elements.

2. Identify the relations of the elements.

3. Identify a particular question that we need to answer.

4. Identify the tools or instruments that help us transform things to solve the problem (Legg \& Hookway, 2019).

Pragmatism applies to many environments. For example, the practical application of pragmatism has been paramount to business organizations. Many organizations have changed their organizational missions to include transformational leadership attitudes. However, even 
business leaders who will not discuss profit-oriented motives in mission statements may still be concerned with increasing revenues and lowering expenses. It is essential to consider the intersection of pragmatism with business operations and the private sector.

\section{The Nature of the Private Sector}

The private sector generally operates from a pragmatic lens, with interest in getting things done effectively and efficiently (Pfeffer, 2008). This practical lens can be seen in change management processes employed in the private sector. Change management processes rule the business landscape; however, change is not an end to itself but a means to an end. One underlying question with which management must be concerned is whether a change is necessary to fulfill the organization's mission (Jacobs \& Keegan, 2018). The decision to make a change comes with several factors, including understanding the required resources, people, time, money, and the potential for gain to evaluate the organization's return on investment (Kellogg, 2019).

A pragmatic approach has been applied throughout business organizations. Sales organizations are tasked with customer acquisition and retention. Operations are responsible for productivity in the production of goods and services. Kanter (2009), when describing management professor Peter Drucker, suggested the role of management is to get work done as efficiently as possible, which is at the heart of pragmatism. Pragmatism, defined as getting things done effectively and efficiently (Pfeffer, 2008), runs throughout business organizations. As presented in the next section, a pragmatic approach to getting the job done is why business organizations have continued to create and rely on cross-functional workgroups to solve complex issues (Cross et al., 2016). 


\section{Cross-Functional Workgroups}

There are multiple reasons for a business organization to form a cross-functional workgroup. Cross-functional workgroups are groups of as few as three and no more than 15 members (Myers \& Anderson, 2008). These groups are comprised of individuals from different disciplines or departments in an organization who come together to collaborate as a team for a specific purpose (Young-Hyman, 2017).

There are multiple reasons an organization would choose to form a cross-functional workgroup. For example, cross-functional workgroups may be used to socialize new ideas and solicit thoughts and ideas with a diverse group, with the intent of creating an efficient process for solving complex issues (Ehrhardt et al., 2004; Osterman, 1994). Organizational initiatives, such as strategic planning and executive leadership, might necessitate the need for cross-functional workgroups (O’Neil \& Salas, 2018). Another reason to create a cross-functional workgroup is to foster dialogue to promote creativity. Love and Roper (2009) studied cross-functional workgroups, individually polling members of those workgroups in the United Kingdom $(1,722)$ and Germany $(1,374)$, noting a rise in innovation of 9.6\%. Diversity in a group's perspectives can create synergy between members and lead to better ideas than the original ones (McMahon et al., 2016; Wolf, 2002). The formation of a cross-functional workgroup provides a forum for soliciting different perspectives from departments or work units that a new idea may create a deep level of understanding of complex interdepartmental business concepts. This understanding may provide the group with the ability to mitigate any unintended consequences before making a change (McMahon et al., 2016; Young \& Henquinet, 2000).

Although cross-functional workgroups can be highly effective, limitations exist. Putting a group of people together and calling them a team does not, by itself, create a team (Katzenbach 
\& Smith, 1992). Katzenbach and Smith (1992) identified three traits as crucial when forming successful cross-functional teams: (a) technical or functional expertise, (b) problem-solving and decision-making skills, and (c) interpersonal skills. While these traits are crucial, they are not enough to form a team; the creation of a cross-functional workgroup by itself does not guarantee benefits (O’Neil \& Salas, 2018). In some instances, barriers exist between individuals from diverse operational backgrounds. Frequently, departments compete for organizational resources. This competition creates functional silos that must be dismantled before cross-functional synergy can be obtained.

\section{Reasons to Create a Team}

Yuan, Olfman, and Yi (2016) argued turning a group into a team increases the likelihood of group effectiveness. Team creation is a tool organizations have constructed for a variety of reasons. The nature of a team creates a bond among members who may feel as though they are more than coworkers or business acquaintances. A bond creates a sense between members they have become friends (Jones \& George, 1998). The existence of these bonds has been shown to benefit employee retention (Jones \& George, 1998). Employee retention is related to stronger job satisfaction, positive peer relationships, and in-depth work engagement. In their study of 450 respondents who work in the financial services sector in Pakistan, using multiple regression models, Rahman, Rehman, Imran, and Aslam (2017) found working in functioning teams, engagement $(\beta=0.37, \rho<0.000)$ and relational psychological content $(\beta=0.43, \rho<0.001)$ has a direct relationship with the employee's job satisfaction.

Teams outperform ad-hoc workgroups or individuals working alone (Katzenbach \& Smith, 1992). The interdependence paradigm suggests a team can create something greater together than the individuals in that group could by themselves (Covey, 2004). Teams 
outperforming individuals working alone is especially true when teams are composed of individuals with complementary skills and diversity of thought (Katzenbach \& Smith, 1992). To understand the dynamics of a team, a description of what traits define a team must be understood.

\section{Traits of a Team}

Katzenbach and Smith (1992) posited there are five levels with which a small group could be described:

1. A working group is a small group of individuals who interact primarily to share information and allow individuals to make decisions that enable them to perform their functions. There is no shared sense among members of common purpose or accountability to each other.

2. A pseudo team is a collection of individuals with a need to share information, no common purpose, and whose own self-goals may detract from the needs of other members. In a pseudo-team, the time individuals spent with other members of the pseudo team detracts from available time for individual goals.

3. A potential team is a group of individuals who come together when there is a clear, significant need. This group lacks a shared sense of purpose and may lack the discipline to organize a common work approach.

4. A real team is a small group of people with complementary skills who are committed to a shared sense of purpose, common goals, and a process to work together, trust each other, and hold each other accountable.

5. A high-performance team is a group that meets all of the conditions for a real team, and members exhibit care for other members' successes. 
Katzenbach and Smith stated the pseudo team is less effective than a working group. What differentiates a pseudo team from a working group is the sharing of information, and, in a pseudo team, individuals are concerned with their own interests rather than a collective purpose. In a pseudo team, individuals act as if working together is a waste of their time. Katzenbach and Smith (1992) claimed, in a pseudo team, "the whole is less than the sum of the individual parts" (p. 17), pointing out the formation of a real team is extremely beneficial to the organization.

A team can be summarized as a group of individuals with a shared sense of purpose who are willing to hold members accountable and who have developed a sense of trust for each other and the group (Katzenbach \& Smith, 1992). Scholars have recognized the element of trust as a crucial component in the creation of a team (Webber, 2008; Yuan et al., 2016). Transformational leadership is the basis for intellectual stimulation, individual consideration, and shared vision (Bass, 1985; Burns, 1978). Creating a shared vision is the primary factor that allows a group of individuals to form a team (Katzenbach \& Smith, 1992). Trust is typically viewed as a crucial dimension in developing relationships, which enables groups to create a shared vision (Katzenbach \& Smith, 1992).

In the following section, I offer a working description of trust, derived from the literature. This description highlights components and conditions that allow for trust and is necessary before the processes in which trust can be built.

\section{Trust}

Scholars have examined the construct of trust and its impact on relationships in business organizations (Mayer et al., 1995; Rousseau et al., 1998). Interorganizational business relationships include those between the company and its customers (Akrout \& Diallo, 2017), suppliers (Handfield \& Bechtel, 2002), and joint ventures (Currall \& Inkpen, 2002). Trusting and 
being trusted are vital elements in establishing a business relationship (Currall \& Judge, 1995).

Fehr (2009) stated, "Trust plays a role in almost all human relationships. It permeates friendship relations, family relations, and economic relations. People rely on the support of their friends, children trust their parents, and sellers trust their buyers to pay the bill” (p. 235). As Arrow (1972) argued, "Virtually every commercial transaction has in itself an element of trust. ... It can be plausibly argued that much of the economic backwardness in the world can be explained by the lack of mutual confidence" (p. 357).

\section{Definition of Trust}

There are several definitions of trust in the literature. The most frequently cited definition of trust in the literature is "the willingness to be vulnerable to the actions of another party based on the expectation that the other will perform a particular action important to the trustor, irrespective of the ability to monitor or control that other party" (Mayer et al., 1995, p. 712). Rousseau et al. (1998) offered another definition of trust: "Trust is a psychological state comprising the intention to accept vulnerability based on positive expectations of the intentions or behavior of another" (p. 395). The definition of trust Mayer et al. (1995) provided has been criticized as being one dimensional. Webber (2008) stated a vast majority of the literature (94\%) related to trust is based on the single construct of cognitive-based trust. Webber's criticism of Mayer et al. (1995) and Rousseau et al. (1998) as one dimensional has focused on the word expectation. Still, affective qualities can be shown with the word intention in Rousseau et al.'s definition and willingness in Mayer et al.'s definition, rendering Webber's critique troublesome. Both definitions infer the multidimensional constructs of cognitive and affective trust embedded in their descriptions. 


\section{Types of Trust}

Concepts of trust have been broken down into two categories: (a) cognitive trust, which revolves around competency, reliability, and calculative assessments (Chua et al. 2008) and (b) affective trust, which is relational and intuitive (Dowell, Morrison, \& Heffernan, 2015). Trust can be based on either concept; however, trust based on both cognitive and affective components is more profound and more powerful (B. K. Choi et al., 2014). In Table 1, differences between scholarly definitions of cognitive and affective trust are shown. Both constructs are discussed in the following section.

Table 1

Definitions of Cognitive vs. Affective Trust

\begin{tabular}{lll}
\hline Study & Cognitive Trust & Affective Trust \\
\hline B. K. Choi, Moon, \& Nae (2014) & $\begin{array}{l}\text { Task-related, knowledge, } \\
\text { expertise }\end{array}$ & Mutual respect, mutual care \\
Chua, Ingram, \& Morris (2008) & $\begin{array}{l}\text { From the head (competence, } \\
\text { reliability, calculative } \\
\text { assessment) }\end{array}$ & $\begin{array}{l}\text { From the heart (feelings, } \\
\text { motives, empathy, rapport) }\end{array}$ \\
Dowell, Morrison, \& Heffernan (2015) & $\begin{array}{l}\text { Compency, integrity, } \\
\text { goodwill } \\
\text { Reliability, dependability }\end{array}$ & Relational, intuitive \\
McAllister (1995) & Interpersonal care and concern \\
\hline
\end{tabular}

Cognitive trust. Cognition-based trust is conditioned upon the level of ability, knowledge, reliability, and dependability of the trustee (B. K. Choi et al., 2014). Cognitive trust has also been described as reliance-based trust, where the trustor is reliant on the trustee and has faith in the competency of the trustee to perform the expected task (Gillespie, 2003). The belief of another's ability relates directly to the competency of the person who is to be trusted (McAllister, 1995; Schaubroeck, Lam, \& Peng, 2011), with competency meaning the individual has the necessary knowledge, skills, or talent to perform the task. In a study of 458 small 
businesses (fewer than 20 employees), measuring the effect of different components on trust, including goodwill and integrity, competency had the largest total effect of the cognitive-based trust variables studied (0.391; Dowell et al., 2015). Competency is seen as specific to a task; for instance, one may be capable of painting a house and, therefore, deemed competent as a house painter. If the expectations for that same individual are to paint a portrait, and they do not possess the skill set required, then they will not be viewed as a competent portrait artist.

Reliability and dependability are similar constructs. Both terms indicate an individual can be counted on to deliver on their commitment, promise, or task (B. K. Choi et al., 2014; McAllister, 1995). Trust can turn into distrust if the trustee is not willing or able to honor their commitment (Lewicki, McAllister, \& Bies, 1998). Cognitive trust, therefore, is validated through action or behavior, honoring commitments, completing assigned tasks, or delivering on the promises made (Chua et al., 2008).

Communication plays a role in the development of cognitive trust. In cognitive trust, the role of communication is paramount in establishing trust. The frequency of communication and the quality of communication are vital components in building trust (Thomas, Zolin, \& Hartman, 2009). Quality of communication is described as communicating enough information as well as accurate and relevant information. Thomas et al. (2007) found correlations between the quality of communication and trust $(n=206, r=.37, p<.001)$ was stronger than between enough communication and trust $(n=206, r=.19, p<.17)$ concluding the perceived quality of information is a significant contributor in determining others' reliability, dependability, and competence, which are contributing factors in the determination of cognitive trust (McAllister, 1995; Schaubroeck et al., 2011; Thomas et al., 2009). 
Cognitive trust is derived from specific knowledge (B. K. Choi et al., 2014; Chua et al., 2008). Components of cognitive trust, therefore, are comprised of behavioral clues as described previously. Cognitive trust may influence affective trust because it is based on the feeling one may have toward another, while these feelings, in part, are based on the trustee's behaviors. The reverse, however, is not true. Affective trust is not a precondition to cognitive trust; cognitive trust can be built based on competence and performance measures (McAlister, 1995). In many ways, affective and cognitive trust are related concepts; however, affective trust may be influenced through behaviors of the trustee if those behaviors are based on perceptions of benevolence rather than competency (McAllister, 1995).

Affective trust. Affective trust is a feeling one is respected, supported, and cared for (B. K. Choi et al., 2014; McAllister, 1995). It is a form of trust that requires an emotional investment between the trustee and the trustor, as shown by Chua et al. (2008) in their study of 101 managers who were attending executive MBA courses at a large East Coast university. In that study, affective trust was influenced by friendship $(B=0.87, p<.01)$. Affective trust, therefore, is developed through emotions built over time (Chua et al., 2008) through personal interactions between individuals (Nienaber, Hofeditz, \& Romeike, 2015). Gillespie (2003) defined the term disclosure-based trust in the same way other scholars have described affective based trust.

Communication is vital to building affective trust (McAllister, 1995); however, it is the frequency of communication, as opposed to the quality of communication, indicated as the driving factor in affective trust (Nienaber et al., 2015). Nienaber et al. (2015) noted the frequency of communication because the more often people talk, the higher the likelihood they are to show affection toward each other. More affection creates a greater willingness to be vulnerable with another (Nienaber et al., 2015). 
Emotions may influence one's level of trust more than the observed behaviors of the trustee (McAllister, 1995). Feelings of wanting to trust another may be based on that individual's previous behaviors; however, with affective trust, past actions noted are those intended to provide assistance, care, or empathy, as opposed to those that determine trustee competence (Webber, 2008). Trustee competence is a condition of cognitive trust. Observed behaviors that lead to cognitive trust may influence affective trust (McAllister, 1995).

Affective trust is described as the type of trust that comes from the heart (Chua et al., 2008) and has been developed through emotions or feelings for another. Many other words have been used when scholars describe affective trust, including emotional trust, genuine care and concern, and safety (McAllister, 1995; Schaubroeck et al., 2011). Attitudes about trust include components of affective trust, even though affective trust is comprised of learned emotional feelings created through the development of relationships (Stack, 1978); however, the propensity to trust, as shown by Couch and Jones (1997), may be inherent in the natural psychological state of the individual. As a result, affective trust is believed to consist of two main elements: (a) relational trust and (b) intuitive trust (Dowell et al., 2015). Relational trust is built through similarities and frequency of communication. Intuitive trust, however, is constructed by one's attitude or propensity to trust. According to existing scholarly literature, neither cognitive nor affective trust is independent of one another. There are elements of both that crossover between the other.

\section{Crossover Between Cognitive and Affective Trust}

The lines between cognitive and affective trust often become blurred. Affective trust is based, in part, on the behaviors of others that lead to the emotional response (Webber, 2008). Cognitive trust has components described as goodwill or benevolence (Mayer et al., 1995), both 
of which can also be said of affective trust. The difference here is, with cognitive trust, emotions are based on previous behaviors of the trustee (Dowell et al., 2015) rather than intrinsic psychological factors. Webber (2008) found, in a study of 79 student workgroups comprised of teams of $3(n=9)$ and $4(n=69)$, that cognitive trust correlates positively $(\beta=0.64, p<.01)$. In the following sections, I divide trust development into three areas: (a) components, (b) characteristics, and (c) conditions.

Components of trust. Trust has been divided into three essential components: (a) trustworthiness, (b) exhibiting trusting behavior, and (c) distrust (Glanville \& Paxton, 2007). A. M. Evans and Revelle (2008) identified a fourth component of trust: the propensity to trust. The first two constructs rely heavily upon each other and are used to validate each other. By exhibiting trusting behavior, one inherently becomes more trustworthy (Glanville \& Paxton, 2007). When an individual is more trustworthy, others are more likely to show trusting behaviors toward that person (Glanville \& Paxton, 2007).

Trustworthiness. Trustworthiness means being worthy of trust given by others. More broadly, trustworthiness has been defined as "a belief about the probability of reciprocation based initially on implicit judgments, and then dynamically updated based on experiences" (Chang, Doll, Wout, Frank, \& Sanfey, 2010, p. 87). One experimental design study used to display trustworthiness was shown using game theory and an investment game (Berg, Dickhaut, \& McCabe, 1995). This experiment, consisting of 32 pairs of students at a midwestern university, was designed to measure the concept of trust through reciprocity; suggested during the game, if Player A were to demonstrate a leap of faith in Player B by providing Player B a sum of money without the knowledge of their intention, this would demonstrate Player B's trustworthiness (Berg et al., 1995). This act would suggest something about Player A and their 
propensity to trust, which may have no connection whatsoever to Player B's trustworthiness. Extending trust to one is an act denoting the other's trustworthiness (Berg et al., 1995). Providing benefits to another without explicit knowledge or reciprocity demonstrates the receiver of the trusting act is worthy of one's trust (Molm, Takahashi, \& Peterson, 2000). In this manner, the giving party shows they are trustworthy by extending trust to the receiving party.

Trustworthiness may be incident specific, and "individuals [may] have different types of experiences in different localized settings" (Glanville \& Paxton, 2007, p. 232). This concept follows the cognitive theory of trust, where the trustor uses their historical inferences and experiences to assess the other party's trustworthiness. The apparent trustworthiness of an individual may then be determined using both affective and cognitive processes.

A moral dimension may also be present in the concept of trustworthiness. Hardin (2002) summarized that the trustee has an incentive to be trustworthy; the motivation lies in deriving value in maintaining a relationship in the future. A moral dimension related to trustworthiness was also noted by Simpson (2013) and was somewhat opposed to the rational theory of selfinterest: "Some socially important forms of trustworthiness cannot be explained as (merely) instrumentally rational behavior.... Character is an alternative explanation for some of the forms of trustworthiness that we actually observe" (p. 544).

Trusting behavior. Trusting has been described as a spectrum between completely distrusting and completely trusting (Aver \& Halldorsson, 2010). There is a wide range of possibilities between the two ends of that spectrum. Completely trusting would be the willingness of a party to believe a person or group of people will cooperate in such a way as to fulfill the intent of the act. In contrast, trusting others reflects one's belief others are not only 
competent and have the ability to perform but are also responsible and possess the intention to perform (Hill \& O’Hara, 2006).

Exhibiting trusting behavior (i.e., believing in communication in ambiguous situations; Rotter, 1980) is an example of being vulnerable to another. The vulnerability described also suggests an element of one's ability to accept the risk of trusting the other. Vulnerability is contrasted with risk aversion, and vulnerability will only become visible after trust is established (Eckel \& Wilson, 2004).

Some argue mitigation of inherent risk is used as a protective measure noted as trust but verify, popularized by President Ronald Regan, when dealing with the Soviet Union and disarmament in the late 1980s (Watson, 2011). In this model, the trustor provides the trustee room to operate and will verify the work has been done and the commitment, or promise, has been kept. A contrary point of view Schoorman, Mayer, and Davis (2007) suggested is the act of verifying, which, by its nature, shows a level of distrust. The act of checking up on the trustee suggests the trustor may not believe the commitment will be kept. The act of verifying, therefore, demonstrates a lack of trust that may not be classified as distrust (Lewicki et al., 1998).

Distrust. Distrust is characterized by the belief or expectation other's intentions are in opposition to one's best interest and may act in direct opposition, causing harm to one's interest (Lewicki et al., 1998). In other words, distrust is often viewed as the opposite of trust. Distrust in others is characterized by several factors, including fear, skepticism, cynicism, wariness, watchfulness, and vigilance (Lewicki et al., 1998).

Distrust is a construct that can be associated with a low propensity to trust. There are also conditional factors associated with distrust. These include seeing others as belonging to a group outside our own, and even as an outcome of a third party's influence, in the form of gossip 
(Kramer, 1999). Distrust is also a condition that can be earned. When another breaks an actual or social contract, distrust is immediately realized (Kramer, 1999).

Propensity to trust. A. M. Evans and Revelle (2008) suggested an attitude of trust is, in part, based on the personality of an individual. These personality traits are enduring and not easily influenced. Key among these traits are openness and vulnerability. These personality traits are consistent in individuals who would be described as having a propensity to trust (A. M. Evans \& Revelle, 2008).

The propensity to trust has been described as a component of trust. One study described one's propensity to trust as a necessary component for the formation of building trust quickly, or swift trust (Meyerson, Weick, \& Kramer, 1996). A high propensity to trust others is exhibited in some individuals; this propensity allows for a quicker acceptance of the vulnerability inherent in a trusting relationship (H. Gill, Boies, Finegan, \& McNally, 2005). One advantage for those with a high propensity to trust is the ability to create ad-hoc teams effectively (Tatham \& Kovacs, 2010). An example of when an ad hoc team would be useful is during a crisis management situation, where the time to form and make crucial decisions is limited (Tatham \& Kovacs, 2010).

Disadvantages are also present when there is a high propensity to trust. A willingness to trust others before demonstrable traits are present leads to situations where trust is taken advantage of and harm is created (Eckel \& Wilson, 2004). Therefore, there is more risk for those who possess a propensity to trust because they may be more willing to take a risk based on factors that are not verified (A. M. Evans \& Revelle, 2008). Lewicki et al. (1998) theorized a low propensity to trust might be a positive trait in team development, as it may reduce the risk of groupthink in that team. 
There are conflicting theories of how individuals develop their propensity to trust or not to trust. The propensity to trust others may be an innate psychological trait or a trait acquired through early childhood experiences (Couch \& Jones, 1997). Under the psychological propensity theory, the extent to which propensity to trust is high or low influences one's trustworthiness (Couch \& Jones, 1997; Uslaner, 1999). Couch and Jones (1997), using psychological propensity theory, stated the want or willingness to trust is developed biologically or in the early childhood development process and is unwavering throughout life, regardless of experiences.

A contrasting view of the psychological propensity theory is the propensity to trust stems from a social-learning perspective (Glanville \& Paxton, 2007; Stack, 1978). Stack (1978) asserted people generalize about others based on their experiences of how other people have treated them. The social-learning perspective demonstrates an evolutionary process, where events throughout one's life influence one's propensity to trust.

Glanville and Paxton (2007) studied the social-learning perspective and posited high trust could produce a greater degree of generalized trust. Generalized trust is a construct closely related to the propensity to trust. The social learning perspective can also clarify a low propensity to trust. High trust can develop into low trust through behaviors that challenge the trustworthiness of individuals, leading to distrust (Schoorman et al., 2007).

Characteristics of the components of trust. Components are elements of a larger whole, and those components possess characteristics that are features or qualities of those components. The attributes of trustworthiness and exhibition of trusting behaviors consist of (a) humility, (b) empathy, and (c) vulnerability (Aver \& Halldorsson, 2010; Berg et al., 1995; Glaser, Laibson, Scheinkman, \& Souter, 2000). In this section, I review the literature on these critical characteristics. 
Humility. Scholars have struggled to develop a definitive definition of humility (Davis, Worthington, \& Hook, 2010). While it might be easy to describe terms not associated with humility, arrogance, pride, or self-importance (Rowatt, Ottebreit, Nesselroade, \& Cunningham, 2002), "the absence of something negative does not necessarily imply the presence of something positive" (Davis et al., 2010, p. 243). There are, however, closely aligned words some have used to describe humility, such as modesty or open mindedness (Rowatt et al., 2002). These terms may represent some of the characteristics of a humble person; however, Davis et al. (2010) informed the context in the communication process in the CoT. Those characteristics are:

1. Other-orientedness in ones' relationships with others rather than selfishness;

2. The tendency to express positive other-orientated emotions in one's relationships (e.g., empathy, compassion, sympathy, and love);

3. The ability to regulate self-oriented emotions, such as pride and excitement about one's accomplishments in socially acceptable ways; and

4. Having an accurate view of self (Davis et al., 2010, p. 248).

Humility can be described as an accurate and realistic view of self-knowledge and the communication of that knowledge with others.

Humility is often viewed as a crucial component in trustworthiness (Nielsen, Marrone, \& Slay, 2010). Humility can manifest in several ways, such as the ability to be open to new paradigms, the ability to ask for advice, eagerness to learn from others, and acknowledgment of one's mistakes and limitations (Vera \& Rodriguez-Lopez, 2004). Displaying humility enables one to become trusted by another (Thielmann \& Hilbig, 2014). High humility in the trustor allows the trustor to have a greater sense that an unknown trustee is trustworthy (Thielmann $\&$ Hilbig, 2014). The display of humility garners trust efficacy (Nielsen et al., 2010). While 
humility is a characteristic embedded in the construct of trust, it is not the sole characteristic necessary.

Empathy. Empathy has been defined in the literature as the ability to understand another's motives, values, and emotions (Salovey \& Mayer, 1990). Goleman (2000) expanded this definition by offering three types of empathy: (a) cognitive, (b) emotional, and (c) empathic concern. Cognitive empathy is the ability to understand the world through another's point of view. This form of empathy informs individuals of how they can communicate effectively with someone. Emotional empathy is described as developing an understanding of how another person is feeling. Covey (2004) emphasized emotional empathy in describing a style of listening, termed empathic listening. Covey described empathic listening as listening to understand, as opposed to listening to reply.

Emotional empathy allows individuals to make a deeper connection with individuals and enables them to recognize they are being heard and understood (Covey, 2004). Typically, this form of empathy requires senses other than being audible; reading facial clues and other body language assist in this understanding. Empathic concern is more profound than cognitive or emotional empathy. It is the type of empathy that relates to parents' love for their children; this form of care is at the heart level of human emotion. In the context of a working relationship, empathic concern allows others to know they will receive support (Goleman, 2000).

While all three types of empathy can aid in the ability to communicate, it is the emotional empathy that provides the most significant impact on the development of trust (Goleman, 2000). Emotional empathy allows people to feel they have been heard, which is a powerful tool in building trust (Covey, 2004). Trust is built through empathic listening because one person has shown an interest in another and what the other is saying (Covey 2004; Schein, 2013). To display 
empathy requires one to be vulnerable. Garner (2009) stated, "To be with another in this way means for that the time being, you lay aside your views and values to enter another's world without prejudice" (p. 85). The last characteristic, which defines the framework for the development of trust, is vulnerability. Vulnerability may be the most important of the listed attributes as the word itself is used in the majority of scholarly definitions of trust (Mayer et al., 1995; Rousseau et al., 1988).

Vulnerability. The ability to be vulnerable provides considerable risk, yet it is that risk that is described in the definition of trust. Nienaber et al. (2015) stated, "Vulnerability is the key manifestation of trust between individuals" (p. 568). This statement is in alignment with the definition of trust used by Rosseau et al. (1988): "Trust is a psychological state comprising the intention to accept vulnerability based on positive expectations of the intentions or behavior or another" (p. 395). Mayer et al. (1995), who is often cited along with Rosseau with a complementary definition of trust, stated, "The willingness to be vulnerable to the actions of another party based on the expectation that the other will perform a particular action important to the trustor, irrespective of the ability to monitor or control that other party" (p. 712). All three of the aforementioned definitions reference vulnerability as the manifestation of trust.

Different disciplines have included different definitions of vulnerability, The United Nations in describing vulnerability towards natural disasters stated, "The concept of vulnerability stresses the fundamental importance of examining the preconditions and context of societies and communities (for example, different social groups) and elements at risk" (Birkman, 2013, p. 10). In the social sciences, Chambers (2006) defined vulnerability as exposure of contingencies and stress, and difficulty in coping with them. Vulnerability has thus two sides: an external side of risks, shocks, and stress to which an individual or 
household is subject; and an internal side which is defenselessness, meaning lack of means to cope without damaging loss. (p. 33)

To be vulnerable is risky, and risk can produce stress. The willingness to accept risk is a sign of trusting behavior (Rotter, 1980). The willingness to accept risk is directly related to the acceptance of vulnerability and a state related to cognitive trust (Nienaber et al., 2015). Nevertheless, without risk, there is no need for trust and, thus, no reason for vulnerability. Put another way, without the acceptance of vulnerability, there is no trust (Mayer et al., 1995).

Displaying vulnerability is a crucial factor in encouraging others to trust. Zak (2017) stated, "Vulnerability is a sign of strength because it signals teamwork rather than dominance" (p. 156). The act of trusting another is a display on one's own trustworthiness: "One of the ways of encouraging others to trust you is to demonstrate your trust in them by committing, in words or deed, to the action that make you potentially vulnerable to opportunistic actions by the other party” (Huang \& Wilkinson, 2013, p. 464).

In this section, I have identified three characteristics of trustworthiness and exhibiting trusting behavior: (a) humility, (b) empathy, and (c) vulnerability. All three characteristics play a role in the development of trust, yet before trust can entirely be developed, some conditions also must be met. In the following section, I describe these conditions for building trust and why they are necessary for trust to be fully established.

Conditions for trust. Trust development has been viewed as a slow, iterative process through a series of positive, reciprocal acts between parties (Weber, Malhotra, \& Murnigham, 2004). Recognition of self-interest leads to the positive intention of trust development with parties. The development of trust is possible when tangible benefits are present and when at least 
one party recognizes the benefits and inherent risks associated with trusting (Weber et al., 2004). The intention of one party must be present to begin the development cycle.

Intention. Intention is having a desire to accept vulnerability and possessing expectations or wishes of the trustee (Rousseau et al., 1998). Mayer et al. (1995) substituted intention with the term willingness. In Rosseau et al.'s (1998) and Mayer et al.'s (1995) definitions, intention and willingness were used as actions related to vulnerability, which is a critical construct in the development of trust.

To provide consistency throughout this study, I use the word intention synonymously with willingness. The definitions I use for trust are grounded in the work of Mayer et al. (1995) and Rousseau et al. (1998), who both recognized the intention to be vulnerable to the acts of others as a condition of trust. It is an act of faith to be vulnerable to others, faith that the other will not abuse that trust and cause harm.

An intention is necessary from the trustee and the trustor. Rousseau et al.'s (1998) said the vulnerability the trustor faces is based on the intentions of the trustee. These intentions are related to willingness to complete the task or honor the commitment to the trustee. To be trustworthy, one must desire (possess the intention) to be worthy of trust (A. M. Evans \& Revelle, 2008). An intention to be trustworthy enables the maintenance of a positive relationship and may be the only motivation needed for the trustee to deliver on the promise.

As I identified in my theory embedded in the CoT, possessing the intention to trust is a condition that must be present to start the cycle, and sincerity allows the circle to continue. However, as I will show in the next section, without one being reliable or dependable, trust development is unlikely to occur. 
Reliability and dependability. Scholars have recognized reliability as a critical influencer in the formation of cognition-based trust (Chua et al., 2008; McAllister, 1995). McAllister (1995) cited the ability to deliver on one's promises made to another as a condition of affective trust. Dependability differs from reliability because of the aspect of vulnerability in the definition, where one actor is dependent on another to deliver whatever outcome is necessary. The ability to deliver also requires competence in the task at hand.

Given that, competency also plays a role in dependability (Dowell et al., 2015). Trust is a construct scholars have agreed takes time to develop (Weber et al., 2004). It typically involves repeated cycles of actors proving dependability before being deemed reliable (Chua et al., 2008). Reliability and dependability are elements that complete one path through the CoT, which then allows participants to lead to the party's recognition of the other's sincerity, beginning the next cycle in the CoT.

Sincerity. Sincerity is often used as a synonym of authenticity (Avolio \& Gardner, 2005); although similar, there is a difference. As discussed previously, authenticity is about being true to oneself and one's beliefs (Novicevic, Harvey, Buckley, Brown, \& Evans, 2006) and allowing one's true self to be seen (Brown, 2010). Authenticity is a condition of ethical choices (Jackson, 2005) and a state of being (Kernis, 2003; Ryan \& Deci, 2001). Authentic behavior has been described as a consistent application of words and actions based on beliefs and values (George, 2007). It has been a trait associated with the foundation for leadership (Benard, 1938). Concepts of authentic leadership can be found in transformational leadership theory (Bass \& Steidlmeier, 1999).

Avolio and Gardner (2005) differentiated authenticity from sincerity, where sincerity refers to the "outward expression of feelings and thoughts that are aligned with the reality 
experienced by the self. This definition implies that one is interaction with an 'other' besides oneself” (p. 320). R. Gill (2011) stated “a mismatch between actions and espoused values denotes hypocrisy, which destroys credibility and trust” (p. 161). In organizational terms, authenticity is derived from a combination of transparency, honesty, experienced-informed intuition, and moral courage (Novicevic, Harvey, Bucklye, Brown, \& Evans, 2006). When authentic characteristics translate and are understood by others, sincerity is present, and trust is developed with individuals and throughout the organization (Benard, 1938). Sincerity allows others to know where one is coming from, mitigating some risks and allowing for others to trust more readily (George, 2007). The recognition of sincerity in and between the parties leads to the next cycle, in which respect is earned.

Respect. To respect something is to hold it in high regard; yet, respect is a multifaceted construct. Darwall (1977) defined two distinct forms of respect: (a) recognition and (b) appraisal. Each kind of respect has its subtleties. Recognition respect stems from a moral position; it is the type of respect every person deserves (Darwall, 1977). Recognition respect acknowledges the dignity in another human being or respect for persons (Cranor, 1975). Unlike recognition respect, appraisal respect is earned. Appraisal respect is granted based on another's appraisal of some characteristic or skill in an individual (Darwall, 1977). Appraisal respect requires the rationale for giving respect is based in fact (Cranor, 1975).

Humility's relationship to respect is apparent in Schein's (2013) book, Humble Inquiry. In the book, Schein described three types of humility: (a) basic humility, (b) optional humility, and (c) here and now humility. Basic humility is the humility where one shows deference to positional or social power. Schein described basic humility as a condition rather than a choice. In optional humility, one feels a sense of respect and deference based on another's 
accomplishments. In here and now humility, one lowers their status because of a dependency one may have with another. In Schein's work, respect is transposed with humility, seemingly because the respect described in all three definitions translates to the action of humility or showing deference. Respect is a precursor to the development of trust; without respect, there is not trust. Next, I explore how trust has been traditionally developed and how this fits into the CoT process.

\section{Trust Development}

The traditional approach to trust development is a slow and deliberate process (Weber et al., 2004). If one party understands the benefits outweigh the risks of being vulnerable, this process can successfully begin. It requires one party to make an intentional first step and to enact trusting behavior. The recipient of this trusting behavior can respond in a variety of ways, from no action to reciprocation to an outright rejection of outreach. If trusting action is reciprocated, the cycle of trust development has begun (Weber et al., 2004). The back-and-forth nature of trusting behavior and reciprocity starts with small gestures and gradually grows to show trust has developed between parties. While typically slow and deliberate, temporal considerations can be mitigated if the parties recognize the value of their self-interest in developing a trusting relationship (Weber et al., 2004).

Characteristics of trustworthiness, humility, empathy, and vulnerability do not have a prescription for teaching but can be modeled and learned. One must learn and practice these characteristics of trustworthiness, an effort requiring humility, empathy, and vulnerability, which takes time because they are not innate human behaviors (Vera \& Rodriguez-Lopez, 2004). There is no prescription for teaching trusting behaviors. While trusting behaviors may be present in those who possess the propensity to trust, those without the propensity to trust can learn to 
exhibit trusting behaviors by observing and modeling the acts of those who display trustworthiness.

\section{Summary}

The literature has shown that; trust between parties is a crucial element in the formation of a functional team (Katzenbach \& Smith, 1992). Trust is one of three criteria deemed necessary to develop a team from a group; the other criteria are sharing a clear purpose and alignment in their vision (Katzenbach \& Smith, 1992). If any of the criteria are not present, a cross-functional workgroup may not be able to form into a team. Trust may become the glue that binds together a group's shared purpose and a shared vision. Developing trust between group members to assist in its transformation to a team is worth the investment of time and effort in building crossfunctional teams (Katzenbach \& Smith, 1992).

Trust is divided into two categories: (a) affective and (b) cognitive. Affective trust can be shown through emotions or genuine care or concern; it comes from the heart (Chua et al., 2008; McAllister, 1995). Cognitive trust can be shown through behaviors where competence, reliability, and dependability are the guiding factors (B. K. Choi et al., 2014; McAllister, 1995; Schaubroeck et al., 2011). Nuances have been made between attitude and behavioral trust (Ahmed \& Salas, 2009). Trust can be understood as having trust as an expectation versus using trust to decide on taking action (Currall \& Inkpen, 2002). Both cognitive and affective trust have been linked to encompassing attitude and behavioral concerns (D. Johnson \& Grayson, 2005; McAllister, 1995; Schaubroeck et al., 2011; Webber, 2008).

Trusting behaviors are displayed more quickly by those who possess a propensity to trust. The propensity to trust is thought to come from psychological traits developed innately or in early childhood experiences (Couch \& Jones, 1997). These traits are typically unwavering and 
last through one's lifetime (Glanville \& Paxton, 2007). Those who display trusting behaviors manifest a willingness to be vulnerable.

Trustworthiness is a construct that is earned. Others grant it in their belief of one's trustworthiness rather than something that can be proven. When others are willing to be vulnerable - to give trust - they take the risk one is trustworthy (Hill \& O'Hara, 2006). One way to display trustworthiness is to give another trust (Berg et al., 1995).

Inherent in every trust scenario are two constructs: (a) intention and (b) vulnerability (Mayer et al., 1995; Rousseau et al., 1998). To trust, or to be trustworthy, is an intentional act, requiring both willingness and desire. There must be a willingness to trust and a desire to be trustworthy. Nienaber et al. (2015) noted, "Vulnerability is the key manifestation of trust between individuals" (p. 568). Actors must display vulnerability; without vulnerability, there is no trust, and, without risk, there is no need to trust.

Throughout the literature review, I have shown vulnerability is present and works in concert with humility and empathy to form a trusting relationship. Having the intention to build trust is mandatory, and actors must also show authenticity, which can transform into respect, laying the groundwork for a relationship built on trust. In this study, I posit if all positive relationships require trust to survive and thrive, a business relationship, whether inter- or intraorganizational, will be no different. Management, employees, peer groups, and cross-functional intradepartmental relationships may benefit from increased trust among individuals and groups. 


\section{CHAPTER THREE - METHODOLOGY}

The intervention, which is the focus of this study, was previously administered to crossfunctional groups in three small business organizations. To date, the evidence gathered in three previous workgroups has provided anecdotal evidence to suggest trust is affected positively in workgroups that have completed a similar intervention; however, in earlier applications, I had not collected any data on development of trust in the groups.

This study is the first attempt to collect data on subject groups to evaluate the intervention on its effectiveness in building trust in a cross-functional workgroup. Also, the data collected provided valuable insights into understanding what iterations are needed to improve the process of teaching communication techniques directed toward cross-functional workgroups. Patton (1997) stated, "Program evaluation is undertaken to inform decisions, clarify options, identify improvements, and provide information about programs and policies in contextual boundaries of time, place, values and politics" (p. 24). Because the goals of this study are consistent with Patton's (1997) description, a mixed-methods approach was appropriate.

The research objective was to determine the effectiveness of an intervention in building trust in a cross-functional workgroup. The intervention was a 13-week course designed to teach communication processes and applications in a group or classroom setting. I hypothesized the communication intervention would result in increased levels of affective-based trust or, as Gillespie (2003) defined it, disclosure-based trust. I also hypothesized cognitive-based trust or reliance-based trust (Gillespie, 2003) would grow more with the groups exposed to the intervention than with a comparison group.

Through this study, I analyzed the effectiveness of the course in building trust in the groups. While the intervention was designed to teach communication techniques, a specified 
outcome was to build trust in the workgroup. As discussed in Chapters 1 and 2, trust is an oftenoverlooked factor in the transformation of a group into a functional team.

A repeated measure within- and between-group design quantitative study provided statistics I analyzed to determine specific outcomes and determine the effectiveness of the intervention. Adding qualitative research allowed me to understand the impact the intervention had on participants. This understanding of the effect the intervention had on participants permitted a thorough evaluation of the program. This evaluation provided data to determine if changes to the curriculum are necessary to meet the program's objectives of improving trust in a cross-functional workgroup through better communication.

\section{Program Evaluation}

Program evaluations are performed for a variety of reasons, including informing decisions, clarifying options, and providing information leading to program improvements (Patton, 1997). A quantitative study alone could have been used to evaluate the effectiveness of this course to make a merit-based decision about choosing to continue or terminate the program. A qualitative study alone could have provided enough data to make improvements in the curriculum based on participants' likes and dislikes yet would offer little assistance leading to go/no-go decisions. In combining quantitative and qualitative methods, I had data to suggest the effectiveness of developing trust in a cross-functional group and an in-depth look at components

of the intervention and the relationship to the desired outcomes. Furthermore, the qualitative data led to insights that allowed me to revise the process and materials for the course in the future.

\section{Research Paradigm and Philosophy}

The paradigm of pragmatism is often used in mixed-method research (Muijs, 2011). A pragmatic lens works well with a mixed-method approach because the practical, results-driven 
solution can maximize the benefits of multiple methods of analysis (R. B. Johnson \&

Onwuegbuzie, 2004), while a quantitatively oriented positivist seeks the truth. The qualitatively oriented constructivist seeks an understanding rather than a fixed reality. Pragmatists seek

practical solutions (R. B. Johnson \& Onwuegbuzie, 2004; Legg \& Hookway, 2019). The pragmatist is not as interested in discovering the truth from the positivist point of view or the constructivist yearning to understand where knowledge comes from. The pragmatist is interested in finding applications that solve real-world problems as opposed to theoretical solutions (Urdan, 2010). Because I was interested in finding an application that would solve a real-world problem, this study used both quantitative and qualitative methods in the design.

In this study, I uncovered quantitative data that allowed me to determine the effectiveness of the intervention in building trust in a cross-functional group. Quantitative data obtained from a postintervention participant satisfaction survey were used to determine the results of six categories of the intervention process. By using qualitative methods, I gained insight and an understanding from participants' points of view of which processes used in the intervention were effective in building trust. Also, I exposed participants' thoughts, suggestions, and ideas on ways to improve the intervention for future deployment.

\section{Research Design}

The study was intended to analyze the potential effectiveness of a communication course designed to build trust in a cross-functional workgroup. In this section, I define the process of a mixed-method study, with a quasi-experimental design, detailing the target population and the quantitative and qualitative methods used in this study.

A mixed-method approach combines elements of quantitative and qualitative research (Tashakkori \& Creswell, 2007). Mixed-methods research is appropriate when there are at least 
two types of research questions - data collection procedures and analysis of that data required different methods (Tashakkori \& Creswell, 2007). In this study, a mixed-method research design allowed me to understand program effectiveness and identify areas of improvement. Mixedmethods research can be used for a variety of reasons, including verification purposes, estimating possible error in underlying measures, facilitating the monitoring of data collected, and probing a data set to determine its meaning (Sechrest \& Sidani, 1995). Dzurec and Abraham (1993) shared six beliefs regarding the utility of mixed-methods research. Three of these beliefs about mixedmethods resonated with my purpose for studying the effects of the intervention in crossfunctional workgroups. Those beliefs are (a) the pursuit of complexity reduction to enhance understanding, (b) the pursuit of truthfulness, which is most important to me as a pragmatist, (c) the probing of a data set to determine its meaning (Dzurec \& Abraham, 1993).

Researchers employ mixed-method research studies when they believe this approach is the best way to get answers to the research questions they are attempting to answer (R. B. Johnson \& Onwuegbuzie, 2004). Mixed-methods research literature began with Campbell and Fiske's (1959) introduction of a method of construct validation of research.

Construct validation is defined as ensuring the tests employed are measuring what they purport to be measuring (Creswell, 2012; Cronbach \& Meehl, 1955). Construct validation is the process of combining multiple methods of study of the same phenomena. Construct validation is a byproduct of triangulation, a term used when alternate perspectives are used to validate findings (Salkind, 2010). Triangulation is the convergence of data from multiple sources (Bouchard, 1976; Mertens \& Hesse-Biber, 2012). In this study, I attempted to triangulate data received through focus groups, individual interviews, my field notes, and the survey. The process I employed for triangulation is detailed in the data collection and analysis section. 
Mixed-method research incorporates multiple data collection strategies (R. B. Johnson \& Onwuegbuzie, 2004). This study used three distinct forms of data collection strategies; with each strategy, I used multiple tools to obtain data. Using quantitative research methods, I deployed the Behavioural Trust Inventory (BTI), as both a pre- and post-test, and the participant satisfaction survey. I obtained qualitative data with focus group sessions, individual interviews, and openended questions in the participant satisfaction survey. These data were supported with and supplemented by detailed field notes I recorded at the end of each session, including the focus group session. Additional field notes were recorded by the observer after the sessions she attended.

In this study, a mixed-method, quasi-experimental design was selected because it was the most appropriate method to answer the research questions. According to Creswell (2012), a quasi-experiment "includes assignment, but not random assignment to a group" (p. 309). A quasi-experimental design differs from an experimental design. In a classic experimental design, the subject group is developed from a random population sample. In contrast, in a quasiexperimental design, a random sample of the population is not possible; the subjects of the study are chosen to represent a population with criteria selected by the researcher (Muijs, 2011).

The business organizations included in this study were selected based on a convenience sample, which is a sample in which the researcher selects participants because they are available and willing (Creswell, 2012). The business organizations were chosen because they were willing to allow midlevel managers to go through the communication course. Convenience sampling indicates participant organizations met the established criteria for voluntary involvement (Creswell, 2012). Groups were constructed of individuals who volunteered from the chosen organizations. These individuals fit the selection criteria for inclusion in the study. Those 
qualifications included the requirements of being full-time employees of the company. Each participant held a position as a supervisor, manager, or director. One limitation was the group consisted of no more than two participants from a given department.

The quasi-experimental design study is similar to experimental design, in that both design methodologies begin with research objectives and a hypothesis (Creswell, 2012). To obtain a repeated measure, within-group, and between-group design study, a pretest was administered to participants prior to any course materials being delivered to participants. Once the pretest was conducted, participants were taken through the 13-week course on developing effective communication. At the end of the intervention, each participant completed their posttest, which included the same questions as the pretest. The comparison group was subject to the same preand post-test without the intervention. The comparison group was comprised of individuals who possessed qualifications for inclusion in the study that were the same as the research subject group's composition (Mujis, 2011). Those qualifications are detailed in the discussion of the subject population.

\section{Research Design Process}

Consistent with the purpose of the study, which was to determine the effectiveness of the intervention on building trust in a cross-functional workgroup in small business organizations, I conducted the study using two independent participant groups and a single comparison group. The groups studied were selected based on well-defined criteria described in the following section (Creswell, 2012).

\section{Subject Population}

Participant groups were selected from for-profit, small business organizations located in Southern California. These organizations were chosen because they fit the study criteria as small 
business organizations. Before this research, I established relationships with both organizations' senior executives at all three companies. Participant selection was left to the executive management team in each organization. Both companies were provided with an IRB approved recruitment letter (see Appendix A) and were asked to recruit between 8 and 12 volunteers from their middle management personnel.

Although the U.S. Small Business Association (2019) places all of the groups under their small business category, there are differences in the size and makeup of these organizations. Group 1 was from a manufacturing firm of 35 full-time employees in a single location. This company was a relatively small organization, with revenues between $\$ 7-10$ million each year. Group 2 was from a company in the insurance industry, with 140 full-time employees in two locations. Their headquarters were in Southern California, and their secondary office was in Texas. The workgroup that took part in the study had participants from both locations. Group 2 was a larger business, with revenues between $\$ 40-50$ million per year. The primary industry of Group 3, the comparison group, is providing adult learning to businesses. They have 225 employees in 10 locations through four Western states: California, Nevada, Arizona, and Utah. Their revenues are between $\$ 20-25$ million per year. Group 3's participation was limited to an initial preview of the study and the pre- and post-test. Each business represents a different industry. The smaller organization, Group 1, specialized in research and design in the manufacturing sector. Group 2 was a business service organization specializing in insurance products. Both participant organizations had deployed cross-functional workgroups previously; however, neither had facilitated specific training to build trust with those cross-functional groups. 
The demographic information of the individual participants in each group was collected using the pretest survey. The essential component of the demographic data for this study was the professional title, as it was part of the selection criteria for inclusion in the study. Other categorical data were collected, which may become relevant in future studies. These categories included gender, age range, education levels, and titles. A notable omission in the demographic information is I did not collect any information on race or ethnicity that is common in other studies (see Table 2).

Table 2

Demographic Information of Participants

\begin{tabular}{lcccccc}
\hline Variable & Group 1 & \multicolumn{2}{c}{ Group 2 } & \multicolumn{2}{c}{ Group 3 } \\
\hline $\begin{array}{l}\text { Gender } \\
\quad \text { Male }\end{array}$ & 7 & & 8 & & 9 & \\
$\quad$ Female & 4 & $(57 \%)$ & 2 & $(25 \%)$ & 7 & $(78 \%)$ \\
Age & 3 & $(43 \%)$ & 6 & $(75 \%)$ & 2 & $(22 \%)$ \\
$\quad 18-35$ & 2 & $(29 \%)$ & 1 & $(13 \%)$ & 3 & $(33 \%)$ \\
$\quad 36-50$ & 3 & $(43 \%)$ & 7 & $(88 \%)$ & 4 & $(44 \%)$ \\
$\quad 51-65$ & 2 & $(29 \%)$ & 0 & $(0 \%)$ & 2 & $(22 \%)$ \\
Education & 3 & $(43 \%)$ & 4 & $(50 \%)$ & 2 & $(22 \%)$ \\
$\quad$ HS/GED & 1 & $(14 \%)$ & 1 & $(13 \%)$ & 2 & $(22 \%)$ \\
$\quad$ AA/AS & 3 & $(43 \%)$ & 2 & $(25 \%)$ & 4 & $(44 \%)$ \\
$\quad$ BA/BS & 0 & $(0 \%)$ & 1 & $(13 \%)$ & 1 & $(11 \%)$ \\
$\quad$ MA/MS & & & & & & \\
Title & 1 & $(14 \%)$ & 2 & $(25 \%)$ & 1 & $(11 \%)$ \\
$\quad$ Supervisor & 1 & $(14 \%)$ & 6 & $(75 \%)$ & 6 & $(67 \%)$ \\
$\quad$ Manager & 5 & $(71 \%)$ & 0 & $(0 \%)$ & 2 & $(22 \%)$ \\
$\quad$ Director & & & & & & \\
\hline
\end{tabular}

The data analysis excluded any participant who started but failed to finish the 13-week program. Both participant groups had individual members drop out of the course before its completion. As noted in the requirements of participation, no individual could miss more than three of the scheduled classes and continue with the program. Group 1 had one participant drop out voluntarily just before Week 8 for personal reasons. In Group 2, two of the original 
participants voluntarily dropped out. Both stated an unexpected workload increase created by a potential change in ownership of the organization—one just before Week 3 and the other just before Week 5. Two additional participants were dropped before Week 8 because participants had missed four classes over the first seven weeks. Tables 3 and 4 show each participant and their attendance during the intervention.

Table 3

Attendance of Participants in Group 1

\begin{tabular}{ccccccccccccccc}
\hline Week & 1 & 2 & 3 & 4 & 5 & 6 & 7 & 8 & 9 & 10 & 11 & 12 & 13 & Focus \\
\hline 1 & $\mathrm{~A}$ & $\mathrm{x}$ & $\mathrm{x}$ & $\mathrm{x}$ & $\mathrm{x}$ & $\mathrm{x}$ & $\mathrm{x}$ & $\mathrm{A}$ & $\mathrm{x}$ & $\mathrm{x}$ & $\mathrm{A}$ & $\mathrm{x}$ & $\mathrm{x}$ & $\mathrm{x}$ \\
2 & $\mathrm{x}$ & $\mathrm{x}$ & $\mathrm{x}$ & $\mathrm{A}$ & $\mathrm{x}$ & $\mathrm{x}$ & $\mathrm{x}$ & $\mathrm{A}$ & $\mathrm{x}$ & $\mathrm{x}$ & $\mathrm{x}$ & $\mathrm{x}$ & $\mathrm{x}$ & $\mathrm{x}$ \\
3 & $\mathrm{x}$ & $\mathrm{x}$ & $\mathrm{x}$ & $\mathrm{x}$ & $\mathrm{x}$ & $\mathrm{x}$ & $\mathrm{x}$ & $\mathrm{x}$ & $\mathrm{x}$ & $\mathrm{x}$ & $\mathrm{x}$ & $\mathrm{x}$ & $\mathrm{x}$ & $\mathrm{x}$ \\
4 & $\mathrm{x}$ & $\mathrm{x}$ & $\mathrm{x}$ & $\mathrm{x}$ & $\mathrm{x}$ & $\mathrm{x}$ & $\mathrm{x}$ & $\mathrm{A}$ & $\mathrm{A}$ & $\mathrm{x}$ & $\mathrm{x}$ & $\mathrm{x}$ & $\mathrm{x}$ & $\mathrm{x}$ \\
5 & $\mathrm{x}$ & $\mathrm{x}$ & $\mathrm{x}$ & $\mathrm{x}$ & $\mathrm{x}$ & $\mathrm{x}$ & $\mathrm{x}$ & $\mathrm{x}$ & $\mathrm{x}$ & $\mathrm{x}$ & $\mathrm{A}$ & $\mathrm{x}$ & $\mathrm{x}$ & $\mathrm{x}$ \\
6 & $\mathrm{x}$ & $\mathrm{x}$ & $\mathrm{x}$ & $\mathrm{A}$ & $\mathrm{x}$ & $\mathrm{x}$ & $\mathrm{x}$ & $\mathrm{x}$ & $\mathrm{x}$ & $\mathrm{x}$ & $\mathrm{x}$ & $\mathrm{x}$ & $\mathrm{A}$ & $\mathrm{x}$ \\
7 & $\mathrm{x}$ & $\mathrm{x}$ & $\mathrm{x}$ & $\mathrm{x}$ & $\mathrm{x}$ & $\mathrm{x}$ & $\mathrm{x}$ & $\mathrm{x}$ & $\mathrm{x}$ & $\mathrm{x}$ & $\mathrm{x}$ & $\mathrm{x}$ & $\mathrm{x}$ & $\mathrm{x}$ \\
8 & $\mathrm{x}$ & $\mathrm{x}$ & $\mathrm{x}$ & $\mathrm{x}$ & $\mathrm{x}$ & $\mathrm{A}$ & $\mathrm{A}$ & $\mathrm{D}$ & $\mathrm{D}$ & $\mathrm{D}$ & $\mathrm{D}$ & $\mathrm{D}$ & $\mathrm{D}$ & $\mathrm{D}$ \\
\hline
\end{tabular}

Note. $\mathrm{A}=$ Absent, $\mathrm{R}=$ Remote, $\mathrm{D}=$ Dropped, $\mathrm{x}=$ Present - includes dropped participants

Table 4

Attendance of Participants in Group 2

\begin{tabular}{ccccccccccccccc}
\hline Week & 1 & 2 & 3 & 4 & 5 & 6 & 7 & 8 & 9 & 10 & 11 & 12 & 13 & Focus \\
\hline 1 & $\mathrm{~A}$ & $\mathrm{x}$ & $\mathrm{x}$ & $\mathrm{x}$ & $\mathrm{x}$ & $\mathrm{x}$ & $\mathrm{R}$ & $\mathrm{x}$ & $\mathrm{x}$ & $\mathrm{x}$ & $\mathrm{x}$ & $\mathrm{x}$ & $\mathrm{x}$ & $\mathrm{x}$ \\
2 & $\mathrm{~A}$ & $\mathrm{x}$ & $\mathrm{A}$ & $\mathrm{x}$ & $\mathrm{x}$ & $\mathrm{x}$ & $\mathrm{x}$ & $\mathrm{x}$ & $\mathrm{x}$ & $\mathrm{x}$ & $\mathrm{x}$ & $\mathrm{x}$ & $\mathrm{x}$ & $\mathrm{x}$ \\
3 & $\mathrm{x}$ & $\mathrm{x}$ & $\mathrm{x}$ & $\mathrm{x}$ & $\mathrm{x}$ & $\mathrm{x}$ & $\mathrm{x}$ & $\mathrm{x}$ & $\mathrm{x}$ & $\mathrm{A}$ & $\mathrm{x}$ & $\mathrm{A}$ & $\mathrm{x}$ & $\mathrm{x}$ \\
4 & $\mathrm{x}$ & $\mathrm{x}$ & $\mathrm{x}$ & $\mathrm{x}$ & $\mathrm{x}$ & $\mathrm{x}$ & $\mathrm{x}$ & $\mathrm{x}$ & $\mathrm{x}$ & $\mathrm{x}$ & $\mathrm{x}$ & $\mathrm{x}$ & $\mathrm{A}$ & $\mathrm{x}$ \\
5 & $\mathrm{x}$ & $\mathrm{x}$ & $\mathrm{A}$ & $\mathrm{x}$ & $\mathrm{x}$ & $\mathrm{A}$ & $\mathrm{x}$ & $\mathrm{x}$ & $\mathrm{x}$ & $\mathrm{x}$ & $\mathrm{x}$ & $\mathrm{x}$ & $\mathrm{x}$ & $\mathrm{x}$ \\
6 & $\mathrm{x}$ & $\mathrm{x}$ & $\mathrm{x}$ & $\mathrm{x}$ & $\mathrm{x}$ & $\mathrm{x}$ & $\mathrm{x}$ & $\mathrm{x}$ & $\mathrm{A}$ & $\mathrm{x}$ & $\mathrm{A}$ & $\mathrm{A}$ & $\mathrm{x}$ & $\mathrm{x}$ \\
7 & $\mathrm{x}$ & $\mathrm{A}$ & $\mathrm{x}$ & $\mathrm{A}$ & $\mathrm{R}$ & $\mathrm{x}$ & $\mathrm{x}$ & $\mathrm{x}$ & $\mathrm{x}$ & $\mathrm{x}$ & $\mathrm{x}$ & $\mathrm{x}$ & $\mathrm{x}$ & $\mathrm{x}$ \\
8 & $\mathrm{x}$ & $\mathrm{x}$ & $\mathrm{x}$ & $\mathrm{x}$ & $\mathrm{x}$ & $\mathrm{x}$ & $\mathrm{A}$ & $\mathrm{x}$ & $\mathrm{x}$ & $\mathrm{x}$ & $\mathrm{x}$ & $\mathrm{x}$ & $\mathrm{x}$ & $\mathrm{x}$ \\
9 & $\mathrm{x}$ & $\mathrm{A}$ & $\mathrm{D}$ & $\mathrm{D}$ & $\mathrm{D}$ & $\mathrm{D}$ & $\mathrm{D}$ & $\mathrm{D}$ & $\mathrm{D}$ & $\mathrm{D}$ & $\mathrm{D}$ & $\mathrm{D}$ & $\mathrm{D}$ & $\mathrm{D}$ \\
10 & $\mathrm{x}$ & $\mathrm{x}$ & $\mathrm{A}$ & $\mathrm{A}$ & $\mathrm{D}$ & $\mathrm{D}$ & $\mathrm{D}$ & $\mathrm{D}$ & $\mathrm{D}$ & $\mathrm{D}$ & $\mathrm{D}$ & $\mathrm{D}$ & $\mathrm{D}$ & $\mathrm{D}$ \\
11 & $\mathrm{~A}$ & $\mathrm{x}$ & $\mathrm{x}$ & $\mathrm{x}$ & $\mathrm{A}$ & $\mathrm{A}$ & $\mathrm{x}$ & $\mathrm{D}$ & $\mathrm{D}$ & $\mathrm{D}$ & $\mathrm{D}$ & $\mathrm{D}$ & $\mathrm{D}$ & $\mathrm{D}$ \\
12 & $\mathrm{x}$ & $\mathrm{x}$ & $\mathrm{A}$ & $\mathrm{A}$ & $\mathrm{x}$ & $\mathrm{x}$ & $\mathrm{A}$ & $\mathrm{D}$ & $\mathrm{D}$ & $\mathrm{D}$ & $\mathrm{D}$ & $\mathrm{D}$ & $\mathrm{D}$ & $\mathrm{D}$ \\
\hline
\end{tabular}

Note. $\mathrm{A}=$ Absent, $\mathrm{R}=$ Remote, $\mathrm{D}=$ Dropped $\mathrm{x}=$ Present - includes dropped participants 
Participant groups' business organizations provided participants time away from their workdays to complete the 90-minute session each week. These sessions were held weekly for 13 weeks during regular business hours. Neither the participant group nor the comparison group participants or their companies were offered additional incentives for participation.

Group 1 began the course with eight participating employees, and Group 2 started with 12 participants. The criterion for inclusion in the study was status as a direct employee of the business organization. Also, participants had to possess a midlevel management position, such as that of a director, manager, or supervisor. Participants had to represent a minimum of four departments in the organization, with no more than two individuals participating from the same department. It was a vital component of the study to analyze the effectiveness of the intervention in a true cross-functional workgroup. The limit of no more than two participants from a single department ensured a true cross-functional workgroup.

Consistent with regulations regarding the use of human subjects in research, as described in the Belmont Report (U.S. Department of Health and Human Services, Office for Human Research Protections, 2018), each participant, from all three groups, were provided with written documentation detailing their rights regarding the research. Each participant received a notice of informed consent (see Appendix B). This form was delivered in written form and verbally at the beginning of the first session. Informed consent included a description of the research, any potential risks and benefits, and a statement allowing participants to ask any questions they may have had. An additional announcement was made, confirming that participation was voluntary and that participants could withdraw at any time without reprisal.

The informed consent document and discussion detailed confidentiality in the research. The names of the organizations were exchanged for numeric codes in my personal codebook. 
Each participant was also assigned a numeric code to replace their name for all surveys, interviews, and in my field notes. I maintained a codebook throughout the study, which was not made available to any other person. In the written findings of the study, I replaced participants' numbers with gender-neutral pseudonyms, which allowed the written descriptions of events to flow. My commitment to participants, identified in the informed consent process, was there would be no personally identifiable information provided outside of the group.

\section{Intervention Design}

The coursework used in the intervention was designed to teach communication techniques to small workgroups. Several of the concepts used in this intervention were influenced by my time in the MLD and PhD programs at Chapman University. These included having participants establish ground rules for the class. This is an essential element for several reasons. The first is, by having the group establish ground rules, minimal effort is required to enforce those rules. The second is allowing the group to set the rules defers typical power structures and suggests I am with them as a facilitator rather than an instructor or authority figure. The classroom structure is very similar to that of a graduate school course, as there is a reading requirement, written reflection of that reading, and exercises developed to reinforce the lesson assigned each week. In-class time is spent sharing each other's understanding and experiences. The process was one that encouraged listening and sharing to engage in productive dialogue. The key objective in the process was to teach practices that would allow group members to foster humility, empathy, and vulnerability in the group. Learning objectives for the intervention were to:

- Identify when a topic becomes a crucial conversation;

- Understand the value of listening to understand; 
- Develop the skills to share information with others without eliciting confrontation; and

- Discover how to mitigate conflict, encourage dialogue, and create synergistic resolutions.

Both Groups 1 and 2 participated in the 13-week intervention. I noted the attendance of each participant every week (see Tables 3 and 4). One additional session was dedicated to the focus group interview, which took place 2 weeks after completion of the final course session.

The course was scheduled for a weekly 90-minute facilitated group experience. These courses were held in each company's conference room. These rooms each had a large conference table with chairs surrounding that table. I ensured there were sufficient chairs, and I also removed any unused chairs and placed them away from the table. The coursework was supplemented by approximately 60 minutes of weekly homework. The homework consisted of reading a chapter in Crucial Conversations (Patterson, Grenny, McMillan, \& Switzler, 2012) and completing a written concept matrix and observation exercise. A semi-structured style was adopted to allow participants the freedom to explore their own and their peers' thoughts and ideas on the subject matter. The course followed a consistent pattern between both groups.

Week 1. The first session began with introductions. I started introductions by presenting my qualifications, both professional and academic. I went on to submit the purpose of the course as part of a study for my doctoral dissertation, as well as my relationships with the executive management in their organization. I introduced the observer and her qualifications and purpose to ensure I would provide consistent application between both participant groups and interrater reliability for the study. I then informed the group the observer would be present in three other sessions during Week 7, Week 13, and for the focus group interview. After that, I asked each 
member to introduce themselves, the department in which they work, and their title. Next, I passed out the course syllabus (see Appendix C), asked participants to read through the document, and asked if there were any questions on the format and requirements for each of them.

The next section of Week 1 was devoted to the informed consent document each participant was asked to sign. The class then took time to read the informed consent document (see Appendix B), and I asked if there were any questions I could answer. Then I took time to answer each question before asking them to sign the document if they wished to continue in the course. Once I had all of the informed consent documents in hand, I distributed the Behavioural Trust Inventory pretest (see Appendix E). I asked each participant to answer the survey questions as presented, with the stipulation that when answering questions about their team, they should consider the team the group present with them in the class.

After everybody had returned their pretest survey questions, which the observer collected and placed in a sealed envelope, I gave a short lecture on the elements of a team, which included having a unified mission and trust in one another. I then presented a short assignment, where I asked each participant to pick an area of their expertise, what I described as their superpower, and to tell the group what that expertise is, how they use it, and why they value the skill. To ease the potential of others being uncomfortable with this seemingly self-serving presentation, I began the exercise. I explained my superpower is the ability to reframe a conversation, in particular a conversation where people have different opinions. I reframe these ideas in my mind in a way that allows me to explore other realities so I can gain a better understanding of people and their positions. 
I ended this first session by handing out the textbook, the concept matrix, and the original model of the Circle of Trust (CoT), which are embedded in Appendix C, Lesson 1. I first talked through my theory of the CoT and asked if there were questions on this concept. Next, I detailed the purpose of the concept matrix and how they were expected to use this tool for the next 12 weeks. The concept matrix was provided to students in printed form, expressly to limit their ability to type in their responses. Participants were instructed to write out their responses to the provided document in the space provided. To use the concept matrix, each participant needed to first determine the key point of the chapter they had just read and state that point in the first column labeled for that chapter. In the next column, participants needed to describe what that concept meant in their own words. The final column is where participants described how they might use the concept in their own lives.

The strength of the concept matrix is twofold. First, there is limited space for participants to write their responses, which forces them to be very concise in their descriptions, forming a deeper understanding of the material (Mueller \& Oppenheimer, 2014). The second follows in learning theory that the act of handwriting helps learners to solidify the knowledge in their memory (Bohay, Blakely, Tamplin, \& Radvansky, 2011).

I ended both sessions by asking for questions anybody may have about the course, its purpose, their role in the study, or expectations that may be placed on them. There was a consistent pattern followed for Weeks 2 through 12, which is detailed next.

Weeks 2-12. Beginning in Week 2 and going through Week 12, the format was structured the same way. I welcomed participants and started with an icebreaker. Next, we reviewed the previous week's lesson. Next, I asked each participant to share what they wrote on the concept matrix about the current week's reading. Following the concept matrix discussion, I 
asked for volunteers to discuss the exercise they were asked to complete from the previous week. After these discussions, I described the following week's activity. Every session ended with a quote of the week, and I asked if anybody in the group had anything else they wanted to say before we closed.

The icebreaker format was consistent each week with both groups. I would ask, "Who had a good week?” If they went into detail about an event, I would always ask a follow-up question based on the issues they were describing. Not all of the opening stories were positive, and in the case where a participant would describe an adverse event, I always followed up by asking, "Would you like to talk about that now?" In most cases, a short discussion would follow, and I always asked a follow-up question based on some aspect of their story. These follow-up questions were purposeful. The intention behind them was to promote one of the tools that suggests interest in the story and to demonstrate I was listening intently. These icebreaker openings generally lasted between 5 and 10 minutes and always at the start of class. The intention behind icebreakers is to get participants comfortable speaking at the beginning of each session (Krueger \& Casey, 2015).

Following the opening icebreaker, I asked each group member to discuss what they read in the assigned chapter of our textbook, using their concept matrix as a guide. Each participant discussed the primary takeaway from the assigned chapter, what that concept meant to them, and finally an example of how they could use this concept in their day-to-day lives. Again, following the principles I teach in active listening, I always had a question ready for participants based on their interpretation of the concept they were discussing. In many instances, I did not need to ask my question, as others in the group were also provided the opportunity to discuss the presenter's 
point of view or ask clarifying questions. The goal of this discussion was to facilitate peer-topeer learning and sharing ideas as outlined in Gestalt language protocol (GLP; Stathakis, 2013).

The next step of the process was when I asked for volunteers from the group to discuss their take-home assignments. This section differed from the discussion on the concept matrix in that participants were not required to discuss their experiences with the exercises. I did, however, encourage each person to talk through what they saw, how they reacted, and the results they observed as a gift they were giving to their cohort. These exercises were designed to allow participants to practice skills, see reactions, and reflect on their experiences. Sharing that experience with others in their group served dual purposes. The first was for the benefit of others to understand different perspectives of the same exercise, The second purpose, which I find important, was to allow the participant who was sharing to become the teacher, a crucial aspect of retaining the lesson for participants (Koh, Lee, \& Lim, 2018). In my role as facilitator, I listened to find a follow-up or clarifying question as participants shared their stories. Yet, I would only insert these questions if other participants did not present questions or comments of their own.

Following the dialogue on the exercises, I presented the assignment for the following week. During Weeks 2 through 12, these assignments included reading the next chapter in Crucial Conversations (Patterson et al., 2012), analyzing the section using the concept matrix, and assigning an exercise. Each week, I also presented two additional resources. Most weeks, this was a key term and definition; however, on occasion, these resources were external website locations, as described in the course lesson plan (see Appendix C). Before concluding the session, I asked the group if there were any outstanding issues, comments, or concerns they may wish to discuss. If time permitted, we held that discussion; however, if time did not allow, I 
asked if we could put the discussion on hold and bring it back up at the start of the next session. I closed each session with a quote from a famous figure related to the current lesson (see Appendix C).

Week 13. The last regularly scheduled session differed from the previous 11 only slightly. The class read through their concept matrix on the final chapter of Crucial Conversations. However, we devoted less time to this summary chapter because we spent additional time on the previous exercise. In Week 12, I asked each participant to pick a topic we had covered during our time together (see Appendix C, Lesson 13) and write a blog article of between 600 and 800 words they would read aloud to the entire class. Reading the blog articles took approximately one hour for each group to complete. Everyone in each group completed this assignment and read their blog out loud to the class. There was an exception, which was in Group 2. One participant was unable to attend the last session, so she emailed me her blog article and asked that I read it for her, which I did.

After each participant read their blog, I asked participants if they would like to share any reflections they had on the time we had spent together. Everybody in attendance from both groups did take a turn on this reflection and what the course meant to them. I followed that discussion by announcing that the observer would administer the posttest as I left the room. The observer collected each of the posttest surveys and placed them in a sealed envelope before presenting the package to me to store and use later in my analysis.

Course delivery differences. I did make every attempt to provide a consistent presentation of course materials to both classes. However, there were a few differences in this delivery. The first was I had made a conscious decision to alter my style of dress between the two classes. I did this as an attempt to fit into the specific culture of each group. For instance, 
with Group 1, a manufacturing company, I wore jeans, casual shoes, and a collared short-sleeved shirt. When I presented to Group 2, a professional services organization, I wore slacks, dress shoes, and a button-down, long-sleeved shirt.

Another difference was there were 2 weeks in Group 1 where we did not have the group read through their concept matrix. Bypassing this vital element of the course was not by design but was part of the semi-structured nature of the course. There were 2 weeks where the check-in question at the beginning of class led to discussions of problems within the organization. I made a conscious decision to allow the discussion of the organizational dysfunction to continue for two reasons. The first is the group was practicing what they were learning about how to handle a crucial conversation. They kept the room safe, discussed their positions in a respectful manner, and seemed to be using the tools they were taught to listen to the alternate point of view. The second reason I felt I should allow the conversation to continue is because, as a pragmatist, I believed it would be the best course of action. I would allow the group to enter into dialogue, which may lead to a solution. Both of these sessions that went off course, I felt, were prime examples of the group entering into crucial conversations.

\section{Sources of Data Collection}

This study incorporated multiple sources of data, including quantitative data collected from the pre- and post-test, a participant satisfaction survey administered by the outside observer after the focus group session, and attendance records I maintained for each session. The qualitative data included detailed field notes complied after each session, field notes from the three meetings attended by an outside observer, transcripts of focus group sessions, and transcripts from individual interviews with selected participants. Additionally, a participant satisfaction survey was administered to each member of the participant groups. 


\section{Quantitative Design and Analysis}

I employed a repeated measure in- and between-groups design (Creswell, 2012). The quasi-experiment included a previously validated pre- and post-test, the BTI (Gillespie, 2003), taken by all three groups. As stated earlier, Groups 1 and 2 participated in the 13-week course (see the course syllabus in Appendix D. The comparison group did not participate in the coursework or any part of the designed intervention. Consistent with the process for participant groups, comparison group participants received the posttest 13 weeks after the pretest. The comparison group took the test and retest using the same 13-week gap in their testing to control for temporal effects.

\section{The Behavioural Trust Inventory}

The Behavioural Trust Inventory (BTI; Gillespie, 2003) is a 10-item, 7-point Likert-style questionnaire (see Appendix E). The full scale score range is 7-70, and subscale score ranges are 7-35, with higher scores indicating greater levels of trust. The BTI was explicitly designed to measure a person's willingness to be vulnerable with others (Gillespie, 2003). It is a multidimensional tool that measures a combination of reliance-based trust (items 1-5) and disclosure-based trust (items 6-10) in members of a group (Gillespie, 2003).

The original BTI validation sample included 77 project leaders and 234 team members from extensive research and development organizations in Australia. A second, or crossvalidation sample, included 67 managers and 214 team members. All participation was voluntary; the survey was conducted with pen and paper, with an overall response rate of $64 \%$ between the two samples (Gillespie, 2012). An exploratory factor analysis yielded two factors (Reliance and Disclosure) that accounted for $69 \%$ of the variance, and the subscales correlated at .61 and .71. Confirmatory factor analysis supported the two-factor structure of the measure. 
Cronbach's alphas ranged from .90 to .93 , indicating strong internal consistency. No test-retest study is reported. Therefore, the temporal stability of the measure is unknown.

The BTI was correlated with several measures of trust, including the Conditions of Trust Inventory, a measure of disposition to trust, and various brief measures of perceived distrust, trust, common values, interdependence, and perceptions of relationships. The results indicated adequate convergent and divergent validity. For example, the BTI correlated .80 (Reliance) and .65 (Disclosure) with the trustworthiness scale and -.74 and -.66 with the distrust scale. In studies since the initial validation, the BTI has been shown to be a reliable and valid instrument (Gillespie, 2012; McEvily \& Tortoriello, 2011). For example, in a cross-validation study with 539 participants in South Africa, Heyns and Rothmann (2015) found the BTI correlated adequately with the Organizational Trust Instrument trustworthy subscales of Benevolence ( $r=$ .61 with Reliance; $r=.57$ with Disclosure) and Integrity $(r=.64 ; .61)$.

\section{BTI Administration}

I administered the pre- and post-test in person. The pretest was conducted after the introduction during the first class, and the posttest was conducted at the end of the last scheduled session. For Group 1, there was one participant who was unable to attend the first class session, and I met with this participant individually before the second scheduled class. In Group 2, two participants were not present during the first class. One participant in Group 2 was in the remote office, so I conducted a Go-to-Meeting session and led the introduction and administered the test to both participants online at the same time before the second scheduled meeting. The posttest was taken on the last day of coursework with both participant groups; all participants who remained in the program were present during their regularly scheduled session. 
The pre- and post-test were executed using paper and pen. While the use of an electronic survey would have allowed easier retrieval of data, paper and pen allowed the survey to be taken during the first and last intervention classes without the need for electronic devices, access to the Internet, or other possible limitations. I manually inputted test scores into Microsoft Excel and maintained the physical tests in a secure location in my office.

\section{Data Analysis}

Using the BTI as the pretest, I established a baseline for each member and each group for the dependent variables of reliance-based and disclosure-based trust. I combined both reliance and disclosure totals for the third dependent variable labeled as total trust. These dependent variables are measured by the subject's willingness to be vulnerable with others in their group (Creswell, 2012).

The BTI was used again with all three groups 13 weeks later to measure reliance-based trust, disclosure-based trust, and total trust. The analysis allowed for noting examining outcomes for each participant before and after the intervention. These outcomes were examined for selfreported levels of trust by members on each of the three dependent variables. I also totaled member's scores in each of the three groups to create group scores for the same dependent variables. I measured the postintervention differences between both participant groups (Group 1 and 2) scores with the comparison group (Group 3). The methods of analysis used were the reliable change index (RCI) and Cohen's $d$.

Statistics used in quantitative methods, such as $t$ tests or ANOVA, are inappropriate for small group analysis. Both $t$ tests and ANOVA require statistical significance to be deemed reliable (Urdan, 2010). Statistical significance refers to the probability the statistics generated from the sample represent a genuine phenomenon that can be inferred throughout the population 
in which the sample was obtained; however, statistical significance is a function of the sample size (Kirk, 1996). A statistically significant score can be obtained, regardless of any substantial effect, by using a large sample (Sullivan \& Feinn, 2012). This study was limited to two participant groups, and one comparison group, with a total of 23 total respondents. I eliminated ANOVA due to the small sample size of each group. Also, statistical significance is not the same as practical significance. Statistical significance means results obtained were not influenced by chance, while practical significance is a term used to discuss if results were useful in everyday life (Kirk, 1996).

In this study, I chose to use effect size for the difference in levels of trust of participants of each group noted before and after the intervention. Effect size is defined as the degree of association between an effect and the dependent variable, without regard to sample size (Sullivan \& Feinn, 2012; Urdan, 2010). The effect size is also the appropriate test to measure the difference between the experimental groups' postintervention and the comparison group's posttest trust scores. The test chosen for the effect size of comparisons in each case is Cohen's $d$.

\section{Cohen's $d$}

Cohen (1977) developed this formula to estimate the standardized effect size for a sample:

$$
\mathrm{d}=\frac{\bar{X}_{1}-\bar{X}_{2}}{s_{\text {pooled }}} \text { where } s_{\text {pooled }}=\sqrt{\frac{\left(n_{1}-1\right) s_{1}^{2}+\left(n_{2}-1\right) s_{2}^{2}}{n_{1}+n_{2}-2}}
$$

Cohen's $d$ is a number that represents a standard deviation so 1.0 is one standard deviation from the mean. Cohen stated an effect size of .2 would be considered small, .5 would be considered medium, and .8 or above would be considered a large effect. Put another way, a small effect 
would be difficult to notice with the naked eye. A medium effect would probably be large enough to see with the naked eye, and a large effect is easily perceived (Cohen, 1977).

This study used Cohen's $d$ to analyze the standardized mean difference in each of the three groups for the between-group effect. This was accomplished by taking the mean score of the group's posttest $\bar{x}_{2}$, subtracting the mean score of the posttest $\bar{x}_{1}$, and then dividing this by the pooled standard difference

$$
\left(s_{\text {pooled }}\right)
$$

from both the pre- and post-test:

$$
s_{\text {pooled }}=\sqrt{\frac{\left(n_{1}-1\right) s_{1}^{2}+\left(n_{2}-1\right) s_{\frac{2}{2}}}{n_{1}+n_{2}-2}}
$$

I applied Cohen's $d$ to each of the constructs measured: reliance-based trust, disclosure-based trust, and the overall trust score from each group.

\section{Participant Analysis}

As the research question specifically called for an analysis of the effect of the intervention, Cohen's $d$ was applied between both subject groups' posttest scores as they related to the comparison group's posttest score, where the participant group means became $x_{1}$ and the comparison group means for each construct became $x_{2}$. The pooled standard difference used the corresponding standard deviation for each of the scales mentioned previously.

The effect of the intervention at the group level was essential in determining if the program had merit. I also wanted to measure the impact of the intervention at the participant level. Statistics such as a $t$ test would not be a good source of information for small sample sizes, and the small sample size in the three groups $(n=7,8$, and 9). I chose to use a method that has 
been used as a reliable single case statistic to show the effect size (Busse, McGill, \& Kennedy, 2014; Jacobson \& Truax, 1991).

\section{Reliable Change Index}

The Reliable Change Index (RCI) is a metric used to evaluate whether a change over time of an individual score is considered statistically significant. The RCI was initially established as a process to demonstrate clinical significance (Jacobson \& Truax, 1991):

$$
\mathrm{RC}=\frac{x_{2}-x_{1}}{S_{\text {diff }}} \quad S_{\text {diff }}=\sqrt{2(S E)^{2}} \quad \mathrm{SE}=S_{1} \sqrt{1}-r_{x x}
$$

Clinical significance is a change in the status of an individual after an intervention or clinical trial (Jacobson \& Truax, 1991). This status is important at the individual level, as opposed to an intervention noting statistical significance based on a large sample size. The theory is that the change noted is important to an individual after treatment, regardless if the change was enough to establish the statistical significance of a larger population. This theory holds in the current study; the differences in levels of trust will make a difference both to the individuals and to the group.

Components of the RCI include the scale score of the BTI pretest taken by each person in all three groups $X^{1}$, the scale score or the same BTI taken 13 weeks after the pretest, $X^{2}$, and the standard difference from each scale. The formula is

$$
\frac{X_{2}-X_{1}}{S_{\text {diff }}} . \text { Where, } S_{\text {diff }}=\sqrt{2(S E)^{2}} ; \mathrm{SE}=S_{1} \sqrt{1}-r_{x x}
$$

Where $r$ is the test-retest reliability of the scale. Because the BTI has no test-retest data, I used Cronbach's alpha of .90 noted in the validation literature of Gillespie (2012), as my sample size was too small to create valid reliability data on its own. An online calculator (Zahara \& Hedge, 2010) was used to calculate the RCI scores. 


\section{Evaluating Reliable Change}

Jacobson and Truax (1991) established an RCI score of 1.96 or greater as statistically significant because "an RC larger than 1.96 would be unlikely to occur $(p<.05)$ without actual change" (p. 14). Busse et al. (2014) proposed a slightly different and more detailed model to determine the effectiveness of the intervention. RCI scores higher than 1.8 indicate a strong positive change, whereas RCI scores between 0.7-1.7 reflect a moderate positive change, and RCI scores between 0.6 and -.6 show no change. Scores between -0.7 and -1.7 indicate a moderate, negative effect, and scores less than -1.8 show a strong, negative effect.

\section{Qualitative Design and Analysis}

In addition to the quantitative analysis of pre- and post-test results collected from the BTI survey and participant satisfaction survey, a qualitative approach was used in this mixed-method research. Qualitative research is used when the researcher is interested in how individuals interact with a phenomenon and their experiences with that phenomenon (Merriam \& Associates, 2002). I used three distinct forms of qualitative research: (a) detailed field notes of observations made during each intervention class, supplemented by field notes conducted by the outside observer on three occasions with each participant group; (b) focus group sessions with all participants in both subject groups; and (c) individual interviews with four participants from both subject groups. Descriptions of the processes for the field notes, the structure of the focus group, and individual interviews are described next.

\section{Field Notes}

During each classroom session of the intervention, I took extensive field notes in separate journals kept for each group. These field notes were compiled within 45 minutes after each session. The field notes included my observations of behaviors I noticed during meetings. The 
field notes also contained paraphrasing of the content and tone of participants' dialogue.

Paraphrasing was necessary because the protocol did not allow for an audio recording of the sessions.

Observation research can be vital, as it provides the researcher access to the subjects, allowing the researcher to find out what happened during the intervention (Muijs, 2011). I recorded strong emotions or indifference detected from participants during course sessions. In my field notes, I detailed content and participant language. I also took note of body language I observed during the course sessions.

There were multiple purposes for these field notes. The records were pivotal in allowing me to reflect throughout the process to provide a check on a bias (Creswell, 2012). The field notes also provided an additional source of data for the triangulation of my conclusions. Another important use of the field notes was to assist in identifying which participants I wanted to include in the individual interviews after the focus group sessions. I also detailed my feelings about the sessions. The purpose of noting my experiences and emotions was to recognize bias in my role as the researcher. I describe these feelings and prejudices in Chapter 4.

\section{Focus Group Structure}

Focus groups are used to collect qualitative data from participants who may share similar experiences with the subject matter (Creswell, 2012). A focus group is an interview conducted by a facilitator who asks the group a range of questions designed to allow flow between participants (Krueger \& Casey, 2015). The facilitator should begin the questioning with the intention of ensuring all participants are comfortable speaking and controlling the space. Hence, no one in the group dominates the conversation (Krueger \& Casey, 2015). One drawback of the focus group is the facilitator may have trouble taking notes, which is why I audio taped focus 
groups. The concern with audio taping a focus group session is it can be difficult to transcribe and attribute quotes to particular participants (Creswell, 2012).

Focus groups were conducted in the same space in which the intervention took place for both groups: This was the conference room of the company in which each group worked. The purpose of using the same place was to provide participants with a level of comfort and familiarity with the surroundings (Krueger \& Casey, 2015). Focus group sessions for both groups were held 2 weeks after the final meeting of the course. Both focus groups were scheduled for 90 minutes. Focus groups were conducted during regular business hours using the same time slot during which the course sessions were performed.

I acted as the facilitator of the focus group. As the facilitator, I used a semi-structured interview guide. Questions were piloted with a similarly constructed cross-functional workgroup. The pilot group was chosen from a group that had participated in a similar communication intervention. I used a semi-structured format to ensure participants expressed themselves and their opinions about the value and limitations of the program. The semi-structured questions allowed for a free flow of dialogue and the ability for participants to dive deeply into a topic or to migrate the conversation to areas they felt necessary.

The role of a facilitator in a focus group is to solicit dialogue with and between participants rather than lead the group to answers (Parker \& Tritter, 2006). I employed an outside observer who was present during the focus group. The observer was paid a fee for her services, as outlined in Appendix G. This observer was introduced to both groups on the first day of the course and again on the sixth session. The observer's role was announced during all three appearances to participants. The rationale for introducing the observer during the previous 
sessions was to allow for familiarity, so participants would feel comfortable with the observer's presence during the focus group interview.

\section{Development of Questions for the Focus Group}

The interview protocol for the focus group was designed to answer the study's research questions (Krueger \& Casey, 2015), while the focus group interview guide (see Appendix H) encompassed several types of questions detailed next. Key questions directly associated with the research questions for the focus group included:

- What effect, if any, will an intervention based on improving communication in a cross-functional workgroup have the level of trust in the group?

- What role, if any, does empathic listening play in the development of trust in a crossfunctional workgroup?

- What role, if any, does Gestalt language protocol play in the development of trust in a cross-functional workgroup?

- How could the program improve to reach the stated objectives below?

- Identify when a topic becomes a crucial conversation;

- Understand the value of listening to understand;

○ Develop the skills to share information with others without eliciting confrontation;

- Discover how to mitigate conflict, encourage dialogue, and create synergistic resolutions.

I conducted a pilot focus group with a group that previously undertook an intervention similar to what I used as the facilitator. This pilot group consisted of 10 individuals who had approximately the same makeup as members of the participant groups. They were all middle 
management from a small business organization located in Orange County, California. Each participant represented a different department, with representatives from all areas of the company, including design, operations, customer service, quality assurance, and finance.

The purpose of this pilot was to gauge the group's ability to solicit the necessary information to address the research questions. The pilot group also provided valuable feedback about the appropriateness of items selected for the study. While the coursework had been altered since this group completed the course, the objectives had not changed. The pilot focus group allowed me to ask questions aloud in front of a familiar audience while being attentive to potential concerns in questions or language used. The pilot created an opportunity to gauge the length of time each item might take to complete with a full-sized focus group. This information provided me with the data required to ensure the focus group was limited to the 90 -minute time commitment. Less than 2 hours is both a physical and psychological limit for most adults participating in an activity such as a focus group (Krueger \& Casey, 2015).

The initial set of questions was placed in a sequence of categories. Categories of items included opening questions, introductory questions, transition questions, key questions, and ending questions (Krueger \& Casey, 2015). These categories were sequenced to lead participants through the process in an organized yet meaningful way. The sequencing also included moving from general questions to more specific issues; there were follow-up questions about crucial points (Krueger \& Casey, 2015). I define crucial points in this study as any comment made by a participant that related directly to one of the research questions or the course format, materials, or instruction. 


\section{Types of Focus Group Questions}

I conducted both focus groups using a semi-structured approach for two purposes: (a) to ensure I stayed on track and obtained answers related to the primary research question and (b) to allow the dialogue to migrate to what was essential to participants (Krueger \& Casey, 2015). The goal was to provide rich data surrounding the research questions without stifling participants' imagination or forcing participants in unwanted directions. Focus group sessions were designed with a systematic approach. This approach took steps to lead participants to feel they were free to voice their opinions and to feel their thoughts and ideas mattered to the research. The path led participants through the process, diving deeply into the subject matter.

Opening questions were asked to create space for each participant to feel they were heard. Opening questions were designed so each participant had an opportunity to speak early in the process (Krueger \& Casey, 2015). The longer someone takes to talk in the group, the less likely it will be they will speak later in front of that group (Krueger \& Casey, 2015). The group needed to know everyone's thoughts were welcomed and important. Examples of the opening questions included asking each participant to provide their name, title, and department in the company where they worked.

Introductory questions were designed to prepare participants to think about the main program topics and their involvement in the program (Krueger \& Casey, 2015). I asked participants about the time they spent on the coursework, such as discussing their overall experience with the course material and the appropriateness of homework assignments.

Transitional questions are designed to move the discussion into the critical areas of the study design (Krueger \& Casey, 2015). I asked questions about what was learned during the program. These questions began with fundamental communication techniques such as listening 
to understand and sharing from experience. Follow-up questions were derived from answers participants provided to earlier questions. Participants were asked if any techniques taught during the course altered their communication and relationships in their offices.

The key questions surrounded the research questions (Krueger \& Casey, 2015). I asked participants to think about relationships in the group and if they believed they were stronger now than they were before the program. The point here was to determine if they felt they trusted the other group members more at the end of the program than they did prior to taking this course.

Consistent with the semi-structured format, the direction the discussion followed determined the follow-up questions asked. When the key question on relationship development was answered in the affirmative, I asked if trust played a significant role in the development of the relationship. Again, I followed the lead of participants' answers. When the increased trust was a consideration in the development of positive relationships, I asked if they could differentiate between reliance-based or cognitive trust and disclosure-based or affective trust by using commonly understood terms.

Definitions related to cognitive trust included competence, reliability, and calculative assessment. I asked participants to describe affective trust, which provided for feelings, motives, empathy, and rapport (Chua et al., 2008). These components of trust align with the descriptions embedded in the BTI (Gillespie, 2012). Gillespie (2012) defined cognitive trust elements as reliance-based trust and affective trust as disclosure-based trust.

Concluding questions were asked to ensure all parties had an opportunity to disclose issues of significance about the intervention, the process, or the outcomes (Krueger \& Casey, 2015). The questions were posed in such a way to allow for reflection of previous discussions and any issues not previously discussed. The following prompt was presented: "Please think 
back throughout this focus group interview on any comments made by you or others, and, if you would like to add anything or create the context for any comments, please do so." The next prompt was, "Think back through the experience of the intervention, and, if you feel anything of significance has been left unsaid, please take a moment to do that now."

I tried to understand if participants believed the intervention led to the stated outcomes of improving communication and how that related to the level of trust they experienced in the group. Also, I wanted to discover if participants felt there were some tangible improvements I could deploy in the future with this intervention. Finally, participants were allowed to express thoughts, feelings, or reflections they felt may have been missed during the focus group.

\section{Individual Interviews}

Individual interviews are time consuming because, as opposed to interviewing several participants at once as in focus group interviews, the researcher interviews one participant at a time. The ideal candidate for an individual interview is one comfortable in speaking their mind and willing to share their knowledge (Creswell, 2012). During a one-on-one interview, the researcher can go deeper with this participant, initially asking broader, open-ended questions and then more detailed questions based on the responses to the general questions (Creswell, 2012). Open-ended questions allow the participant to answer the question with their point of view and unique perspective (Creswell, 2012).

The criteria I used to determine which subject I asked to participate in another round of interviews was threefold. From the quantitative data, I looked for outliers or data that fell outside the norm in each group. I found one participant in Group 1, whose scores were negatively impacted between the pre- and post-test. Other outliers fell on the other side of the spectrum, and their mean average score showed increases in their trust of the group. The next criterion was 
those who, during the focus group, displayed extreme emotion during the question-and-answer period. Focus groups were extremely positive; no one showed negative emotions, which meant I was limited to participants who showed excitement and appreciation when describing their feelings. I also used my field notes and those from the observer, which were written after the focus group, to aid in this selection. Finally, I looked back at my field notes again, looking for entries where a participant displayed a deep understanding of the content and displayed strong emotion when discussing their knowledge or how they might apply a construct in their lives. I also used my field notes to remember the circumstances when a participant had a stressful day in the class. In one case, the field notes triangulated well with the quantitative data with the participant whose survey questions displayed a decrease in trust, making the selection of this individual essential to include in the one-on-one interview process.

Once I identified candidates for the individual interviews, I went through the same process described previously for informed consent, in that I provided a verbal explanation and received a signed informed consent document. I asked for and received permission to audio record the individual interview from each participant.

I started interviews with general questions about experiences in the class. In each case, the broader general questions led to particular questions based on reasons I included them in the interviews. My goal was to deepen my understanding of their experiences in the class, to learn what lessons resonated with them and the lessons with which they did not agree. These interviews are what Charmaz (2014) described as intense interviews. Each meeting was designed with the specific subject in mind based on the criteria described previously. Intense interviews are meant to understand the participant's experience, their views, and their insights into the program. 
All questions were open-ended, providing opportunities for participants to tell their stories and determine the direction of their responses (Krueger \& Casey, 2015). Open-ended questions can be described as questions that cannot be answered with a yes or a no response. They may begin with statements such as:

- Tell me more about

- Describe for me

- Please explain your views on

- Think back

The purpose of individual interviews was to gather as much specific data as possible from participants.

\section{Transcription of Collected Interview Data}

The first step after each interview, whether it was a focus group or individual interview, was to transcribe the recorded conversation. I used a paid online transcription service called Otter. Otter is a fee-based online service to which I uploaded the recorded conversation, and, in approximately 30 minutes, I received a Microsoft Word version of the recording.

Editing these transcriptions was done in three parts. The first was to eliminate any names and replace those with the coded numbers I had previously recorded. The next step was to look for glaring errors. These errors included run-on sentences from one speaker to the other. Another mistake that needed correction was the adjustment of words the computer program misunderstood. I manually made adjustments on the Word document to correct for this. I read each transcript while listening to recorded interviews and to make final adjustments.

This process allowed me to note changes in pitch and tone, which signified emotions I detected during the meeting. This choice of using the online service was made to save time in 
this process. I believe the auditing process I undertook with the transcription allowed me to immerse myself with the interviews fully, providing contextual reminders prior to coding (Charmaz, 2014; Merriam \& Associates, 2002).

\section{Coding and Analysis}

Coding the qualitative data was the next step. During the initial coding phase, I used an open-coding process, which included individual labeling statements participants made into broad concepts underlying the observation (Merriam \& Associates, 2002). These open codes were based on my interpretation of what the subject said and how they said it. The next step in the process was to use a method termed axial coding, which is to take the statements gathered and placed in the open code categories and compare them against other coded categories with the intent to identify a common core category from the data (Merriam \& Associates, 2002). With the common core categories labeled, I looked for themes that emerged in the data (Charmaz, 2014). In the analysis phase, I remained open to the data, looking at the themes to interpret their meaning. What I looked for were fit and relevance. My intention was to compare the relationships between the qualitative data with the quantitative data and to ask if these data were congruent - and, if not, to understand why not. Relevance is understood as whether or not the interpretation of the data creates a relationship between the subject matter and the outcomes.

By deploying a mixed-method approach, I used the quantitative measurements from the BTI to determine if the intervention had a positive effect on building trust in the cross-functional workgroups. Furthermore, the qualitative data I collected and analyzed assisted me in understanding if the techniques used in the intervention were effective in building trust. Lastly, the qualitative data also provided me with information directly from participants on process 
improvements that could be made in the future. The methods chosen for this study were sufficient to provide answers to the research questions.

\section{Program Evaluation Design and Analysis}

To evaluate the effectiveness of the intervention from participants' points of view, I used a postcourse survey instrument (see Appendix I). The survey was adapted from an instrument developed in conjunction with the Kirkpatrick method by Dr. Barbara Bucklin (B. Bucklin, personal communication, October 14, 2009).

\section{Postcourse Participant Survey}

The evaluation survey was used to ask participants to rate the delivery or the learning outcomes, objectives, materials, facilitator, content, and relevancy to their professional development. These categories were scored by asking participants to rate the items using a 5point Likert-style questionnaire, where $1=$ strongly disagree, $2=$ disagree, $3=$ neither disagree nor agree, $4=$ agree, and $5=$ strongly agree. The survey also asked open-ended questions, allowing participants to write in qualitative responses for what they found most useful, least useful, and suggestions on areas where the course could improve. This analysis was supplemented by reflections from participants in the focus groups and the individual interviews.

The observer administered the postcourse evaluation just after the focus group session with each participant group. The survey was a pen and paper survey, and I asked the observer to collect the responses and keep the surveys from me until after I had the opportunity to transcribe, code, and analyze the qualitative data collected from the focus groups and individual interviews. This procedure was for the implicit purpose of shielding praise or critique, which could have potentially clouded the analysis of the interviews. After receiving the surveys from the observer, I used an Excel spreadsheet, listing each question and responses from each participant. This 
procedure allowed me to create summaries of the responses and aggregate the scores for each of the categories. I went back 3 days later and checked to ensure entries were recorded accurately. The qualitative questions were subject to the same coding process as the transcribed interviews, which was to code each line initially and then create categories and finally themes.

\section{Kirkpatrick Method of Analysis}

The primary instrument in the study of participants' experiences was a survey tool adapted to reflect the Level 1 and 2 evaluation (Kirkpatrick \& Kirkpatrick, 2016) of the coursework. The survey tool (see Appendix I) I used was adapted from a tool used by Dr. Barbara Bucklin. Bucklin created a version of the survey tool she uses in her own work delivering training programs to organizations.

Donald L. Kirkpatrick developed the four levels of training program evaluations in his doctoral dissertation at the University of Wisconsin in 1954 and later, with his son, enhanced the process and renamed this model the new world Kirkpatrick model (Kirkpatrick model). This model was based on the industrial systems design process that uses the acronym ADDIE. ADDIE stands for analysis, design, development, implement, and evaluate (Kirkpatrick \& Kirkpatrick, 2016).

The Kirkpatrick model is comprised of four levels of evaluation: Level $1=$ Reaction, Level 2 = Learning, Level 3 = Behavior, and Level $4=$ Results. The reaction level includes such elements as the trainees' level of engagement with the material, the relevance to their intended outcome, and the trainee's satisfaction in the process. The learning level gauges the effectiveness of transmitting knowledge, the necessary skills, and the confidence level of the trainee. The behavior level reflects the degree to which the trainee applies the skills they have been taught, 
while the results level is focused on the tangible results associated with the training program to the work the trainee is focused on (Kirkpatrick \& Kirkpatrick, 2016).

\section{Approval to Conduct Research}

Before any work began on this project, I was required to submit the specifics of the study to Chapman University's Institutional Review Board (IRB). The IRB review process validates that any potential risk to participants has been acknowledged. I was working with human subjects and dealing with sensitive topics that could potentially cause harm in the workplace. The IRB process assesses the risks participation may pose to human subjects being studied. It is essential to recognize and practice ethical treatment of human subjects in research (U.S. Code of Federal Regulations, Department of Health and Human Services, 2009) and understand the impact, if any, on human subjects who have participated in the study. The IRB process has three classifications of review: exempt, expedited, and full review. While this is not a vulnerable population, the risk inherent with the type of vulnerability included in the intervention elevated this study to an expedited classification (IRB).

In preparation for submission to the IRB for approval, I completed the required certification process provided through the Collaborative Institutional Training Initiative (CITI) training course. This was the second time I had completed the certification process with CITI, as it was a component of the coursework when I began doctoral studies at Chapman University in

2015. The rules for IRB require a refresher course of the CITI training program if the course has not been completed in the previous 3 years.

\section{Scope of Work and Timeline}

The scope of work consisted of preparation for and acceptance by the IRB at Chapman University and the formation of the groups to be studied. Data development and collection 
included administration of the pretest on the first day of the 13-week intervention, field notes after each classroom session of the 13-week intervention, and the posttest administered at the last class. Postintervention work included a focus group interview with both subject groups and interviews with selected participants from each group. Postintervention work also included a detailed analysis of the quantitative data, coding of the focus group sessions, coding of the individual interviews, and analysis of the coded interviews prior to writing up the results. The timeline for this scope of work is provided in Table 5.

\section{Table 5}

Dissertation Timeline

\begin{tabular}{ll}
\hline Date & Process \\
\hline May 29, 2019 & Dissertation proposal defense \\
May 30, 2019 & Submit to IRB \\
July 9, 2019 & Acceptance by IRB \\
July 16, 2019 & Selection of participants \\
June-October, 2019 & Intervention coursework \\
October 9-18, 2019 & Administer Posttests (3 groups) \\
October 22, 2019 & Focus Group Interview Group 1 \\
October 26, 2019 & Individual Interviews Group 1 \\
November 1, 2019 & Focus Group Interview Group 2 \\
November 1-5, 2019 & Individual Interviews Group 2 \\
November 2019 & Transcription and Coding \\
February 2020 & Quantitative Data Analysis \\
May 2020 & Draft to Chair and Methodologist \\
June 1-6, 2020 & Edit \\
June 11, 2020 & Submit final version to committee \\
June 2020 & Dissertation Defense \\
June, July 2020 & Revisions and final approval \\
August 14, 2020 & Submission to the library \\
\hline
\end{tabular}

\section{Research Significance}

The hypothesis for this study was based on the limited application of the intervention. My hypothesis was the intervention designed to improve communication in a cross-functional workgroup would increase the level of both affective and cognitive trust in the group. As 
discussed previously, building trust in a cross-functional workgroup is one major component in elevating the workgroup into a functional team (Jones \& George, 1998; Rahman et al., 2017; Yuan et al., 2016). The value inherent in establishing a functional team is that a functional team will always outperform a group (Katzenbach \& Smith, 1992).

A positive impact of the intervention will allow me to proceed with confidence in my work with small business organizations. This work is intended to enable these organizations to increase their productivity, become effective in organizational change, and limit unintended consequences amid change management processes. The qualitative data gathered allowed me to make any adjustments deemed necessary in the content or delivery of the material in the intervention to foster learning with future cross-functional workgroups.

\section{Ethics}

I had a working relationship with the owners at both firms that were studied. This information was disclosed to participants in writing and verbally. Inclusion in the program was voluntary, and any participant was permitted to drop out of the study without questions or negative commentary to their employer. I announced to participants verbally and in writing that participants' discussions and work products would be held confidential. Disclosure to the employer was limited to the quantitative analysis and did not include personally identifiable information that could be attributed to any participant of the study.

The intervention being studied was developed by me and has only been applied to three groups prior to this study. I administered the intervention and facilitated the focus groups and individual interviews on a program I designed. This fact did create the potential for research bias (Charmaz, 2014). As the developer of the program, there was a strong desire to show the intervention as successful. I have been hypervigilant in the collection of data and the 
interpretation of the qualitative research to avoid the appearance of research bias. My personal reflection documented in my field notes was one of the ways I controlled for research bias. These notes included observable facts and my own feelings generated from each session. In addition to reflecting with my field notes, I also employed a process of deep reflection as I coded and analyzed the transcripts of both the focus group sessions and individual interviews. Finally, I performed a member check with those I interviewed. This process allowed me to recite back to interviewees a paraphrased version of what I had written about what they said. This step allowed interviewees the opportunity to correct my interpretations, thus enabling me to capture their thoughts as opposed to a misinterpretation of those thoughts (Charmaz, 2014).

Charmaz (2014) presented a code of conduct while performing coding activities, which assisted me in checking my own biases and reflecting on the meaning of the data from the perspectives of the subjects. The code is as follows: (a) remain open, (b) stay close to the data, (c) keep your codes precise and straightforward, (d) construct short codes, (e) preserve actions, (f) compare data with data, and (g) move quickly through the data. This code of conduct guided me as I immersed myself in the data. Before any coding session, I started with a brief meditation session intended to clear the space needed for the task I performed. Following the mediation, I systematically reviewed this code of conduct, which I have printed out on a notecard and affixed above my workspace. These practices gave me the mindset to code and analyze the data.

\section{Summary}

Looking through the lens of pragmatism, the mixed-methods approach to studying the effectiveness of a communication-based intervention designed to build trust in a cross-functional workgroup is an appropriate methodology. Pragmatism couples well with mixed-methods research design and also resonates with the private sector, for which this program was initially 
developed. The private sector, in general, looks at results and is primarily concerned with what works as opposed to developing theoretical models.

The intervention was designed to establish better communication in a group; building trust between group members was a powerful secondary benefit I noticed in the three previous courses I facilitated. The trust I saw was primarily concerned with affective trust, or as Gillespie (2003) called it, disclosure-based trust. While the teaching and coursework were designed to allow individuals to master the art of listening and sharing of information, the CoT process does recognize and speak to cognitive-based or reliance-based trust.

The survey tool used in both the pre- and post-test was previously validated and, to date, has been used in over 40 studies worldwide (Gillespie, 2015). I looked for the variance in the mean average in and between groups. I hypothesized the mean average of disclosure-based trust in the group would increase, and the mean average of disclosure-based trust would follow the same direction between the subject groups and comparison groups. I also hypothesized the mean average of reliance-based trust would show mild to moderate increases in and between groups.

The qualitative methods portion of the study used both focus groups and individual interviews and was designed to analyze the effectiveness of the intervention through participants' experiences (Krueger \& Casey, 2015). This provided a source of rich, thick data used to determine the credibility (internal validity) and transferability of the intervention.

Table 6 provides a summary of the research objectives, methods of analysis, and tools used to note the findings. The primary research question was answered using quantitative research and triangulated with observation. The secondary research questions was addressed with qualitative research methods. Areas for improvements in the intervention came directly from participants and combined both quantitative and qualitative methods. 
Table 6

Methods Used in the Research

\begin{tabular}{|c|c|c|c|c|c|c|c|c|}
\hline $\begin{array}{l}\text { Research } \\
\text { Questions } \\
\end{array}$ & $\begin{array}{l}\text { Primary } \\
\text { Method }\end{array}$ & $\begin{array}{l}\text { Primary } \\
\text { Tool }\end{array}$ & $\begin{array}{l}\text { Analysis } \\
\text { Method }\end{array}$ & $\begin{array}{l}\text { Secondary } \\
\text { Method }\end{array}$ & $\begin{array}{l}\text { Secondary } \\
\text { Tool }\end{array}$ & $\begin{array}{l}\text { Analysis } \\
\text { Method }\end{array}$ & $\begin{array}{l}\text { Additional } \\
\text { Data }\end{array}$ & Source \\
\hline $\begin{array}{l}\text { What effect, if any, } \\
\text { will an intervention } \\
\text { based on improving } \\
\text { communication in a } \\
\text { cross-functional } \\
\text { workgroup have on } \\
\text { the development of } \\
\text { trust in that group? }\end{array}$ & $\begin{array}{l}\text { Quantitative } \\
\text { Analysis }\end{array}$ & $\begin{array}{l}\text { Behavioral } \\
\text { Trust } \\
\text { Inventory }\end{array}$ & RCI & $\begin{array}{l}\text { Quantitative } \\
\text { Analysis }\end{array}$ & BTI & $\begin{array}{l}\text { Cohen's } \\
d\end{array}$ & Observation & Fieldnotes \\
\hline $\begin{array}{l}\text { What role, if any, } \\
\text { does empathic } \\
\text { listening play in the } \\
\text { development of } \\
\text { trust in a cross- } \\
\text { functional } \\
\text { workgroup? }\end{array}$ & $\begin{array}{l}\text { Qualitative } \\
\text { Analysis }\end{array}$ & $\begin{array}{l}\text { Focus } \\
\text { Groups }\end{array}$ & coding & $\begin{array}{l}\text { Qualitative } \\
\text { Analysis }\end{array}$ & Interviews & coding & & \\
\hline $\begin{array}{l}\text { What role, if any, } \\
\text { does Gestalt } \\
\text { language protocol } \\
\text { play in the } \\
\text { development of } \\
\text { trust in a cross- } \\
\text { functional } \\
\text { workgroup? }\end{array}$ & $\begin{array}{l}\text { Qualitative } \\
\text { Analysis }\end{array}$ & $\begin{array}{l}\text { Focus } \\
\text { Groups }\end{array}$ & coding & $\begin{array}{l}\text { Qualitative } \\
\text { Analysis }\end{array}$ & Interviews & coding & & \\
\hline $\begin{array}{l}\text { What improvements } \\
\text { can be made to the } \\
\text { existing course } \\
\text { titled Effective } \\
\text { Communications? }\end{array}$ & $\begin{array}{l}\text { Quantitative } \\
\text { Analysis }\end{array}$ & $\begin{array}{l}\text { Satisfaction } \\
\text { Survey }\end{array}$ & $\begin{array}{l}\text { Raw } \\
\text { Scores }\end{array}$ & $\begin{array}{l}\text { Qualitative } \\
\text { Analysis }\end{array}$ & $\begin{array}{l}\text { Satisfaction } \\
\text { Survey }\end{array}$ & coding & Suggestions & Interviews \\
\hline
\end{tabular}

In the following chapter, I describe findings of the study. Findings are presented to answer the primary research question, followed by the secondary research question. The third section is presented sequentially and is based on the field notes. This section is important, in that it describes a major component of trust, displaying trusting behaviors. I conclude this section with the program analysis, which combines the participant survey results as well as comments that were made by participants in the focus group sessions and during individual interviews. 


\section{CHAPTER FOUR - FINDINGS}

This chapter reviews the findings of this mixed-method design to determine the effectiveness of building trust based on the participation of two cross-functional workgroups in an enhanced communication course. The study found a workgroup consisting of midlevel managers in small business organizations can develop trust with each other and the group by improving their levels of communication, thus addressing the primary research question. This study also found the use of enhanced communication techniques embedded in the course played a significant role in the development of trust, thus addressing the secondary research questions. Findings contained herein point to the effectiveness of the communication intervention on the development of trust in a cross-functional workgroup. Techniques used in the intervention were the subject of the secondary research questions addressed in the qualitative research. Finally, the study found ways participants might improve future versions of this course. Details of the findings are discussed herein.

The findings are organized into three parts. The first is an analysis of the quantitative data obtained with the use of the Behavioural Trust Inventory (BTI) survey instrument (see Appendices $\mathrm{E}$ and F). The next area is the qualitative data relating to the secondary research questions. The secondary research questions included:

- What role, if any, does empathic listening play in the development of trust in a crossfunctional workgroup?

- What role, if any, does Gestalt language protocol play in the development of trust in a cross-functional workgroup?

The qualitative data were comprised of observations from my field notes, focus group sessions with Groups 1 and 2, and individual interviews with four participants from Groups 1 
and 2. The third section in the findings is devoted to the data collected and analyzed to evaluate the course, the materials, the delivery, and usefulness in their careers. Data were collected from the postcourse participant satisfaction (see Appendix I). Survey data were supplemented with qualitative data collected during the focus group sessions and individual interviews.

\section{Quantitative Findings Related to the Primary Research Question}

The results of the BTI are related to the primary research question. Tables 7, 8, and 9 provide the individual's raw pre- and post-test scores to the questions on the BTI. The items on the BTI allowed for a range of answers from 1 (not willing at all) to 7 (completely willing). The individual scores were then summed based on the three scales that were analyzed for this study; reliance based trust (Q 1-5), disclosure-based trust (Q 6-10), and total trust (Q 1-10). The range of potential answers for these scales was 5 to 35 for both reliance and disclosure trust and 10 to 70 for total trust.

Table 7 represents the raw scores from Group 1. Only those participants who finished the course were included in these results. The range of actual answers for the pretest from Group 1 for reliance-based trust was 12 to 32 . The mean score for reliance-based trust was 23.86 . The disclosure-based trust pretest scores ranged from 18 to 31 , with a mean of 22.71 . The range for total trust in Group 1's pretest was 33 to 62 , and the mean was 46.57. Posttest ranges for reliance-based trust were 11 to 33, with a mean of 26.71. The posttest range for disclosure-based trust for Group 1 were 19 to 35 with a mean of 27.71, and posttest total trust ranges were 30 to 66 with a mean score of 54.43 . 
Table 7

Group 1 Raw Scores

\begin{tabular}{ccccccccccccccc}
\hline & & Q1 & Q2 & Q3 & Q4 & Q5 & Q6 & Q7 & Q8 & Q9 & Q10 & Reliance & Disclosure & Total \\
\hline \multirow{2}{*}{1} & Pre & 4 & 4 & 5 & 3 & 6 & 6 & 3 & 1 & 5 & 7 & 22 & 22 & 44 \\
& Post & 6 & 6 & 7 & 7 & 7 & 7 & 6 & 4 & 6 & 7 & 33 & 30 & 63 \\
2 & Pre & 7 & 7 & 4 & 7 & 6 & 7 & 5 & 7 & 7 & 5 & 31 & 31 & 62 \\
& Post & 4 & 1 & 4 & 1 & 1 & 2 & 4 & 2 & 7 & 4 & 11 & 19 & 30 \\
\multirow{2}{*}{3} & Pre & 5 & 3 & 3 & 3 & 6 & 2 & 2 & 2 & 2 & 4 & 20 & 12 & 32 \\
& Post & 6 & 5 & 6 & 5 & 5 & 4 & 4 & 3 & 4 & 4 & 27 & 19 & 46 \\
4 & Pre & 6 & 6 & 5 & 6 & 6 & 5 & 4 & 3 & 5 & 6 & 29 & 23 & 52 \\
& Post & 7 & 6 & 6 & 7 & 7 & 7 & 6 & 7 & 6 & 7 & 33 & 33 & 66 \\
5 & Pre & 4 & 3 & 4 & 4 & 3 & 5 & 5 & 2 & 7 & 5 & 18 & 24 & 42 \\
& Post & 6 & 7 & 6 & 7 & 6 & 7 & 6 & 7 & 7 & 5 & 32 & 32 & 64 \\
6 & Pre & 6 & 6 & 5 & 6 & 6 & 7 & 6 & 6 & 7 & 6 & 29 & 32 & 61 \\
& Post & 6 & 6 & 6 & 6 & 6 & 7 & 7 & 7 & 7 & 7 & 30 & 35 & 65 \\
7 & Pre & 4 & 4 & 3 & 3 & 4 & 4 & 3 & 2 & 2 & 4 & 18 & 15 & 33 \\
& Post & 4 & 3 & 4 & 5 & 5 & 5 & 4 & 6 & 5 & 6 & 21 & 26 & 47 \\
\hline
\end{tabular}

Note. The BTI allows the participant to rate each question from 1 to 7 , with one meaning not willing at all to 7 , meaning completely willing.

Table 8 represents the raw scores from Group 2. Only those participants who finished the course were included in these results. The range of actual answers for the pretest from Group 2 for reliance-based trust was 23 to 36 . The mean score for reliance-based trust was 29.50 . The disclosure-based trust pretest scores ranged from 5 to 29, with a mean of 20.13. The range for total trust in Group 2's pretest was 39 to 62, and the mean was 49.63. Posttest ranges for reliance-based trust were 30 to 34 with a mean of 32.00 . The posttest range for disclosure-based trust for Group 2 were 12 to 32 with a mean of 26.13, and posttest total trust ranges were 45 to 64 with a mean of 58.13. 
Table 8

Group 2 Raw Scores

\begin{tabular}{ccccccccccccccc}
\hline & & Q1 & Q2 & Q3 & Q4 & Q5 & Q6 & Q7 & Q8 & Q9 & Q10 & Reliance & Disclosure & Total \\
\hline \multirow{2}{*}{1} & Pre & 6 & 3 & 4 & 6 & 5 & 6 & 6 & 5 & 6 & 3 & 24 & 26 & 50 \\
& Post & 6 & 7 & 6 & 7 & 7 & 7 & 6 & 7 & 5 & 6 & 33 & 31 & 64 \\
\multirow{2}{*}{2} & Pre & 7 & 5 & 6 & 6 & 6 & 5 & 5 & 4 & 5 & 7 & 30 & 26 & 56 \\
& Post & 7 & 6 & 6 & 7 & 6 & 7 & 6 & 6 & 6 & 7 & 32 & 32 & 64 \\
& Pre & 7 & 6 & 7 & 7 & 7 & 1 & 1 & 1 & 1 & 1 & 34 & 5 & 39 \\
& Post & 7 & 7 & 7 & 5 & 7 & 2 & 5 & 2 & 1 & 2 & 33 & 12 & 45 \\
& Pre & 5 & 4 & 4 & 5 & 5 & 3 & 3 & 3 & 3 & 4 & 23 & 16 & 39 \\
& Post & 7 & 5 & 5 & 6 & 7 & 7 & 6 & 6 & 5 & 6 & 30 & 30 & 60 \\
5 & Pre & 7 & 5 & 6 & 6 & 7 & 5 & 4 & 3 & 5 & 3 & 31 & 20 & 51 \\
& Post & 7 & 6 & 7 & 7 & 7 & 5 & 4 & 4 & 5 & 5 & 34 & 23 & 57 \\
& 6re & 7 & 6 & 6 & 7 & 7 & 7 & 6 & 2 & 7 & 7 & 33 & 29 & 62 \\
& Post & 7 & 7 & 5 & 7 & 7 & 7 & 5 & 1 & 7 & 7 & 33 & 27 & 60 \\
7 & Pre & 7 & 7 & 7 & 7 & 7 & 5 & 2 & 3 & 6 & 2 & 35 & 18 & 53 \\
& Post & 7 & 6 & 6 & 5 & 6 & 7 & 5 & 5 & 6 & 5 & 30 & 28 & 58 \\
& 8re & 6 & 6 & 5 & 4 & 5 & 5 & 3 & 4 & 3 & 6 & 23 & 21 & 47 \\
& Post & 7 & 7 & 4 & 6 & 7 & 7 & 4 & 5 & 4 & 6 & 31 & 26 & 57 \\
\hline
\end{tabular}

Note. The BTI allows the participant to rate each question from 1 to 7 , with one meaning not willing at all to 7 meaning completely willing.

Table 9 represents the raw scores from Group 3, the comparison group. The range of actual answers for the pretest from Group 3 for reliance based trust was 9 to 35 . The mean score for reliance-based trust was 26.22. The disclosure-based trust pretest scores ranged from 7 to 27 , with a mean of 26.22. The range for total trust in Group 3's pretest was 27 to 60 , and the mean was 45.00. Posttest ranges for reliance-based trust in Group 3 were 4 to 34, with a mean of 25.33. The posttest range for disclosure-based trust for Group 3 were 7 to 29 with a mean of 17.22 , and posttest total trust ranges were 18 to 60 with a mean of 42.56 . 
Table 9

Group 3 Raw Scores

\begin{tabular}{ccccccccccccccc}
\hline & & Q1 & Q2 & Q3 & Q4 & Q5 & Q6 & Q7 & Q8 & Q9 & Q10 & Reliance & Disclosure & Total \\
\hline \multirow{2}{*}{1} & Pre & 5 & 5 & 4 & 3 & 3 & 2 & 2 & 1 & 1 & 1 & 20 & 7 & 27 \\
& Post & 5 & 4 & 4 & 4 & 5 & 3 & 2 & 2 & 2 & 2 & 22 & 11 & 33 \\
2 & Pre & 7 & 7 & 6 & 7 & 6 & 4 & 7 & 5 & 6 & 5 & 33 & 27 & 60 \\
& Post & 6 & 6 & 6 & 6 & 6 & 4 & 6 & 3 & 6 & 3 & 30 & 22 & 52 \\
3 & Pre & 6 & 6 & 5 & 6 & 5 & 5 & 4 & 5 & 3 & 4 & 28 & 21 & 49 \\
& Post & 6 & 6 & 6 & 5 & 6 & 4 & 4 & 4 & 4 & 2 & 29 & 18 & 47 \\
4 & Pre & 5 & 6 & 4 & 6 & 5 & 2 & 2 & 2 & 2 & 2 & 26 & 10 & 36 \\
& Post & 6 & 5 & 5 & 5 & 5 & 3 & 5 & 5 & 4 & 2 & 26 & 19 & 45 \\
5 & Pre & 7 & 7 & 7 & 7 & 7 & 4 & 5 & 3 & 3 & 4 & 35 & 19 & 54 \\
& Post & 6 & 4 & 5 & 5 & 5 & 2 & 2 & 1 & 1 & 1 & 25 & 7 & 32 \\
6 & Pre & 7 & 5 & 5 & 7 & 5 & 5 & 5 & 4 & 6 & 4 & 29 & 24 & 53 \\
& Post & 5 & 5 & 4 & 6 & 4 & 4 & 2 & 1 & 6 & 1 & 24 & 14 & 38 \\
7 & Pre & 3 & 1 & 1 & 2 & 2 & 5 & 5 & 3 & 2 & 5 & 9 & 20 & 29 \\
& Post & 3 & 2 & 1 & 2 & 1 & 1 & 2 & 2 & 2 & 2 & 9 & 9 & 18 \\
8 & Pre & 6 & 6 & 5 & 5 & 5 & 4 & 6 & 3 & 4 & 7 & 27 & 24 & 51 \\
& Post & 6 & 6 & 5 & 6 & 6 & 6 & 7 & 3 & 6 & 7 & 29 & 29 & 58 \\
9 & Pre & 7 & 5 & 5 & 6 & 6 & 5 & 5 & 4 & 5 & 6 & 29 & 25 & 54 \\
& Post & 7 & 6 & 7 & 7 & 7 & 4 & 6 & 4 & 6 & 6 & 34 & 26 & 60 \\
\hline
\end{tabular}

Note. The BTI allows the participant to rate each question from 1 to 7 , with one meaning not willing at all to 7 meaning completely willing

\section{Individual Analysis}

With one notable exception, many individuals from Group 1 showed significant change $(\mathrm{RCI}>1.96)$ between their pre- and post-test scores (see Table 10). Participant 2 in Group 1 showed a dramatic decrease in all three scales, with their reliance-based trust reporting a -7.93 RCI, disclosure-based trust showing a -3.61 , and their overall trust coming in at a -5.84 RCI. These results were alarming, leading me to wonder what else was happening with this individual. To further understand these scores, I ensured I included this participant in the individual interviews. The exception made for Participant 2, and the reason for her exclusion, is noted in the qualitative section on distrust. With that information, I chose to run the between-group effect size and RCI with their scores but also exclude her scores. When that participant was omitted, the 
mean difference of the remaining participants was an RCI of 2.645 for reliance-based trust, 2.358 for disclosure-based trust, and an RCI mean of 2.65 for total trust.

Table 10

Group 1 RCI Scale Analysis

\begin{tabular}{cccccccccc}
\hline Participant & \multicolumn{3}{c}{ Reliance } & \multicolumn{3}{c}{ Disclosure } & \multicolumn{3}{c}{ Total } \\
\hline 1 & $\frac{\text { Pre }}{22}$ & $\frac{\text { Post }}{33}$ & $\underline{\text { RCI }}$ & $\frac{\text { Pre }}{4.36}$ & $\frac{\text { Post }}{30}$ & $\underline{\text { RCI }}$ & $\frac{\text { Pre }}{2.41}$ & $\frac{\text { Post }}{63}$ & $\underline{\text { RCI }}$ \\
2 & 31 & 11 & -7.93 & 31 & 19 & -3.61 & 62 & 30 & -5.84 \\
3 & 20 & 27 & 2.78 & 12 & 19 & 2.11 & 32 & 46 & 2.56 \\
4 & 29 & 33 & 1.59 & 23 & 33 & 3.01 & 52 & 66 & 2.56 \\
5 & 18 & 32 & 5.55 & 24 & 32 & 2.41 & 42 & 64 & 4.02 \\
6 & 29 & 30 & 0.4 & 32 & 35 & 0.9 & 61 & 65 & 0.73 \\
7 & 18 & 21 & 1.19 & 15 & 26 & 3.31 & 33 & 47 & 2.56 \\
\hline
\end{tabular}

Note. Three scales were used in the study, reliance, disclosure, and total trust. Participants took a pretest and posttest 13 weeks apart, and Reliable Change was calculated for each scale

Group 2 showed similar gains in the level of trust in the group from all but one individual (see Table 11). Participant 6 in Group 2 showed a decrease in the level of trust of the group; however, this participant was not excluded from group scores because no negative ratings rose to the $>1.96$ thresholds, showing a statistically significant drop in her trust levels. A point of interest in these scores was the hypothesis disclosure-based trust would dramatically increase, and reliance-based trust would increase. Both hypotheses were incorrect. In Group 2, the mean RCI of the individual participants was 1.35 for reliance-based trust, only 1.78 for disclose-based trust, and 1.72 for total trust. 
Table 11

Group 2 RCI Scale Analysis

\begin{tabular}{cccccccccc}
\hline Participant & \multicolumn{3}{c}{ Reliance } & \multicolumn{3}{c}{ Disclosure } & \multicolumn{3}{c}{ Total } \\
\hline 1 & $\frac{\text { Pre }}{24}$ & $\frac{\text { Post }}{33}$ & $\frac{\text { RCI }}{4.86}$ & $\frac{\text { Pre }}{26}$ & $\frac{\text { Post }}{31}$ & $\frac{\text { RCI }}{1.48}$ & $\frac{\text { Pre }}{50}$ & $\frac{\text { Post }}{64}$ & $\frac{\text { RCI }}{2.86}$ \\
2 & 30 & 32 & 1.08 & 26 & 32 & 1.78 & 56 & 64 & 1.63 \\
3 & 34 & 33 & -0.54 & 5 & 12 & 2.07 & 39 & 45 & 1.22 \\
4 & 23 & 30 & 3.78 & 16 & 30 & 4.15 & 39 & 60 & 4.29 \\
5 & 31 & 34 & 1.62 & 20 & 23 & 0.89 & 51 & 57 & 1.22 \\
6 & 33 & 33 & 0.00 & 29 & 27 & -0.59 & 62 & 60 & -0.49 \\
7 & 35 & 30 & -2.7 & 18 & 28 & 2.96 & 53 & 58 & 1.02 \\
8 & 26 & 31 & 2.7 & 21 & 26 & 1.48 & 47 & 57 & 2.04 \\
\hline
\end{tabular}

Note. Three scales were used in the study, reliance, disclosure, and total trust. Participants took a pretest and posttest 13 weeks apart, and Reliable Change was calculated for each scale.

I ran the RCI calculations on the comparison group (see Table 12). This analysis shows the comparison group members, on the whole, differed from the participant group's results. The comparison group's scores were inconsistent. Only one participant showed a significant increase $(\mathrm{RCI}>1.96)$ in any of the scales. That was Participant 4 , whose disclosure-based trust changed from a pretest score of 10 to a posttest score of 19; the posttest score was just slightly higher than the mean posttest disclosure score for this group (17.22). No participant in Group 3 achieved a total-trust RCI higher than the 1.96 thresholds, and more than half of participants showed a decreased level of trust in their group. Without the advantage of interviewing the members of this group, I could not make any determinations on why distrust was present in this group. The mean RCI scores for the individuals in the comparison group were -0.26 for reliance-based trust, -0.82 for disclosure-based trust, and -0.64 for overall trust. 
Table 12

Group 3 RCI Scale Analysis

\begin{tabular}{cccccccccc}
\hline Participant & \multicolumn{3}{c}{ Reliance } & \multicolumn{3}{c}{ Disclosure } & \multicolumn{3}{c}{ Total } \\
\hline 1 & $\underline{\text { Pre }}$ & $\underline{\text { Post }}$ & $\underline{\text { RCI }}$ & $\frac{\text { Pre }}{7}$ & $\frac{\text { Post }}{11}$ & $\underline{\text { RCI }}$ & $\frac{\text { Pre }}{27}$ & $\underline{\text { Post }}$ & $\underline{\text { RCI }}$ \\
2 & 33 & 30 & -0.58 & 27 & 22 & -1.69 & 60 & 52 & -1.53 \\
3 & 28 & 29 & 0.29 & 21 & 18 & -1.01 & 49 & 47 & -0.38 \\
4 & 26 & 26 & 0.00 & 10 & 19 & 3.04 & 36 & 45 & 1.72 \\
5 & 35 & 25 & -2.89 & 19 & 7 & -4.05 & 54 & 32 & -4.21 \\
6 & 29 & 24 & -1.45 & 24 & 14 & -3.37 & 53 & 38 & -2.87 \\
7 & 9 & 9 & 0.00 & 20 & 9 & -3.71 & 29 & 18 & -2.10 \\
8 & 27 & 29 & 0.58 & 24 & 29 & 1.69 & 51 & 58 & 1.34 \\
9 & 29 & 34 & 1.45 & 25 & 26 & 0.34 & 54 & 60 & 1.15 \\
\hline
\end{tabular}

\section{Within-Group Analysis}

The purpose of this study is explicitly interested in group dynamics and the level of trust that can be established in a group with the chosen intervention. To analyze the levels of trust developed within each group, I ran the group's mean scores from each of the three scales through two separate tests comparing the mean scores of each group's pretest to their posttest to establish the effectiveness of the chosen intervention (see Table 13). The first statistic is Cohen's $d$, which is a method to determine the strength of the relationship between two variables. I also ran RCI for each of the dependent variables. The variables here are the results of the pre- and post-test, with the difference attributed to the intervention for participant groups. Initially, I included every participant who completed the course in the analysis (see Table 13). With these data, results in Group 1 are moderate in all three scales about effect size. The results of data analysis showed reliance had an effect size of 0.409 , disclosure nearly 0.713 , and total trust 0.604 . These numbers are quite lower than the effect size noted in Group 2, which were 0.726 in reliance, 0.857 for disclosure, and 1.21 for total trust. Group 3's effects were mild at best. Results were 0.12, 0.218, and 0.193; without the advent of any intervention, minimal impact would be noted with the comparison group's trust in its boundaries. 
Table 13

Cohen's d and RCI With Outlier

\begin{tabular}{lccccc}
\hline & & & & Cohen's & \\
& Mean & $n$ & $S D$ & $d$ & RCI \\
\cline { 2 - 5 } Group 1 reliance Pre & 23.86 & 7 & 5.64 & 0.409 & \multirow{2}{*}{1.13} \\
Group 1 reliance Post & 26.71 & 7 & 8.14 & & \\
Group 1 disclosure Pre & 22.71 & 7 & 7.43 & 0.713 & 1.505 \\
Group 1 disclosure Post & 27.71 & 7 & 6.58 & & \\
Group 1 total Pre & 46.57 & 7 & 12.25 & 0.604 & 1.278 \\
Group 1 total Post & 54.43 & 7 & 13.75 & & \\
& & & & & \\
Group 2 reliance Pre & 29.50 & 8 & 4.63 & 0.726 & 1.207 \\
Group 2 reliance Post & 32.00 & 8 & 1.51 & & \\
Group 2 disclosure Pre & 20.13 & 8 & 7.55 & 0.857 & 1.777 \\
Group 2 disclosure Post & 26.13 & 8 & 6.40 & & \\
Group 2 total Pre & 49.63 & 8 & 7.93 & 1.21 & 2.397 \\
Group 2 total Post & 58.13 & 8 & 5.99 & & \\
& & & & & \\
Group 3 reliance Pre & 26.22 & 9 & 7.73 & 0.12 & -0.257 \\
Group 3 reliance Post & 25.33 & 9 & 7.16 & & \\
Group 3 disclosure Pre & 18.78 & 9 & 6.63 & 0.218 & -0.526 \\
Group 3 disclosure Post & 17.22 & 9 & 7.61 & & \\
Group 3 total Pre & 45.00 & 9 & 11.69 & 0.193 & -0.467 \\
Group 3 total Post & 42.56 & 9 & 13.62 & & \\
\hline
\end{tabular}

Cohen (1977) considered a score of .02 to be a small effect, .05 to be a medium effect, and .8 to be a large effect. An effect size greater than 1 represents that the difference between the two means is larger than one standard deviation. I also ran the RCI for each of the scales in each group. I took each group and scale in each group and treated it as an individual case.

After realizing Participant 2 in Group 1 had a negative effect on the group's trust ratings, I reran the effect size statistics after excluding their scores. Table 14 shows the results of their exclusion from the group mean scores. The effect size scores all rose to levels greater than one standard deviation, with reliance at 1.356 , disclosure at 1.106 , and total trust at 1.409. Similarly, the RCI showed significant increases without the outlier included. Reliance-based trust was 
posted at an RCI of 2.903, disclosure-based trust was 2.47 , and total trust was 2.908 . All three scores were significant, rising above the $>1.96$ standards.

Table 14

Revised Group 1 Without Outlier

\begin{tabular}{lccccc}
\hline & & & & Cohen's & \\
& Mean & $n$ & $S D$ & $d$ & RCI \\
\hline Group 1 reliance Pre & 22.67 & 6 & 5.13 & \multirow{2}{*}{1.356} & \multirow{2}{*}{2.903} \\
Group 1 reliance Post & 29.33 & 6 & 4.68 & & \\
Group 1 disclosure Pre & 21.33 & 6 & 7.09 & 1.106 & 2.473 \\
Group 1 disclosure Post & 29.17 & 6 & 5.85 & & \\
Group 1 total Pre & 44.00 & 6 & 11.15 & \multirow{2}{*}{1.409} & 2.908 \\
Group 1 total Post & 58.50 & 6 & 9.35 & & \\
\hline
\end{tabular}

Note. Group 1 scores changed dramatically by eliminating an outlier in all three variables, reliance, disclosure, and total trust

\section{Between-Group Analysis}

The final area for which the results of the BTI survey were used was to compare group scores for each of the three scales to that of Group 3 (comparison group). This between-group comparison demonstrates the effectiveness of the communication course regarding building trust in a group. The statistic used to measure the variance between groups is Cohen's $d$, which is used to measure effect size.

The initial effect size was run between the groups, including all participants (see Table 15). The reliance-based trust scores postintervention showed a large effect of 1.29 for Group 2 when analyzed against the comparison group, and a mild effect of only 0.18 for Group 1 when compared to the comparison group. The disclosure-based trust scores showed a large effect size 
of 1.27 for Group 2 and 1.48 for Group 1, even when the outlier was included. Total trust effect scores were both categorized as large, with Group 2 at 1.48 and Group 1 at 0.87 .

Table 15

Cohen's d Between-Group Analysis

\begin{tabular}{lcccc}
\hline & Mean & $n$ & $S D$ & $\begin{array}{c}\text { Cohen's } d \text { with } \\
\text { comparison }\end{array}$ \\
\hline Group 1 Reliance & 26.71 & 7 & 8.14 & 0.18 \\
Group 2 reliance & 32.00 & 8 & 1.51 & 1.29 \\
Comparison reliance & 25.33 & 9 & 7.16 & \\
& & & & 1.48 \\
Group 1 disclosure & 27.71 & 7 & 6.58 & 1.27 \\
Group 2 disclosure & 26.13 & 8 & 6.40 & \\
Group 3 disclosure & 17.22 & 9 & 7.61 & 0.87 \\
Group 1 total & 54.43 & 7 & 13.75 & 1.48 \\
Group 2 total & 58.13 & 8 & 5.99 & \\
Group 3 total & 42.56 & 9 & 13.62 & \\
\hline
\end{tabular}

Note. Both participant group's posttest scores were compared to the comparison group. This table includes the outlier from Group 1.

The results were skewed with the inclusion of the outlier in Group 1. In Table 16, the outliers' scores were excluded from the rerun of the statistics. The reliance-based trust Cohen's $d$ score rose to the level of a medium effect; also, both the disclosure and total trust scores rose considerably. Group 1's Cohen's $d$ scores were 1.76 for disclosure-based trust and 1.36 for total trust as compared to the group that did not participate in the intervention. 
Table 16

Cohen's d Excluding Outlier From Group 1

\begin{tabular}{lcccc}
\hline & Mean & $n$ & $S D$ & $\begin{array}{c}\text { Cohen's } d \text { with } \\
\text { comparison }\end{array}$ \\
\hline Group 1 reliance & 29.33 & 6 & 4.68 & 0.66 \\
Group 3 reliance & 25.33 & 9 & 7.16 & \\
Group 1 disclosure & 29.17 & 6 & 5.85 & 1.76 \\
Group 3 disclosure & 17.22 & 9 & 7.61 & \\
Group 1 total & 58.50 & 6 & 9.35 & 1.36 \\
Group 3 total & 42.56 & 9 & 13.62 & \\
\hline
\end{tabular}

Note. Participant 2's scores were removed, and Group 1's posttest scores were compared to the comparison group in all three areas of trust.

\section{Summary of Quantitative Findings}

Due to the nature of the communication course, I hypothesized all three measurements of trust would increase in the individuals and groups that participated in the intervention; however, I hypothesized disclosure or affective trust would increase substantially, while reliance or cognitive-based trust would rise, though not as much. This hypothesis was incorrect. Reliancebased trust rose higher in both participant groups as an average of individual scores than did disclosure-based trust. When measuring in group levels of trust, and when the outlier in Group 1 was eliminated, the hypothesis was supported where the effect of the intervention ranged from medium to very large in all three scales we measured.

The data obtained from the pretest and posttest scores of participant groups provided strong evidence the intervention had a substantial effect on most of the individual members of these groups. The level of trust in all three scales rose to a level of significance in these groups. Furthermore, data from both participant groups showed meaningful differences in the level of trust in their membership. Substantial differences were found between participant groups when compared to the comparison group. 
The between-group analysis compared both participant groups (Groups 1 and 2) with Group 3, allowed for a noticeable difference postintervention. In this case, with Group 1, reliance-based trust showed a moderate difference in reliance-based trust compared to Group 3, and disclosure-based trust was dramatically affected for Group 1 postintervention. Total trust was also much higher postintervention with Group 1 compared to the group that did not go through the course (Group 3). With Group 2, all three scales of trust measured displayed a large effect when compared to Group 3. To answer the secondary research questions on the specific methods that were the focus of instruction during the intervention, I used qualitative analysis.

\section{Qualitative Analysis}

The scope of the qualitative research in this study was restricted to the two participant groups; the comparison group's input was limited to the quantitative portion of the study. Qualitative data were collected in four areas. First, I analyzed the detailed field notes, which I recorded just after each session. The field notes used in this analysis were taken immediately after the focus group sessions with both participant groups. Because the course sessions were not audio recorded, I paraphrased comments participants made that I felt were relevant. Second, both participant groups participated in separate focus group sessions with their responses recorded, transcribed, and coded. Third, four participants from each group were selected to participate in individual interviews; these interviews were also recorded, transcribed, and coded. Fourth, an independent observer, whose primary responsibility was to rate the consistency of the application of the coursework and focus group, provided feedback on participants she observed in the form of detailed field notes. The observer's field notes were collected during Weeks 1, 6, 13, and the focus group sessions with both participant groups. The observer's field notes were primarily used to validate my observations and field notes. 
The analysis focused on three areas: (a) participants' relationships toward each other, (b) the relationship between communication and trust development, (c) participants' viewpoints related to the secondary research questions, and (d) participants' reflection on the value of the course. A subsection of participants' reflections on the value of the course led to analysis on where improvements in the course could be achieved for future iterations. The areas for improvement will be discussed in a separate section because it will include quantitative analysis along with quantitative results from the survey.

To present the effectiveness of the communication intervention on a cross-functional workgroup, I analyzed data from each qualitative method of this study. Analysis of the qualitative data began with coding each of the focus groups and interview sessions. I used a commercial online service called Otter for transcription of the recordings. As discussed in Chapter 3, the original transcribed documents received from Otter required some editing, as the online program did not understand and decipher all speakers' words accurately. The process of making these corrections enabled me to listen intently to the focus groups and interviews once again, allowing me the opportunity to refresh myself with the voice inflection and emotion of the conversations.

During the process of coding, categories emerged consistent with the categories described in the literature related to trust and its development. Three primary areas apparent in the interviews include components of trust, characteristics of trust, and conditions for trust. In addition to categories that support the findings, I provided an analysis of the data related to the secondary research questions. The secondary research questions are:

- Does empathic listening play in the development of trust in a cross-functional workgroup? 
- Does Gestalt language protocol play in the development of trust in a cross-functional workgroup?

Before addressing the secondary research questions, it is essential to lay the groundwork on participants' views on where trust comes from, how trust is identified, and the conditions that must be present to build trust in a cross-functional group. These components are essential and critical to this study. After describing their thoughts on these subjects, I address the two secondary research questions.

\section{Trust and Distrust}

The components of trust participants referenced included exhibiting trusting behaviors and distrust. Exhibiting trusting behaviors is reflected positively, while distrust is a construct that must be overcome to develop trust. While exploring distrust was not an area I initially considered, it was displayed during the course sessions and was also reflected in the BTI scores of one individual. This anomaly created the opportunity to explore where the distrust may have come from. The conversation led to questioning the outlier and others on their propensities to trust. Components and characteristics that were displayed and discussed in participant groups are addressed and analyzed individually in the following section.

Displays of trust and distrust during the course. During sessions with both groups, trusting behaviors were displayed. The field notes I recorded after each session aided in exploring actions that demonstrated trusting behaviors. While some trusting behaviors were exhibited by individuals early in the class, on a group level, trusting behaviors were not apparent or noticed until after each group participated in several course sessions. It was in Week 3 that I first noticed and recorded trusting behaviors demonstrated in Group 1. It was not until Week 8 that Group 2 began to display trusting behaviors in the group, as discussed later in this section. 
The following sections are listed chronologically, by group, to show progression and, in some cases, regression in the display of trusting behaviors.

Group 1. During the third session in Group 1, when I first started to see trusting behavior in the group, Perry displayed both vulnerability and humility when he told a story about a workrelated incident. He described the scenario and his reaction to the event, which was to place blame on specific individuals. He described a process of reflection, and how this reflection enabled him to publicly issue a sincere apology to two group members. These apologies are paraphrased in this section, taken from my field notes. Perry said he owed Landry an apology, because he had blamed Landry for a situation and said some inappropriate remarks to her and to others about her. What he said he should have done is ask for more information to add to the "pool of shared knowledge." Perry faced Landry and apologized. Perry then addressed Perry directly stating Perry had warned and advised him to speak directly to Landry and that he had gotten caught up in his own story. Perry then admitted he had gotten so caught up in his own story, which was where he made assumptions and got off track. This act of contrition displayed humility and vulnerability on Reilly's part. Landry and Perry both were quick to accept Reilly's apology, which set the stage for some very open dialogue within the group.

This dialogue included some serious discussion about the CEO of the company. Landry told a story where she was recently let down by the boss, claiming she went to the CEO 3 weeks prior with a problem he had ignored. Now that same problem had come back, and the CEO blamed her for not fixing the problem initially. Denver then said he was frustrated the CEO was not part of this group taking the course and suggested the CEO needs coaching one on one if he is not going to go through this course with the rest of the group. Both Landry and Denver displayed vulnerability by bringing the boss into a discussion with such a large group. I asked 
why they chose to bring this up in the group, and Denver said it was the ground rules the group had made on the first day. Denver said the ground rule that said "what is said here stays here" is what allowed him to bring it up with this group.

Vulnerability was also apparent during Week 4 in Group 1. During the icebreaker session at the beginning of the class, Perry shared he was still dealing with some loneliness; this was the first time anyone in the group brought personal feelings into the session. Perry talked about being separated from his wife because he had moved to California for this new job and his wife had to stay in Illinois for a while. He said he could not wait until she joined him in their new home. Perry went on and told everybody how appreciative he was that everyone in this group made him feel welcome. Perry went on to address the group and told of a conversation he had with Denver earlier in the week, giving credit to the process of this class and how everybody had embraced the concepts. He said he discussed with Denver the way people are treating him now that the group is in this class together, and that is what is keeping him at the company.

I also noticed instances of vulnerability in Group 1 during Week 7. Perry spoke about what he called a "personal butt-kicking." When he was asked to explain what that meant, Perry talked about the self-reflection he did and how it was difficult yet rewarding. He also shared his serious attempts at self-monitoring. As he told his story about being in this industry for many years, it has mostly been a boy's club atmosphere, and now he was starting to reflect and see how inappropriate he had been at times, and not just with women in the office. Perry said he now could see how even with Reilly he could voice things differently, show more respect, and get better results.

Also, during Week 7, the conversation migrated to personal relationships. These conversations about personal relationships displayed significant trusting behaviors with several 
participants in Group 1. Reilly changed the topic away from company-specific situations to the relationship with his father. Related to this parental relationship, Reilly admitted the relationship with his father had affected every aspect of his life and how he operated. At one point in his conversation, Reilly was visibly emotional and had tears in his eyes. What I observed throughout the room was a sense of empathy among members for both Perry and Reilly. Storm spoke about this empathy with appreciation as they said they appreciated that both Reilly and Perry opened up about what was going on in their lives. It made Storm feel good that they trusted enough to share. Storm went on to say they were not used to people being so open. Storm stated it was difficult for them to do that, but that they would try. In previous sessions, Storm had seemed to be an introvert - they had been quiet and did not volunteer information about their life. Storm did, however, answer direct questions about the assignment, but, on this day, it was different, as they decided to share personal frustrations with their husband. Storm talked about how much they loved their spouse but at the same time was frustrated with them because they did not communicate as much as they would like. Storm said they do not always get to say what they feel they need to say and want to see how these tools will work in their home. As they shared, I observed two distinct emotions. At first, Storm displayed anger toward their spouse and later a sense of relief when they recognized compassion from their cohort. Storm was moved by the empathy directed toward them and verbally thanked the group for the care they received; this was a new sense of vulnerability that I had not seen in Storm previously.

While Week 7 was emotional, and the group provided safety for some to share personal stories, there were two noticeable exceptions. Frankie was less vocal during this session compared to previous weeks. When they did speak, their demeanor was defensive; they also used sarcasm on two occasions. Sidney, who was a self-described introvert, was noticeably holding 
back. Sidney did not engage in any conversation, so at one point, late in the session, I asked Sidney directly what they were feeling, and the response was, "This is pushing me out of my comfort zone."

The next two sessions took a dramatic turn. The trusting behavior exhibited during the previous weeks had vanished. The room was more hostile during both weeks. I also noted there were only five participants during Week 8. Although one participant was ill that day, Frankie and Landry were in the office and refused to attend class. The tension during Week 8 was palpable; those who were in class provided some insight. Perry was emphatic as they spoke about their disappointment in some of their peers. Perry's frustration boiled over. When thinking about the two participants who chose not to attend the class, they commented about their frustrations, stating there was something in this class for everybody. Perry went on with self-analysis and claimed this class had forced them to look at themselves and make some changes. Perry said they would be hard to make but said they were good for them, and they could not believe others made a choice not to attend.

Week 9 continued with a negative and uncomfortable feeling in the room. Several people made dramatic negative statements about the mood in the office. Many of their sentiments were directed toward the CEO and some unrealistic expectations he had placed on leadership team members. Landry complained the CEO just expects too much and is not clear about his expectations. Landry shared that when they bring him some improvements they have made in the department, he just criticizes them and still does not say what it is he wants. Reilly, agreeing with Landry, stated it had been that way ever since they started at the company. They went on to say they do not think the CEO knows what he wants and only tells them what is wrong after they have gone and done so much. The energy in the room was hostile, which resulted in the entire 
session becoming a venting session, and the group was unable to complete the assigned chapter and lesson discussion.

The positive energy came back to the group during Week 10. Perry asked to share; as class started, they apologized to the rest of the class, saying they were sorry for complaining the previous week, that this is still a business, and that they did not think it was appropriate to vent to this group about their boss. His sense of humility allowed the group to relax. Frankie, who was silent the week before, defended their CEO and provided some insight the CEO had stressed that the rest of them did not have or understand. The CEO is the one who has to make payroll every week, and there have been a lot of times he has gone without a paycheck to make sure they get their pay. Several of the others were still melancholy. Then Storm, who was visibly uncomfortable with how the group had piled on the boss in a previous session, said they were not comfortable with all of the stuff people were saying last week either and wished the group would not get into that kind of stuff there. There was a sense of empathy for the CEO after Frankie and Storm's comments.

Group 2. Group 2 was slower to exhibit trusting behaviors than Group 1, and it was not until Week 8 that I noticed behavioral changes in the group. I had noticed during Week 6 the remote participants (in the Dallas office) did not engage in the conversation until they were asked questions. I asked those members a specific question: "Why does it seem that the Dallas office was not as engaged?" Finley, from the Dallas office, answered this question by stating this phenomenon was systemic in the company. They participated in virtual video meetings frequently in their organization. The California office always led those meetings, and typically they were information-only meetings; sharing and ideas were not encouraged. Finley said they resented the dynamics and often felt like the "stepchildren of the company." The other two 
participants from Dallas agreed with their assertion. Members of the group who worked in the California office reported they had never thought about why the California office seemed to dominate the conversation. Armoni commented they should be aware this is happening and see what this group could do about changing it, and others agreed. Royal mentioned they would talk to management about this and see what could be done. Within the California group, it was decided one thing they could do during the course was to look at the camera instead of each other in the room when they were having a discussion.

Week 7 did not bring out changes I had hoped to accomplish. The California group addressed the camera more, and we began the dialogue by asking two Dallas members to speak first; however, it did not bring the group together as fast as everybody hoped. At the end of Week 7, Charlie asked to talk about the "stepchildren" comment Finley made. Charlie showed genuine concern their peers had felt this way; others in California agreed and asked what more could be done. Charlie's show of concern for how the Dallas office felt was a display of empathy that seemed to change some of the group's dynamics. Oakley spoke up for the Dallas office and said they appreciated that the California group thought this was an issue they should deal with, and hearing this was a real concern made her feel better. The Dallas group said they could also do more to break down the barrier.

Week 8 was noticeably different. The small group in Dallas seemed to be more sanguine, which was evident by the laughing and joking they engaged in just before the start of the meeting. Soon after the opening icebreaker section, Oakley, one of three participants from the remote office who called in using Go-to-Meeting video conferencing, wanted to be the first to talk. They shared their understanding of the lesson of the week, what it meant to them, and felt 
for the first time they were truly present. They seemed to be more engaged than in previous weeks. They leaned forward in their chair and asked clarifying questions to others in the group. Another observation from Week 8 was that Justice and Armoni had relaxed with each other: Their body language was different than it had been in previous meetings. These peers sat next to each other in the class for the first time, and when one was speaking, the other would turn to face them. I also noted a difference in facial expressions, as both smiled when they engaged in dialogue. During this session, I asked the group what they noticed. Skyler, who had been reluctant to buy into the program, felt the lessons in the book were valuable, but that it was Justice's willingness to share some personal stories that allowed them to open up themselves. They continued that it was not until Week 7 that they started to buy into the program, but watching Justice and listing to them share so profoundly is what allowed them to decide they could also be more vulnerable.

The trend of exhibiting trusting behaviors continued for the remainder of the sessions in Group 2. In the field notes I noted in Week 9, there was a positive energy in the room, unlike previous meetings. Participants from Dallas were more engaged. Lennon was willing to share their thoughts; they joked with others and smiled more than in previous weeks. I also noticed the bond between Justice and Armoni had grown stronger, with each of them commenting on the other's stories and reflections.

The exercise assigned for the groups after Week 12 was for everybody to pick a subject from the course lessons and write a blog article between 600 and 800 words. They could choose to write on any aspect of the subject if the topic came from the list provided. During Week 13, each participant was asked to read their homework assignment aloud. Each participant was to write a blog article structured around the coursework. Armoni, who had embraced the lessons, 
asked to read their blog article first. They read their blog, which was a personal story reflecting on humility. There were tears shed by others in the group while Armoni was reading. Armoni's emotional reading set the stage for the rest of the group to be extremely engaged throughout the session. My notes reflected a genuine sense of caring for each other and for the group itself. While Group 1 displayed trusting behaviors sooner than Group 2, by the end of the 13 weeks, trusting behaviors were shown by both groups. There was a noticeable exception, which was Group 1. Frankie displayed contempt and even hostility toward others. While distrust was not initially considered for this study, it became apparent after analyzing the results of the BTI that the concept of distrust had to be included and thus is included in the next section.

Distrust and the creation of an outlier. I did not anticipate the potential for issues to arise that the group could not solve in the communication class format; however, as mentioned previously, a particular circumstance emerged in Group 1 outside of the structure of the research that created the need to include an analysis of distrust in the study. I might not have become aware of the situation if it were not for the analysis of the BTI survey. Frankie scored very high in all three categories on the BTI pretest. Their score on reliance was 31 compared to a mean of Group 1 of 23.86. Their disclosure-based trust score was 31 when the mean of their group was 22.71, and total trust was 62 compared to a mean of 46.57 for their cohort. Each score represented greater than one standard deviation higher when compared to the group scores. These scores are consistent with Frankie's self-analysis on their propensity to trust, as noted previously.

The first look at the posttest scores presented a dramatic decrease in Frankie's results. On the reliance scale, their rating had dropped from 31, which was the highest in their cohort, to an 11, while the group means rose from 23.86 to 26.71 . A less dramatic drop, but still significant, 
came in the disclosure posttest, where they dropped from a pretest score of 31 to a posttest score of 19 , while the group overall rose from 22.71 to 27.71 . Results for total trust followed suit. They dropped from a pretest score of 62 to a posttest score of 30. In contrast, Group 1's posttest rose to 54.43 from their pretest mean of 46.57 . It was evident something dramatic had happened, which created the need to include Frankie in individual interviews.

During the individual interview with Frankie, I first asked them about their propensity to trust. They were empathic and a very trusting person, stating:

I'm the personality that I'm going to trust you because I don't know you. And I'm not going to base my history on you. So, when I first meet you, I'm going to trust you. I'm going to trust your word, and I've also learned about myself that word is extremely, extremely important to. So, I'm going to trust you, and I'm going to. I'm going to give you the respect that I would like back.

I then discussed her BTI survey results and asked if they could explain why there was such a stark difference between their pre- and post-test. Their response was lengthy, full of emotion, and somewhat disheveled. They said:

Right after we had the meeting where you asked everybody like if the CEO was to be gone tomorrow, could you guys, as a team, handle, this company? Everybody in the room said they could and would be willing, and then trouble hit us. Our IT systems crashed, and we could not operate. Denver, who is in charge of IT, had a scheduled day off, I tried to call him, and he did not answer his phone. Perry, who is in charge of operations, called in sick that day, and when I called him to tell him about the problem, he said there was nothing he could do. I even tried to call Landry, who is in charge of sales, thinking she could at least call up customers to explain why orders might be late. Well, she did not 
bother to call anyone. We were down for 24 hours, and three of our key leaders were unavailable and left their work for me to handle. They all bailed and did not live up to the promises that they made just a week earlier. I felt betrayed by each of them.

The members of Frankie's group had violated their trust. As Frankie saw it, their group had committed to each other that they would handle the business if the CEO were unavailable, and, at the first sign of crisis, the top three people they were counting on were nowhere to be found. Frankie felt abandoned and left to solve the crisis on their own. It was to them the act of betrayal that led to their distrust of this group's members.

The conversation with Frankie on distrust led me to ask them about their propensity to trust. Their initial ratings of the survey showed they had a high level of all three constructs of trust. The propensity to trust was also something I wanted to explore with others. Lennon was interesting as they were the only other participant whose trust scores regressed. This propensity to trust should also be explored in those whose trust scale showed dramatic increases. My thoughts were that some of the individuals did not score high initially because they had a low propensity to trust. If this was the case and their variance was dramatic, this would provide further evidence of the effectiveness of the communication course's effect on trust.

\section{The Propensity to Trust and Its Effect on the Outcomes}

Frankie stated, "I am a very trusting person." When I asked where that came from, they said, "From trauma." Frankie detailed a traumatic childhood experience. What was most interesting about this is Frankie was not sorry the event happened and felt it made them who they are, which they described: “I didn't want to be that person to judge everybody based on what they look like." 
Justice, during their interview, was asked about their propensity to trust. They stated, "You have to earn my trust." I pressed further to explain what they meant, and they said:

I think it is within myself; I just don't know. I don't like people knowing a lot about me. . .. I'm usually going to sit back and be quiet and just listen and get a feel for you or for the other people, and then maybe jump in.

Others were asked about their propensity to trust. Sidney and Charlie provided similar answers. Sidney responded, "I am usually pretty trusting until you sort of do something to break that trust." Charlie replied, “At work, I tend to be fairly trusting, I think until somebody gives me a reason not to." Charlie explained situations where he is leery, saying, "I think it depends on the scenario, because when it comes to somebody who I think they might want something from me." There were others on the opposite end of the scale.

Storm provided insight into distrust, not as much as where it came from but that it exists. They were asked in their individual interview about their level of trust with a stranger, and for that question, I was the subject of their answer when they stated, "In the beginning? No, I did not walk in trusting you, because I haven't heard you talk or say anything, or communicate with anybody around me." This response contrasted with Sidney and Charlie, as Storm needed to have some familiarity before they grant trust to anybody.

While there were displays of trusting behaviors in both groups, there were also behaviors that showed distrust. Distrust was evident in both groups. In Group 1, two participants' behaviors were recognized explicitly. Sidney's resistance to engage in the types of discussion that represented vulnerability was much more subtle than Frankie's overt displays of distrust, which included purposely missing a session, their use of sarcasm, and their defensive posture. 
In Group 2, distrust was apparent for the first several sessions, and this was due in part to the unique methods used during the course and the unfamiliarity participants had with each other. In Group 2, this resistance did not last, and the group members overcame the physical barriers, with one group in Dallas and the other in Orange County, CA. Once those barriers were addressed, and the smaller group in Dallas felt they too had a voice at the table, the entire dynamics of the group began to change.

\section{Circle of Trust}

The previously mentioned revelations led to the development of trust and the theory known as the CoT. The CoT process influenced the development of the course and had a profound effect on those who participated in the course. The components embedded in the CoT participants spoke about included having an intention to build a relationship, being reliable, and showing respect for others. Participants also believed the underlying lessons that were the subject of the secondary research questions - listening to understand others and sharing from experience - played a major role in their ability to build trust within the group.

Intention. Intention is the first step in the CoT. Without the intention to build trust in a group, there are no other steps. Several members of both groups recognized the importance of building trust. Charlie's story about the intention to be inclusive with the Dallas group was instrumental in allowing the members in Dallas to feel welcome and part of the group. There were specific comments made in both focus group sessions as well.

Storm (Group 1) resonated with the concept of having the intention to believe others are coming from a good place. This aided in their ability to learn to trust: "Have some good intent totally made me think of a different way." They went on to conclude, "Even if I know for a fact 
it's not coming from a good place, I can always just tell myself some good intent and then, later on, step back into the conversation and have that person."

From Group 2, Justice also became a believer that their intention and willingness to believe others have good intentions allowed them to develop better relationships. Justice stated, "The intentions behind certain things are generally, you know, good and come from a good place, and that's allowed me to be more receptive." Later, during the focus group, Justice said, "The greatest thing that's helped me in my relationship with Armoni in this class is it falls back into that respect piece in assuming good intentions."

Reliability and dependability. Members of the first focus group session recognized reliability does play an important role in trust development. Sidney was adamant that honoring all of their commitments is paramount in trust development. They said:

You know through that and in hearing other people and their commitments, and some of the things that are outside of this group happening in a day to day operations. Like reliance, it said things would get done, said would get done.

The lack of reliability others in Group 1 experienced destroyed trust with one member. Breaking the commitments the management of Group 1 had made to each other changed the relationships and the level of trust between Frankie and the group. It is interesting to note this did not affect the trust level with anyone else in the group. It was because they were not directly impacted by the network outage, they had no reason to be bitter. Frankie, on the other hand, could not overcome feelings that the group betrayed them. This sentiment was reflected both in their BTI variances and their comments during their individual interview.

Respect. One theme that made the most impact during the focus group sessions was respect. There were two versions of respect several participants discussed. Respect that comes 
from providing everybody basic human dignity was a major theme. So too was the type of respect earned by individuals with their thoughts, ideas, and behaviors.

Denver understood this concept of recognition respect, as they explained how they apply this in their life by asking themselves a simple question —asking themselves to assume the other person is a rational human and then explore from their point of view caused them to think deeper when providing that level of respect to everybody with whom they come in contact. Reilly characterized respect in their belief that other's opinions are valid, even when they do not mirror our own: "We have to allow ourselves to disagree as well on things." Justice also discussed the importance of respecting others; even those they do not personally like; they said, "I can respect somebody are many different reasons and possibly not like them and many other reasons and still treat them respectfully and have, you know, that regard for them."

Perry, from Group 1, who was new to the organization, talked about earning respect and the lack of respect they felt from their peers before they had earned it:

They didn't respect my point because I am going to assume I'm the new guy. I haven't proved my weight yet. However, as months went on, not just with doing your course, but with reinforcement of my knowledge base in this industry when I was assigning tasks that were being completed in a timely fashion, or working together on tasks, we were succeeding and getting those accomplished as well because the relationship was maturing.

Landry also spoke of the respect that each has earned through the dialogue and process of the course. Landry said, "I think that there's a new level of respect because of the way that it was an open venting session sometimes, and people felt really safe." 


\section{Secondary Research Questions}

The primary research question was essential to understanding if the intervention had an effect on building trust in a cross-functional workgroup. However, it did not address why it was effective. To that end, the secondary research questions were developed to determine the impact on two important themes of the course. Both concepts—listen to understand and Gestalt language protocol—were addressed in participants' focus group sessions, and findings are discussed in the following sections.

Listening to understand. Because listening to understand is a major theme in the course, it was essential to include the role of listening to understand as a secondary research question. The secondary research question was: What role, if any, does listening to understand play in the development of trust? Both groups were adamant this concept and style of listening made a significant impact on their ability to build trust in their groups.

The first question asked in the focus group session about listening to understand was if anybody in the group could define empathic listening. The initial response from Group 1 came from Perry, who said:

To understand, you know one of those start with heart type of things where you just curb what you have to say and let them do all the talking and try to relate from their angle so you can work together to get a mutual opinion.

Reilly clarified, "When you're showing empathy, you see from their perspective as well."

In Group 2, a consensus was reached related to the same question that asked for a definition of empathic listening. Oakley said:

Empathic listening is being able to understand not understand that just me, the way I see

it, my tremendous of summation of it is dealing with the other person is saying what 
they're telling you. And so not only to feeling what they're saying but also their entire being. So, no body language, no facial expression, everything that he is saying, and being totally focusing on that. ... It's just fully committed to his entire story. Everything that he has going on.

In the next series of questions related specifically to the heart of the research question, both groups were asked what role, if any, empathic listening plays in the development of trust?

The responses from Group 1 all seemed to coincide. Perry stated, "It definitely plays a role in building trust because it shows that you're compassionate and you care about the other person's ideas, opinions, ideology, all that stuff." Reilly went on and said:

You see from their perspective as well, and you reflect that back to a person that builds trust. It gives them confidence that they are actually being heard and, thus, feel more free to continue to contribute as opposed to being directed to your purpose or to your end. Landry related this question to a conversation she had with her team outside of the group, where they took the time to understand their point of view on a critical issue. They said:

They were easier to hold their responsibility for that problem that was happening as well. Rather than them being defensive and shutting down and kind of just turning off on me, they were they assumed their responsibility for the issue their portion of it, which was refreshing.

Perry ended this portion of the focus group conversation with an empathic, "It's active listening skills. I just ... it's so amazing. It works.”

Group 2 expressed similar feelings about the effectiveness of listening in the trustbuilding process. Charlie started: 
I think people connect to that more because they realize, oh, other people have this situate or similar situations and if you know directives always feel colder, I think and meaning that, that having that connection will communicate that your thoughts better or will motivate the person to take in and consider it.

Armoni said, "There are benefits and obviously that there's more collaboration, teamwork feels more empowered. They feel like yeah that they matter.” Lennon went on to explain, "Listening to understand was it was a huge win for me everybody. I think everybody struggles with that." They went on with, "Being able to converse more listening understand stepping back, making things safe and not being so stubborn has helped greatly."

Both groups were also asked about obstacles in this process of listening to understand. Two themes came from this discussion; one was that the process takes more time, while the other was that it takes practice to become second nature. Storm from Group 1 started with, "I could see sometimes the pressure of time," and Sidney followed quickly with, "Time, I was going to say time constraints." Several of the members in Group 1 cited an unwilling partner as the issue. When asked to explain, Frankie cited examples of their CEO where they ended up frustrated, because, during interactions with the boss, the CEO did not seem to listen at all and certainly not to understand their point of view. Landry alluded to time but also considered having the mindset to listen when they stated, "I think like external environment to like, what I mean by that is you know, we can't all be approachable for empathetic listening all the time. We have our own stuff we're dealing with at that moment." Landry went on to describe how this concept could be approached:

It's really hard to like, give that attention, you know, so I think like, for empathetic listening to be successful, it almost needs to be like planned or like a cut-out amount of 
time to where you're coming to that conversation prepared to listen, with, like $100 \%$ of your attention to no distractions distract then maybe that's a better way to put it is like if you're distracted.

Reilly presented another obstacle: "Sometimes it's the emotion and the story that I've already told myself, that will deter me from empathetic listening. Because if I have decided going into it that I've already figured it out. I'm not hearing what you're saying." Landry also spoke about the obstacles to listening:

You know, we can't all be approachable for empathetic listening all the time. Like we have our own stuff we're dealing with at that moment. And if somebody walks into your office and you're dealing with like a bunch of problems, or you're at home, and you're, you know, you've got like your toddler running around, and dinner and the dog need to go out, and it's chaos, and you're exhausted from work, and then, you know, somebody needs to vent about a problem at work. It's really hard to like, give that attention, you know, so I think like, for empathetic listening to be successful, it almost needs to be like planned.

The role listening to understand played in developing trust in a cross-functional workgroup combined all three of the underlining components of trust development. Participants felt this concept provided them all a tool they could use to display humility, empathy, and vulnerability. These components created a sense of approachability and created safety, empowerment, and interest in one another.

Gestalt language protocol. The second secondary research question was posed as: Does the Gestalt language protocol (GLP) play a role in the development of trust in a cross-functional workgroup? In the groups, the concept of sharing from experience took a different dimension: 
Participants felt a sense of safety coming from others as they shared their stories and showed vulnerability in the process.

During the focus group, the first question asked of each group was if they could define GLP. Denver, from Group 1, summed it up nicely: "Sharing from personal experience, not just advice giving." Group 2 had more trouble with a definition. They were encouraged to remember what we had talked about with the term. Lennon's definition was widely accepted by their group; they said, "It was just the open dialogue, and people are able to share their experiences." Neither Lennon nor anybody in Group 2 mentioned avoiding giving advice, as Denver had from the other group. Participants in both groups were much more interested in talking about sharing with each other, which took the discussions away from the concept of GLP.

One of the teachings of the course, in line with GLP, is to take the word "should" out of our vocabulary. The concept here is sharing from experience is in opposition to telling others what to do. Justice embraced this concept at work and in their home life and believed they received benefits in both areas:

I've tried really hard to take should out of my vocabulary since starting in here. And but it's been really helpful the idea of it's been really helpful in giving direction to the staff too. So instead of, you know, telling people what I would do in this situation are giving my input, I've tried really hard to step back and kind of not necessarily share my experience and my thoughts until everybody else has had an opportunity to really do that. Justice stated the benefits included more in-depth conversations with their daughter: "The sharing from experience that with my daughter, I have to I think I shared with you guys I have to before she starts talking to me." The benefits extended to subordinates at work, and when they practiced this concept, they found alignment and acceptance. Justice stated: 
Just allowing them to come up with conclusions and answers without any input at all. Not only am I getting the results I want because they tend to actually have the same opinion I would have given you know, in the same situation and but then they, you know, are much more on board with whatever choices they think they made without my input.

Armoni added, “There's more collaboration, teamwork feel, and more empowered. They feel like that they matter." Oakley added, "Also get more of that trust. They're going to sense that you're able to trust them even more."

Not everybody agreed with the concept of sharing only from experience. Landry believed their allowed them to obtain their position in their company, and with that experience, they can benefit others by telling them what they should be doing. Landry explained, "I'm the one with experience is ... that is exactly why I'm here, and these experiences were successful, and they should be implemented here." Landry reasoned they were placed in a position of authority over a struggling department, and the best way to take corrective action was to tell their employees what they should be doing. Landry's remarks sparked some debate among the group.

Sidney spoke up with a contrary but nonaggressive view. Sidney stated, "I think of it like the old sales adage, 'Facts tell, stories sell.' So, stories will actually help bring that person into position, into an atmosphere where they're more willing to participate in the process." Frankie was much more direct in their response to Landry asking and answering their own question, "Does sharing from experience aid in the development of trust from what you've seen and experienced within yourself? Yes."

Group 2 dove deeper into sharing from experience and linked vulnerability and the positive aspects of what being vulnerable can do to build trust and the willingness to display trusting behaviors. Lennon offered: 
I think other people are sharing, and you're vulnerable and just being open. It makes you almost want, just to be human, just also want to share your, maybe similar experiences to maybe make us people that are vulnerable, a little bit more comfortable, even though they're extremely open, but it can make them feel better.

Charlie spoke up next and said:

I think that when we were sharing our own experiences and our own kind of issues or troubles that we have, and getting help from each other, or watching each other work through those things I think is what was creating the trust.

Several members of this group wanted the discussion to move to their difficulties with vulnerability and that their previous experiences had to be overcome. Skyler said, "As people shared with and felt comfortable sharing more personal things that helped me to be able to trust more and open up myself." Lennon agreed they were not ready to be the first to share but found the benefit of sharing their experiences:

Maybe after a class or two of hearing other people actually open up about their personal lives that they would normally not share it kind of made you, it makes you feel comfortable saying that there's no judgment by anybody in the class. It's okay to share your experiences too, and that just gains a lot of trust.

Charlie added:

First of all, and I think that similar to the way I was talking in the class that um sharing, you know your concerns and troubles and obstacles and frustrations with another group, and being met with support and not ridicule or anything like that I think helps to bond you and make you trust, I mean it's, it's, I don't know, they're just connected. The opening up to people, and then having them want to help you. It builds trust. It's a shared 
experience too. If you are telling somebody, “Oh, well, you need to do this," it implies I don't have these problems. I don't know why you're not doing the thing that everybody knows you should do and you've got a problem and I never had that problem. But if you're saying, "I had a similar situation," you're implying that, "Hey, we all run across things, and we can all work through them together."

The groups' interpretation of the GLP differed from the original intention in the CoT. The original purpose of sharing from experience was to emphasize humility. This humility is shown by not assuming you know what is best for another, but your sharing may inspire them to their own thoughts on issues. What was evident during the focus group sessions was that sharing from experience was a very vulnerable trait, one that endeared the listener to the speaker and created a safe space for each to share their experiences as well. Therefore, the role GLP played in the development of trust in a cross-functional workgroup was one of humility, which is significant in the development of trust.

\section{Qualitative Summary}

Multiple sources of data were gathered and analyzed to arrive at the findings to answer the two secondary research questions. Results of the data revealed listening to understand had a profound effect on individuals' ability to relate to their group members. Practicing the techniques described throughout the course allowed them to share, become vulnerable with each other, and respect diverse points of view on a variety of subjects.

The GLP also played a significant role in the groups' transition from separate entities to a feeling of togetherness. However, the GLP was understood from a unique perspective, not one delivered by the facilitator, but one that still had a powerful influence on members. While GLP is a technique to provide dignity to others, highlighted by sharing from experience as opposed to 
telling others what to do, participants understood this concept from a different perspective. They spoke about others sharing from a place of vulnerability, and the impact vulnerability had on themselves. Listening to others share freely allowed them to feel safe and speak freely and openly on sensitive issues. They were leading to a cycle in the group that built a lasting trust between the members.

In the next section, I explore findings from the participant satisfaction survey. The section analyzing the program used both quantitative and qualitative data. This survey, along with comments participants made during the focus group and individual interviews, helped to determine the effectiveness of the delivery of content of the course from participants' points of view.

\section{Program Analysis}

Answering the research questions was only one of the purposes of this study. It was important to the field of continuing education and in my work with the business community to understand if the current version of the existing communication intervention had any impact on building trust in a cross-functional workgroup. Additionally, I wanted to understand what worked and where improvements could be made so future versions of the program would yield better results. An essential element in the study design was to understand participants' experiences with the intervention.

Results of the quantitative data captured from the postcourse participant satisfaction survey (see Appendix I) are summarized in Table 17. The qualitative data are potentially a more significant source of data to understand what improvements can be made for future interactions of the communication intervention. 
Table 17

Participant Groups' Averaged Scores on Satisfaction Survey

\begin{tabular}{llll}
\hline & Group & \\
Question & 1 & 2 & Combined \\
\hline The course was successful in delivering the stated Program & & & \\
Learning Outcomes & $\mathbf{4 . 3 9 3}$ & $\mathbf{4 . 6 9}$ & $\mathbf{4 . 5 5}$ \\
\hline Identify when a topic becomes a crucial conversation; & 4.143 & 4.50 & 4.33 \\
Understand the value of listening to understand; & 4.857 & 5.00 & 4.93 \\
Develop the skills to share information with others without eliciting & & & \\
confrontation; and & 4.143 & 4.63 & 4.40 \\
Discover how to mitigate conflict, encourage dialogue, and create & & & \\
synergistic resolutions. & 4.429 & 4.63 & 4.53 \\
The course was successful in delivering on the stated Course & & & \\
Objectives & $\mathbf{4 . 0 9 5}$ & $\mathbf{4 . 5 4}$ & $\mathbf{4 . 3 3}$ \\
\hline Articulate the theory behind the Circle of Trust and what parts & & & \\
communication plays in the theory. & 3.714 & 4.38 & 4.07 \\
Develop the communication skills to turn a group into a team. & 4.000 & 4.50 & 4.27 \\
Apply the theories into practice in your work and home life. & 4.571 & 4.75 & 4.67 \\
Course Tools & 4.429 & 4.75 & 4.60 \\
\hline The textbook chosen was appropriate for the learning outcomes & 4.857 & 4.75 & 4.80 \\
The concept matrix was a useful guide to assist my understanding of & & & \\
the content & 4.143 & 4.63 & 4.40 \\
The homework assignments added to my understanding of the content & 4.286 & 4.88 & 4.60 \\
Facilitator & $\mathbf{4 . 7 6 2}$ & $\mathbf{4 . 7 9}$ & $\mathbf{4 . 7 8}$ \\
\hline The facilitator was knowledgeable and well prepared & 4.857 & 4.88 & 4.87 \\
The facilitator treated me with respect & 4.714 & 4.75 & 4.73 \\
The facilitator provided useful guidance & 4.714 & 4.75 & 4.73 \\
Content & $\mathbf{4 . 5 0 0}$ & $\mathbf{4 . 6 3}$ & $\mathbf{4 . 5 7}$ \\
\hline The skills learned aided with relationships inside the workplace & 4.286 & 4.63 & 4.47 \\
The skills learned aided with relationships outside the workplace & 4.714 & 4.63 & 4.67 \\
Professional development & $\mathbf{4 . 6 1 9}$ & $\mathbf{4 . 9 2}$ & $\mathbf{4 . 7 8}$ \\
\hline The skills learned are relevant in my current work position & 4.571 & 4.88 & 4.73 \\
The skills learned will aid in my future performance evaluations & 4.429 & 5.00 & 4.73 \\
The skills learned will become more important as I progress in my & & & \\
career & 4.857 & 4.88 & 4.87 \\
\hline Not The scale un & & & \\
\hline
\end{tabular}

Note: The scale used for questions is as follows: $1=$ strongly disagree, $2=$ disagree, $3=$ neither agree or disagree, $4=$ agree , and $5=$ strongly agree .

Critical data can become lost in averages combined into group scores, especially when scores are either extremely high, as in the results presented in Table 17. A closer look at individual scores that challenge the norm is warranted, especially if the goal of the survey is to develop improvements in the program. In Table 18, the individual scores registered from the combined classes are shown. The purpose is to analyze, combined with the qualitative data 
presented later in this chapter, to suggest processes that should be kept and others that could be improved upon for future implementation.

\section{Table 18}

\section{Individual Score Count From Participant Satisfaction Survey}

\begin{tabular}{|c|c|c|c|c|c|}
\hline \multirow[b]{2}{*}{ Question } & \multicolumn{5}{|c|}{ Scores } \\
\hline & 1 & 2 & 3 & 4 & 5 \\
\hline Identify when a topic becomes a crucial conversation; & 0 & 1 & 0 & 7 & 7 \\
\hline Understand the value of listening to understand; & 0 & 0 & 0 & 1 & 14 \\
\hline $\begin{array}{l}\text { Develop the skills to share information with others without eliciting } \\
\text { confrontation; and }\end{array}$ & 0 & 0 & 0 & 9 & 6 \\
\hline $\begin{array}{l}\text { Discover how to mitigate conflict, encourage dialogue, and create } \\
\text { synergistic resolutions. }\end{array}$ & 0 & 0 & 0 & 6 & 9 \\
\hline $\begin{array}{l}\text { Articulate the theory behind the Circle of Trust and what parts } \\
\text { communication plays in the theory. }\end{array}$ & 0 & 1 & 1 & 9 & 4 \\
\hline Develop the communication skills to turn a group into a team. & 0 & 0 & 1 & 9 & 5 \\
\hline Apply the theories into practice in your work and home life. & 0 & 0 & 0 & 5 & 10 \\
\hline The textbook chosen was appropriate for the learning outcomes & 0 & 0 & 0 & 3 & 12 \\
\hline $\begin{array}{l}\text { The concept matrix was a useful guide to assist my understanding of } \\
\text { the content }\end{array}$ & 0 & 2 & 1 & 1 & 11 \\
\hline The homework assignments added to my understanding of the content & 0 & 0 & 2 & 2 & 11 \\
\hline The facilitator was knowledgeable and well prepared & 0 & 0 & 0 & 2 & 13 \\
\hline The facilitator treated me with respect & 0 & 0 & 0 & 4 & 11 \\
\hline The facilitator provided useful guidance & 0 & 0 & 0 & 5 & 10 \\
\hline The skills learned aided with relationships inside the workplace & 0 & 0 & 1 & 6 & 8 \\
\hline The skills learned aided with relationships outside the workplace & 0 & 0 & 0 & 5 & 10 \\
\hline The skills learned are relevant in my current work position & 0 & 0 & 0 & 4 & 11 \\
\hline The skills learned will aid in my future performance evaluations & 0 & 0 & 1 & 2 & 12 \\
\hline $\begin{array}{l}\text { The skills learned will become more important as I progress in my } \\
\text { career }\end{array}$ & 0 & 0 & 0 & 2 & 13 \\
\hline Percentage by score & $0 \%$ & $1 \%$ & $2 \%$ & $30 \%$ & $66 \%$ \\
\hline
\end{tabular}

Note. The scale used for questions is as follows: $1=$ strongly disagree, $2=$ disagree, $3=$ neither agree or disagree, 4 $=$ agree, and $5=$ strongly agree .

While the overwhelming majority of participants rated the items either a $4(30 \%)$ or the top score of 5 (66\%), attention must be paid to the lower end scores. Those scores must be analyzed at the individual level. For instance, it is important to understand why an individual did not feel good about a particular item, and if that was simply a preference or if there was a deficiency with the protocol that should be addressed.

To understand the depth of improvements that can be attained, I looked at each of the questions in the survey that had at least one score below a 4. The next step was to look at the 
answers provided in the open-ended questions for suggestions on improvements or creating clarity for participants. The items where a score of 3 was given (neither disagree nor agree), no corresponding comments were made on those items in the open-ended question section. With that said, I limited the improvements section only to those items that received at least one 1 or 2 rating. Next are the items and comments participants made relating to those items.

Beginning with the program learning outcomes, the only score rated below the threshold noted previously for success was one item from one individual in Group 1. Sidney disagreed (a rating of 2) with the statement that the course was successful in identifying when a topic becomes a crucial conversation. In the section asking for areas of improvement, Sidney noted the group would have benefitted by having "additional hands-on conversations."

An item addressed in the course objectives that received the lowest overall score of any single item (4.07 combined average) was describing the CoT and how the theory uses communication techniques in the development of trust. This item received the fewest scores rated as 4 (strongly agree). One participant scored a 2 (disagree), and one scored a 3. However, neither respondent mentioned the CoT in their open-ended questions, nor did anybody provide any remarks in the focus group sessions.

In the category of course tools, on the item that stated, "The concept matrix was a useful guide to assist my understanding of the content," two participants scored a 2, and one participant scored a 3. One participant in Group 2 scored this item a 2 (disagree) and stated, "I thought there could have been some varying questions for each of the chapters on the matrix. I think there could have been more thought-provoking questions tailored to the chapters." The participant in Group 1 who also scored this item a 2 did not make any additional comments on the survey or in the interviews. 
Several participants from Group 2 commented based on a lack of understanding of the program. Session 1 of the intervention was devoted to providing an orientation for participants. During this session, we discussed participants' role in the study. This discussion included their ability to drop out of the course at any time for any reason without reprisal. This statement was also presented in the informed consent documentation each participant acknowledged with their signature. The rest of the time was used to review the course syllabus and the process and left the balance of the time allotted for questions and answers. Despite that, several participants were unclear on the value proposition. The open-ended questions of the survey yielded several comments on the lack of clarity of the purpose of the intervention.

\section{Clarity on the Value Proposition}

Finley wrote in his participant satisfaction survey, "I did not fully understand the program for a few weeks." Lennon also was unclear at the beginning of the program what the course was supposed to cover and wrote in the participant satisfaction survey, "I would just suggest more clarity on what the course is and how we will be learning. Up to Week 3, it was a little unclear."

Others made similar comments during the focus group interview. From Group 2, Charlie stated, "I guess I probably was thinking it might be more like techniques for managing people as opposed to what it ended up being." Participants from both groups stated their need for management training. Charlie suggested, "dealing with subordinates with poor performance." Finley suggested using the concepts from the reading and applying them specifically to their daily activities at work, which could be useful in their annual review process. While in Group 1, Reilly was even more specific, stating, "Discuss and focus on this company's issues/possible solutions." On the question of how the course could be improved, several other comments 
described in the open-ended questions on the survey were categorized as potential program improvements.

\section{Techniques for Improving the Course}

Three participants made comments relating to the creation of dyads to work through conflict. One specifically thought a peer rating system derived from these pairings might prove helpful. Armoni stated, "Pairing up and being asked to gauge our partner's success is a crucial conversation would have been beneficial." At the same time, Frankie wrote, "Roleplay or walking through some of the skills or creating problems to be solved." In the individual interview, Sidney also suggested roleplaying to be beneficial but as a fallback technique if a real scenario did not play out at work that week.

Along the same lines, although not explicitly mentioning breaking the group into dyads, participants also suggested creating scenarios and acting them out as an aid in learning. Reilly felt we could have used live scenarios to address conflict in their firm. Lennon also commented on the use of live examples from their workplace and stated, "We could have asked for work examples of situations that may have occurred."

\section{Analyzing Positive Scores and Comments}

If analysis on what could be improved is essential, then a similar analysis should be performed of the components for the course that received scores at the higher end of the scale. These become important as the communication intervention is replicated, especially if it is to be reproduced with others administering the coursework. Those items beneficial or appreciated by participants must be taught and impressed upon future facilitators and teachers. Analysis of the qualitative data may shed some insight on where improvements can be made and what features 
of the current intervention should be replicated and taught to future facilitators of the revised program.

Most comments made in the open-ended questions in the survey surrounded two areas. These comments encompassed the techniques and tools used in the process and the concepts embedded in the theory of the CoT.

\section{Concepts Addressed in the Course}

While the groups' understanding of the theory behind the CoT was the lowest rated item in the survey, with an average score of 4.07, participants commented extensively on the theory's components. Specifically, listening to understand stood out, either in direct comments or indirectly, where empathy was implied in the comments.

Seven of the 15 respondents commented explicitly on the group discussions, their impact on their overall learning, and the value of the program. Lennon stated, "The most useful part to me was the table talk about the chapter. .. Hearing everyone's different views really opens your eyes to things you may not have seen before." Justice went a bit deeper on the value of sharing and turned it inward, stating, "I found that being vulnerable at work and being more open, although difficult, proved to be effective."

Vulnerability and empathy both play a part in the CoT as underlining constructs in sharing from experience and listening to understand. Both concepts were addressed repeatedly in the open-ended questions and in the focus group sessions. In addition to the comments noted previously by Reilly, others stressed the safe space that was paramount in allowing participants to share and be vulnerable with one another. Oakley stated, "Learning how to create a safe environment to allow open dialogue to flow freely," was the most useful takeaway from the 
course. Reilly commented on the tools that were learned and applied to create open, effective communication between peers.

Participants also noted empathy and empathic listening; when asked to state what was most useful in the class on the survey, Lennon stated, "Hearing everyone's different views really opens your eyes to things you may not have seen before." Frankie noted, "Learning how to look at other's thought processes from various situations" was the biggest takeaway.

\section{Summary of Program Analysis}

The quantitative data obtained at the conclusion of the course does provide useful information on participants' views of the content and delivery of the content. Using a 5-point Likert scale, each of the major categories was rated higher than an aggregate score of 4.33 with the highest aggregate score of 4.78 assigned to both the facilitator's delivery and the usefulness to participants' professional development. The lowest score on an individual question related to articulating the theory behind the CoT. This item was scored as a 4.07; while still a strong overall score, the CoT played an important role in the development of the course.

Themes obtained from the qualitative data suggested, while participants appreciated the course, there may be areas where improvements could be made. One area that could have been improved was the enlistment of participants. Several participants did not fully understand the purpose of the training, and, in some instances, they did not comprehend that this was a communication course. Instead, they felt they were recruited for a management training course. Another area some, but not all, felt would have been useful would have been to add some roleplaying exercises during our sessions. 


\section{Summary of Findings}

Quantitative data provided the answer to the primary research question. In two levels analyzed, individually and within both groups, trust was developed throughout the 13 weeks the participant groups were involved in the course. In addition, both participant groups' levels of postintervention trust were significantly higher than the comparison group that did not participate in the intervention. In this section, I summarize the findings, leaving the analysis of findings for Chapter 5.

Qualitative data obtained supported the findings of both secondary research questions, which related to two themes that were the focus of the intervention. Listening to understand was the area participants felt made the most impact. This technique taught them to appreciate the differing points of view others may possess and helped create empathy within them. Participants credited sharing from experience as a process that led them to respect others in their groups and to become vulnerable themselves, which led directly to the levels of trust participants felt within their groups.

Participants also displayed appreciation for the process in which the course was conducted. In their participant satisfaction survey, five categories were rated. Delivering on the course objectives compiled score was 4.33. The course tools were rated at 4.60. The facilitator was rated at 4.78 , and the content related to building relationships was rated at 4.57. Participants also felt the course was useful in their professional development, with an aggregate score of 4.78 . Additional comments participants made, both within the survey and during the focus group sessions, suggested participants felt there was a lot of value provided to them as individuals and for them as a group. 
In the next section, I discuss the implications of these findings and provide additional insight into the analysis. In addition, I discuss some potential implications for the private sector and for educational studies. Then, I discuss some limitations of this study and areas for further study before making final recommendations and conclusions. 


\section{CHAPTER FIVE - CONCLUSIONS}

In this study, I explored the effectiveness of a communication course in building trust in a cross-functional workgroup. A mixed-methods design was constructed to provide answers to the primary research question and two subquestions related to my theory of trust building, the Circle of Trust (CoT). In addition to obtaining results to the research questions, I wanted to understand participants' points of view and identify areas where the course was useful and areas where the course could be improved.

Based on quantitative data from the BTI survey, the intervention was an effective tool to develop higher levels of trust in the three constructs measured: (a) reliance-based trust, (b) disclosure-based trust, and (c) total trust. The quantitative data provided information that showed the course used in this intervention was effective in building trust, both at the individual and group levels. Qualitative data provided insight and support of the concepts promoted in the CoT. Two of the components embedded in the theory, empathic listening and Gestalt language protocol (GLP), were the subjects of the secondary research questions. A third component of the method labeled deliver on the promise, while not explicit in the communication training, also became a major influence with one participant during the research process. While dependability, which is implied within the concept of delivering on the promise, was not subject to a secondary research question, it became apparent that delivering on the promise remains a crucial element in the theory behind the CoT. Lastly, a combination of quantitative and qualitative data supported the process and methodology in providing the content of the communication course.

\section{Discussion of Findings}

In this section, I briefly describe the findings of my research and their significance to the study. These findings do support the conclusion that the intervention did play an essential role in 
building trust within the participant groups. This section is presented first with quantitative data supporting the primary research question, followed by qualitative data that addressed the secondary research questions, as well as a mixture of quantitative and qualitative data supporting the process of the intervention.

\section{Primary Research Question}

The primary research question asked in this study was to understand what effect, if any, this intervention based on improving communication in a cross-functional workgroup would have on the development of trust in that group. The research question is vital in that communication plays a role in the development of trust, although previous literature has focused on the frequency and quality of communication (Perry et al., 2009). I examined this research question by measuring the constructs of reliance-based trust, disclosure-based trust, and total trust (Gillespie, 2003). Each of these measures was examined both from an individual and a group level. The group-level measures included both a within-group analysis and compared the levels of trust between the participant groups and comparison group.

Individual participant analysis. The data provided evidence that trust was developed within the individuals who participated in the 13 -week intervention. Twelve of the 15 members of the two participant groups show RCI scores above the 1.96 thresholds denoting statistical significance (Busse et al., 2014). Of the remaining three whose total trust scores did not show a significant increase in their scores, two showed a decrease, with only one of them at a significant level.

The data do support the conclusion that during the 13 weeks in which the intervention was held, trust was developed using the process of the course. The outlier provided a story and potential implications for improvements that could be made within the course, which will be 
discussed in the section on pedagogy later in this chapter. The within-group analysis discussed next will provide additional support for the primary research question.

Within-group analysis. To fully understand the effect on trust with the participant groups, I decided, as discussed in Chapter 4, to eliminate an outlier from the group scores. When the outlier was eliminated from the group scores, Group 1's trust scores rose dramatically in all three areas of trust measured. Group 1's reliance-based trust effect size (measured with Cohen's d) rose from .409 , which is a moderate effect, to a large effect of 1.365 , when their score was eliminated from the group. Disclosure-based trust rose in Group 1 from a moderate .713 Cohen's $d$ score to a large 1.106 , and total trust scores were .604 . Group 1's scores rose to 1.409 using the same Cohen's $d$ statistic. Group 2's Cohen's $d$ scores all displayed a moderate to large effect as well, with reliance-based trust showing .726 , disclosure-based trust showing .857 , and total trust a large 1.21 positive Cohen's $d$ score, contrasting Group 3 whose trust level regressed slightly in all three measures.

The implications of the quantitative data are that the intervention did play a role in the level of trust within each of the participant groups as suggested by their higher scores on the posttest compared to the pretest. Group 3 did not have the advantage of the intervention, and without any additional information on what might have happened within their group during the 13 weeks, the contrast between the comparison group's diminished scores and the participant groups' increased levels of trust leads to the conclusion the intervention played a substantial role in the levels of trust in Groups 1 and 2. Additional analysis and support are provided with a comparison between the participant groups and comparison group.

Between-group analysis. In this section, I compared the scores on all three measurements of trust between Groups 1 and 3, then again between Groups 2 and 3. Again, the 
data show differences between posttest scores in these comparisons show moderate to large effects in all three trust scales. These differences in effect sizes were measured between the groups using Cohen's $d$.

The quantitative findings of this research support the conclusion that the communication course used during this study did provide a strong positive effect in building trust in a crossfunctional workgroup in a small business organization. Prior research on communication has concentrated on the frequency and the quality of communication that leads to building trust (Thomas et al., 2009). Previous research described quality communication as communicating frequently and reliably about relevant information (McAllister, 1995; Schaubroeck et al., 2011; Thomas et al., 2009). The practice used in this current intervention studied here went beyond these constructs of frequency and quality of communication, and I found there are benefits of teaching communication techniques that include listening to understand and sharing from experience. The value of these communication techniques thus became the subject for the secondary research questions discussed next.

\section{Secondary Research Questions}

The building blocks of the CoT and the differentiators between standard trust development were addressed explicitly by the secondary research questions of this study. The secondary research questions addressed two of the primary learning objectives in the communication course - empathic listening and its relationship to building trust as well as GLP and the role it plays in trust development — in a cross-functional workgroup. I address each secondary question individually in the following sections.

The role of empathic listening. Listening with the intention to understand others in the group provided members in the group the opportunity not only to understand but also to 
appreciate others' viewpoints. This appreciation is not to be confused with agreement on those points. Participants confirmed the role of empathic listening as a tool that enabled members of the group to show respect for each other. The process of empathic listening was the area where participants reflected on their own personal growth in their communication and relationship skills.

The first research question surrounding listening skills as a communication aid has been discussed in the previous literature, however not in great length as a method to improve communication skills (Covey, 2004). Empathy has been shown to be a major influence on affective trust (Webber, 2008). The role of empathy has been described as an essential practice in trust development (Vera \& Rodrigues-Lopez, 2004). Furthermore, empathy is also implicit within transformational leadership, explicitly relating to individual consideration (Bass, 1985). The act of listening to understand is linked with showing empathy toward others (Covey, 2004), which created a safe space in the group and helped build respect for others because of the feeling everyone's opinion was valued. As Reilly stated, "It builds trust."

The role of the Gestalt language protocol. The other secondary research question was much more challenging to validate. The research question asked if GLP plays a role in the development of trust in a cross-functional workgroup. All participants did not agree this protocol was valuable.

The debate on the process of GLP and its importance did manifest, however, as Landry explained their expertise in their area is what makes them valuable to a cross-functional group and felt the process led to diminished importance of their thoughts and ideas. Other members of the group challenged Landry's understanding of the importance of this concept, but clearly the concept was not embraced by all. This may be a limitation in how the concept was taught, or it 
could mean GLP has less importance in building trust within a cross-functional workgroup. The business organization, EO, embraces GLP as a process of sharing from experience rather than telling others what to do. This style of communicating allows for others to determine on their own the best course of action for themselves. The organization believes practicing GLP shows respect to others and creates a sense of safety and harmony within their groups (Stathakis, 2013).

Many participants gave credit to the GLP process as they related the concept of sharing their experiences rather than sharing from experience. These participants gave credit for the vulnerability others within the group displayed as their inspiration to become vulnerable within the group. They believed these displays of vulnerability from their peers are what led to trusting others in the group with their own stories and displaying their own vulnerability.

An additional benefit participants discussed was that they had begun using the practice of sharing from experience within their families and with others outside of the group. While we did not collect any specific data to determine the outcomes of practicing GLP outside the group, those who did practice GLP in their family reported improvements in communication at home, which I discuss in the section on research that could be conducted in the future.

\section{Pedagogy of the Intervention}

The course was evaluated using quantitative and qualitative data obtained from the participant satisfaction survey tool (see Appendix I). Additional data were collected during the focus group sessions and individual interviews. This process was developed to view the coursework and its components from participants' points of view. The primary purpose of the participant evaluation was to determine what alterations, if any, should be made to the course.

The only data that were analyzed came from a postintervention participant satisfaction survey. That survey was limited to Kirkpatrick's Level 1 and 2 inquiry, which are the 
participants' reactions to the course and their perceptions of what they learned (Kirkpatrick \& Kirkpatrick, 2015). Without further inquiry in the form of a longitudinal study, could we learn if the course changed behaviors of participants and what the results were from those changes? However, participants did feel the skills they learned were useful in their lives and stated they believed the design of the instruction, which required dialogue between participants, was instrumental in their learning process.

The course was developed using aspects of transformational leadership theory (Bass, 1985; Burns, 1978). The practices used in the course mirrored transformational leadership components. These components included idealized influence in the form of a trained facilitator, who sought to inspire participants by enlisting their engagement and a collaborative dialogue process. Intellectual stimulation was provided through a detailed analysis of the content and the sharing individuals engaged in during each class. Individualized consideration was a constant theme in the course, highlighted by the teaching and practice of listening to understand and the GLP that are the heart of the methodology built within this course.

\section{Implications for the Field}

Trust plays an essential role in the development of relationships (Webber, 2008). What was studied here was the relationship between communication and the development of trust specific to cross-functional workgroups in small, for-profit business organizations. However, some implications go beyond small businesses and extend to the private sector in general. The implications of this study exceed those just to the private sector and may extend beyond the private sector to include education, government, and even nonprofit organizations. In addition, techniques used in the intervention studied here may be useful in a variety of settings and might help with topics that reach beyond the development of trust. 


\section{Implications for the Private Sector}

Cross-functional workgroups continue to be used in business for a variety of reasons (O'Neil \& Salas, 2018). The success of these groups is intensified when groups transition into a team (Yuan et al., 2016). This transition happens when members of the group can establish a clear vision and a unifying mission (Katzenbach \& Smith, 1992). When groups do not succeed in the transition to becoming a team, the lack of trust between members has been shown to be a primary factor in their failure. Therefore, the success of a cross-functional workgroup relies on building trust in the group (Webber, 2008; Yuan et al., 2016).

Trust is crucial for team development and needs to be built from a diverse group of people with differing perspectives and loyalties (Sangeetha \& Kumaran, 2018). Building trust is a slow and iterative process that requires repetition of reciprocal acts (Weber et al., 2004).

This coursework in this study was influenced by transformational leadership principles, idealized influence, intellectual stimulation, individualized consideration, and inspirational

motivation (Burns, 1978). This study challenged the iterative process of building trust slowly. If a group can be brought together and work through a course like the one studied here, we can reasonably conclude this process will develop more trust within a cross-functional workgroup. If a course designed to build trust does produce trust and has shown to be effective, it is not only the content that should be examined but the process as well.

The method employed in this intervention, mirroring that of a graduate school course, is not the norm in a business setting. Typically, when a midlevel manager does seek additional knowledge, the company may send them to an off-site seminar, taught in half-day, all-day, and 2-day formats. According to McKinsey \& Company, a high-profile business and management consulting company, U.S. companies spend \$14 billion sending employees to leadership 
development courses (Gurdjain, Halbeisen, \& Lane, 2014). Results of this type of adult learning are limited. When employees are asked about their experience, they exclaim something along the lines of, "I learned so much," while not remembering many specific outcomes. According to an article in Entrepreneur, adults tend to retain approximately $10 \%$ of what they learn at seminars (Blacharski, 2016).

The results of this study suggest a course designed to mirror a graduate student classroom experience, and brought into a workplace environment, may be effective. The elements that reflected the classroom experience include: (a) facilitation by a trained educator, (b) small groups, and (c) regularly scheduled classes delivered over time. Also, participants were provided lessons, asked to conduct independent research specific to those lessons, and asked to share their discoveries about that research with peers during their weekly sessions, methods that cannot be used in the workshop format. This process was used during this study with the intention to build trust in a cross-functional workgroup and provided positive results.

The implications for the private sector, therefore, are that making efforts to build trust when creating cross-functional workgroups should be a primary consideration. How to build that trust is also important. Switching from the workshop model to one delivered over time, and one that has experiential elements that can be practiced throughout the course, may allow groups to learn, retain, and use that training with better results than with the workshop model.

\section{Implications for Educational Studies}

The postintervention results obtained from the participant evaluation survey and interviews led to the conclusion that process, content, and instruction methods used during the intervention did provide participants tools to improve communication, which led to the development of trust. Participants also believed the trust they built with their group would lead to 
better outcomes in the workplace. What this suggests is the topic of trust development, and the methodology described in the course, could be replicated elsewhere and may be included in the area of educational studies.

Educational classrooms provide a diverse group of people, each with their own points of view and unique life experiences. Similar to the private sector, there are also power dynamics inherent in the classroom. It would seem likely that trust may play an essential role in the classroom. Developing trust between teacher and student and between students would seem to be a good process. Teaching students to be vulnerable, and to share from experience and listen to others with empathy, may lead to more productive discussions within that classroom.

There is also reason to believe adjusting the role of the teacher to that of a facilitator may be a technique used in the education process to minimize the power dynamics of that classroom. Questions remain, however, as to whether changing the power dynamics by themselves would further dialogue between students. At what grade level would be optimal and whether those discussions aid in the learning process is not clear, but these are areas that may be worth testing.

\section{Limitations of the Study}

The data obtained helped me to conclude the intervention did have a positive effect on trust in members of each group. However, there are several limitations inherent in this study. This study was limited to two separate small business organizations that participated in the intervention and only one comparison group. All three organizations were drawn from different industry sectors, so I am unable to suggest these companies are representative of their own industry. The three organizations, while categorized by the U.S. Small Business Administration (2019) as small companies, were very different in their employee count, revenue, and management structure. All of these factors limit the generalizability of the results. 
The selection of participants can also be considered a limitation. I provided each organization with the recruitment letter (see Appendix A) but left it up to each organization to register participants. In this process, I had no additional input. Although participation in the program was intended to be completely voluntary, I cannot verify that participants did not feel some coercion to volunteer from their management. I did collect some demographic information in the pretest process; however, none of that data were considered or analyzed in the results.

Another limitation of the study was that I have potential biases inherent in the design, with existing relationships with ownership and senior management with all three firms. I also constructed the course, and the potential for confirmation biases also exists. This brings in further limitations of the study, which deal with the course materials, instruction methods, and processes. With a single study, there is no way to determine if results would be consistent with what I found if other researchers replicated this study

There were no procedures built into the design to account for negative outcomes between the pre- and post-test. Also, the course did not have any processes in place to account for factors that may happen outside of the course. In the case of Group 1, there was a severe breach of trust that affected one individual; this affected the results and remained unresolved. Another limitation of the study was the design and treatment of Group 3. I did not anticipate a negative outcome between the pre- and post-test and therefore did not account for any follow-up with this group to understand why their levels of trust receded.

\section{Areas for Further Research}

The limitations of the study provide ample examples of areas for further research in the impact of communication improvements on trust. One notable area for further research is expanding this study to more business organizations, which could lead to the ability to generalize 
the findings contained herein. These organizations do not need to be limited to small businesses. Studying midsize and large business organizations could provide valuable context. Also, future studies could focus on intradepartmental trust development using these same techniques. Additionally, this study did not attempt to distinguish any demographic differences between participants. Areas that could be studied would be the effects on trust levels using a similar intervention on different individuals based on age, gender, education levels, position within the organization, or ethnic and cultural differences.

Additional studies could focus on the effects of trust on building a cohesive team. Implications of this study suggest trust plays an essential role in team building. However, without taking the next step in the team-building process - having the group unify on a mission-I am unable to report on the role trust plays in developing that mission. Comparing groups that go through a trust-building intervention to groups that do not go through the training would provide context to the need for such a training course.

Also, this course was dependent on the book Crucial Conversations. It may be interesting to understand if another text may be as useful to teach communication techniques. I would also discover what effect the facilitator has on the results. Are those results dependent on the charisma, educational background, or work experience of the facilitator, as opposed to the course structure and content?

Further study on the benefits of the pedagogical differences between the workshop format and the multisession course model would be valuable, such as understanding if the same course delivered via workshop or over time leads to better results, such as retention, participant experience, and ultimately deeper levels of trust between participants. There are many dependent 
variables within this framework and many different subjects that could be explored, further comparing the pedagogy used in this study.

Participants' reflections on their engagement outside the office with these same techniques also offered hope that this work is not limited to business organizations. Many participants reported using these same techniques in their daily lives with anecdotal evidence of improvements in some of their relationships outside the workplace. These stories lead me to the conclusion that studies on enhanced communication should not be limited to the workplace and may be useful in other areas of participants' lives.

There are many areas of personal relationships. These include, but are not limited to, the relationship between parents and their children, siblings, and couples, all of whom could be the subject of future studies using the communication course. Several participants talked about how they would like their spouses or children to go through a similar course. Many participants completed their weekly exercises using circumstances they found at home with their family and friends rather than just work-related experiences. They shared stories freely about their own family and their weekly experiences. Studying the effect of communication on trust, and its impact on relationships, could prove valuable within intimate relationships, both with nuclear and extended families.

Findings in this study may potentially offer insight into establishing trust, not just in cross-functional workgroups but in other diverse sets of groups. These groups are not limited to just workgroups. Different types of groups are established in several areas that could benefit from building trust as an essential factor in the development of a team (Jones \& George, 1998; Katzenbach \& Smith, 1992; Yuan et al., 2016). Using the same or similar intervention methods 
could benefit other types of groups, even intimate groups. Similar studies could be conducted using sports teams or artistic groups like orchestras or acting troupes.

Other sectors could benefit from trust-building measures. The study could be extended to nonprofit organizations, government agencies, and even the educational system. Understanding the value of trust in the development of cross-functional organizations would be useful to study. In the area of education, understanding the techniques used during the intervention would be beneficial in the areas of disability studies, as would determining the grade level at which it would be beneficial to teach participants the specific techniques to provide the most value. Additional studies to determine the value of developing trust between teachers and students, teachers, and their administration or even administration and school boards could be studied.

Another area that could be studied is the relationships between empathy, vulnerability, and humility to the development of trust. We suggest a strong relationship between these crucial elements does exist, but these areas were not the focus of this study. Further research would be needed to correlate each of these elements empirically to trust and trust development. Studies such as these would further validate the theory behind the CoT.

\section{Significance of the Study}

The significance of this study is multifaceted. The primary goal was to determine if an intervention designed to improve communication would also build trust in a cross-functional workgroup. These cross-functional workgroups continue to be important in the private sector and have not always seen positive results (O'Neil \& Salas, 2018). It is when these groups can transition into a functional team that the benefits are realized (Yuan et al., 2016). The importance of building trust is to allow for a diverse group, to begin to breakdown some of the barriers and allow for the group to transition into a team. Trust is a critical element in the construction of a 
team (Katzenbach \& Smith, 1992). The significance of this study was to demonstrate the

effectiveness of two concepts — listening to understand and sharing from experience — that could be taught within a cross-functional workgroup to build trust within that group.

Additionally, this study was also significant in that it can add to the literature on a different approach to training within the workforce, which potentially improves the effectiveness of that training. This study incorporated a pedagogy that is unusual for a business organization to use, with encouraging results. This process, which was inspired by transformational leadership concepts, can be replicated and tested in other areas of training within the private sector.

\section{Conclusions}

The communication course used in this study is one I developed based on a variety of experiences. Those include the practical business experiences I have gained in 39 years in the private sector, with 36 of those in management positions and 30 of those as the owner of three successful businesses. However, without the experience in the classroom, both as a student and as an educator, the course would never have been constructed. Using theory and practice developed through my experience in higher education allowed me to translate techniques used in the classroom to the conference room.

Cross-functional workgroups are essential in modern business (O'Neil \& Salas, 2018). The formation of these groups can benefit business organizations in many ways, including the speed of development of new ideas and their implementation. Developing the concept of a team is crucial for the cross-functional workgroup to operate effectively (Katzenbach \& Smith, 1992). The differing functions performed by individuals create a diversity of priorities each brings to a group. These differing priorities often lead to siloed thinking, making it challenging to build a real team (Yuan et al., 2016). One can rally around a singular unified mission, which is the 
primary differentiator between a team and a group (Katzenbach \& Smith, 1992). To create a unique vision around the mission requires members of the group trust each other. The need to develop trust with diverse groups is why I developed my theory and methodology to build trust both faster deeper than previously thought possible.

Consistent with my views on pragmatism, and transformational leadership, the CoT is a theory developed around the process of trust development. This process drives individuals through building trust with others rather than concentrating on developing the components and characteristics of trust specifically. These components arrive naturally when practicing the concepts embedded in the CoT.

The intervention that was designed initially to develop better communication in crossfunctional groups has shown to build trust in the groups studied. Unfortunately, the intervention is a vehicle and not a panacea. The process of communicating with others in a specific manner that is prescribed is useful but cannot overcome the distrust created when individuals fail to deliver on the promise.

While participants' overall scores and comments were positive as to the course and its construction and delivery, the program did not provide any contingencies on repairing trust that had been broken, nor did the protocol implicitly create an avenue to explore if any participants felt trust was threatened. I believe this is an area in which the facilitator can be trained to look for clues, whether they are expressed through participants' language, tone, or body language. The course had not been designed with this reality in mind, and therefore the event that happened in Group 1 went unnoticed and therefore remained an unresolved issue that affected the outcomes.

The quantitative and qualitative data provided support to continue to pursue a communication-driven process to develop trust in diverse cross-functional workgroups. While 
the study was not broad enough to generalize for all small business organizations or even all cross-functional workgroups, the qualitative data obtained in the interviews support the quantitative data in my conclusion that the intervention was a success. Trust was developed with individuals and in the group, as opposed to the comparison group where the level of trust deteriorated somewhat during the 13 weeks the study was conducted. Adding in the field notes only furthers this triangulation of data, all of which support the concept and implementation of the course to develop trust in the participant groups and their members.

The communication intervention delivered a multifaceted approach, requiring participants to engage with the take-home exercises, share their experiences, and listen to the experiences of others to learn and grow from each other. Both groups recognized the value of the course, the teaching, and the facilitation of discussions by a professional. The postcourse survey confirmed participants not only learned throughout their experience but also enjoyed the course.

Several participants used these same lessons at home, in their own functional teams, and noted these processes and techniques could translate into other areas of their lives. This course and the process will continue to be delivered to cross-functional workgroups but will also be expanded and studied in other group settings in the future. While the course was not originally intended as a tool to build trust explicitly, results shown with these first groups in encouraging.

I am also pleased with the acceptance of the learning process in a business organization. The methodology of this course, to be delivered over 13 weeks, is not typical in the private sector. This process is one that can be deployed with many different programs and learning objectives. The system can be easily replicated and delivered to businesses of all sizes.

The course used for this study and the pedagogical methodology did allow most members of the participant groups to develop trust within the group and with each other. Building trust is a 
necessary component in turning a group into a team. While there is further study needed to generalize these findings, my recommendation for any business organization attempting to bring different disciplines together to form a cross-functional workgroup is to teach the communication techniques to the members in the group to encourage exploration of the members' work and life circumstances, with the goal of building trust within that group. Trust is an essential component of any positive relationship. This study provides data suggesting improving communication techniques could help develop trust between individuals and groups, and it could benefit any organization wanting to create a system to develop trust within their ranks. 


\section{REFERENCES}

Ahmed, A. M., \& Salas, O. (2009). The relationship between behavioral and attitudinal trust: A cross-cultural study. Review of Social Economy, 47, 457-482.

doi:10.1080/00346760902908625

Akrout, H., \& Diallo, M. F. (2017). Fundamental transformations of trust and its drivers: A multi-stage approach to business to business relationships. Industrial Marketing Management, 66, 159-171. doi:10.1016/j.indmarman.2017.08.003

Arrow, K. J. (1972). Gifts and exchanges. Philosophy \& Public Affairs, 1, 343-362.

Aver, B., \& Halldorsson, F. (2010). Trusting and trustworthiness: What are they, how to measure them, and what affects them. Journal of Economic Psychology, 31, 64-79. doi:10.1016/j.joep.2009.10.001

Avolio, B. J., \& Gardner, W. L. (2005). Authentic leadership development: Getting to the root of positive forms of leadership. The Leadership Quarterly, 16, 315-338. doi:10.1016/j.leaqua.2005.03.001

Ayoko, O. B., Callan, V. J., \& Hartel C. E. J. (2008). The influence of team emotional intelligence climate on conflict and team members' reactions to conflict. Small Group Research, 39, 121-149. doi:10.1177/1046496407304921

Bass, B. M. (1985). Leadership and performance beyond expectations. New York, NY: Free Press.

Bass, B. M. (1990). From transactional to transformational leadership: Learning to share the vision. Organizational Dynamics, 18(3), 19-31. doi:10.1016/0090-2616(90)90061-S 
Bass, B. M., \& Steidlmeier, P. (1999). Ethics, character, and the authentic transformational leadership behavior. The Leadership Quarterly, 10, 181-217. doi:10.1016/S10489843(99)00016-8

Baumeister, R. F., Stillwell, A. M., \& Heatherton, T. F. (1994). Guilt: An interpersonal approach. Psychological Bulletin, 115, 243-267. doi:10.1037/0033-2909.115.2.243

Benard, C. (1938). The functions of the executive. Cambridge, MA: Harvard University Press.

Berg, J., Dickhaut, J., \& McCabe, K. (1995). Trust, reciprocity, and social history. Games and Economic Behavior, 10, 122-142. doi:10.1006/game.1995.1027

Birkman, J. (2013). Measuring vulnerability to natural hazards: Towards disaster resilient societies (2nd ed.). New York, NY: United Nations University Press.

Blacharski, D. (2016). Why high-profile speakers' seminars and workshops don't deliver. Entrepreneur. Retrieved from http://www.entrepreneur.com/article/281383

Bohay, M., Blakely, D., Tamplin, A., \& Radvansky, G. (2011). Note taking, review, memory, and comprehension. American Journal of Psychology, 124, 63-73. doi:10.5406/amerjpsyc.124.1.0063

Boros, S., van Gorp, L., Cardoen, B., \& Boute, R. (2017). Breaking silos: A field experiment on relational conflict management in cross-functional teams. Group Decision and Negotiation, 26, 327-356. doi:10.1007/s10726-016-9487-5

Bouchard, T. J. (1976). Unobtrusive measures: An inventory of uses. Sociological Method and Research, 4, 267-300. doi:10.11771004912417600400301

Busse, R. T., McGill, R. J., \& Kennedy, K. S. (2014). Methods for assessing single-case schoolbased intervention outcomes. Contemporary School Psychology, 19, 136-144. doi:10.1007/s40688-014-0025-7

Burns, J. M. (1978). Leadership. New York, NY: Harper and Row. 
Burns, J. M. (2003). Transforming leadership: A new pursuit of happiness. New York, NY: Grove Press.

Brown, B. (2010). The gifts of imperfection. Center City, MN: Hazelden.

Campbell, D. T., \& Fiske, D. W. (1959). Convergent and discriminant validation by the multitrait-multimethod matrix. Psychological Bulletin, 56, 81-105. doi:10.1037/h0046016

Canary, D. J., Spitzberg, B. H., \& Semic, B. A. (1998). The experience and expression of anger in interpersonal settings. In P. A. Andersen \& L. K. Guerrero (Eds.), Handbook of communications and emotion: Research, theory, applications, and contexts (pp. 189213). San Diego, CA: Academic Press.

Chambers, R. (2006). Vulnerability, coping and policy. Bulletin-Institute of Development Studies, 37(4), 33-40. Retrieved from https://opendocs.ids.ac.uk/opendocs/handle/123456789/662

Chang, L. J., Doll, B. B., Wout, M. v., Frank, M. J., \& Sanfey, A. G. (2010). Seeing is believing: Trustworthiness as a dynamic belief. Cognitive Psychology, 61, 87-105. doi:10.1016/j.cogpsych.2010.03.001

Charmaz, K. (2014). Constructing grounded theory (2nd ed.). Thousand Oaks, CA: Sage.

Choi, B. K., Moon, H. K., \& Nae, E. Y. (2014). Cognition and affect based trust and feedbackseeking behavior: The roles of value, cost, and goal orientations. Journal of Psychology, 148, 603-620. doi:10.1080/00223980.2013.818928

Choi, J. (2006). A motivational theory of charismatic leadership: Envisioning, empathy, and empowerment. Journal of Leadership and Organizational Studies, 13, 24-43. doi:10.1177/10717919070130010501 
Chua, R. Y. J., Ingram, P., \& Morris, M. W. (2008). From the head and the heart: Locating cognition and affect based trust in managers' professional networks. Academy of Management Journal, 51, 436-452. doi:10.5465/amj.2008.32625956

Cohen, J. (1977). Statistical power analysis for the behavioral sciences. New York, NY: Academic Press.

Conger, J. A., \& Kanungo, R. N. (1987). Toward a behavioral theory of charismatic leadership in organizational settings. Academy of Management Review, 12, 637-647. doi:10.5465/amr.1987.4306715

Couch, L. L., \& Jones, W. H. (1997). Measuring levels of trust. Journal of Research in Personality, 31, 319-336. doi:10.1006/jpre.1997.2186

Covey, S. R. (2004). The 7 habits of highly effective people: Powerful lessons in personal change. New York, NY: Simon \& Schuster.

Cranor, C. (1975). Toward a theory of respect for persons. American Philosophical Quarterly, 12, 309-319. Retrieved from: https://www.jstor.org/stable/20009589

Creswell, J. W. (2012). Educational research: Planning, conducting, and evaluating quantitative and qualitative research (4th ed.). Boston, MA: Pearson Education.

Cronbach, L. J., \& Meehl, P. E. (1955). Construct validity in psychological tests. Psychological Bulletin, 52, 281-302. doi:10.1037/h0040957

Cross, R., Rebele, R., \& Grant, A. (2016). Collaborative overload. Harvard Business Review, 94, 74-79. Retrieved from https://hbr.org/2016/01/collaborative-overload

Currall, S. C., \& Inkpen, A. C. (2002). A multilevel approach to trust in joint ventures. Journal of International Business Studies, 33, 479-495. doi:10.1057/palgrave.jibs.8491027 
Currall, S. C., \& Judge, T. A. (1995). Measuring trust between organizational boundary role persons. Organizational Behavioral and Human Decision Processes, 64, 151-170. doi:10.1006/obhd.1995.1097

Darwall, S. L. (1977). Two kinds of respect. Ethics, 88, 36-49. doi:10.1086/292084

Davies, M. F. (1994). Personality and social characteristics. In A. P. Hare, H. H. Blumberg, M. F. Davies, \& M. V. Kent (Eds.), Small group research: A handbook (pp. 41-78). Norwood, NJ: Ablex.

Davis, D. E., Worthington, E. L., Jr., \& Hook, J. N. (2010). Humility: Review of measurement strategies and conceptualization as personality judgment. Journal of Positive Psychology, 5, 243-252. doi:10.1080/17439761003791672

De Long, S. (2014). From jail to jobs: Building bridges between communities to aid in the reduction of recidivism (Unpublished master's capstone). Chapman University, Orange, CA.

Dowell, D., Morrison, M., \& Heffernan, T. (2015). The changing importance of affective trust and cognitive trust across the relationship lifecycle: A study of business-to-business relationships. Industrial Marketing Management, 44, 119-130. doi:10.1016/j.indmarman.2014.10.016

Downton, J. V. (1973). Rebel leadership: Commitment and charisma in the revolutionary process. New York, NY: Free Press.

Dzurec, L. C., \& Abraham, J. L. (1993). The nature of inquiry: Linking quantitative and qualitative research. Advances in Nursing Science, 16, 73-79. doi:10.1097/00012272199309000-00009 
Eckel, C. C., \& Wilson, R. K. (2004). Is trust a risky decision? Journal of Economic Behavior \& Organization, 55, 447-465. doi:10.1016/j.jebo.2003.11.003

Ehrhardt, K., Miller, J., Freeman, S., \& Hom, P. (2014). Examining project commitment incrossfunctional teams: Antecedents and relationship with team performance. Journal of Business \& Psychology, 29, 443-461. doi:10.1007/s10869-013-9325-6

Evans, J. (2009). Inspirational presence: The art of transformational leadership. Garden City, NY: Morgan James.

Evans, A. M., \& Revelle, W. (2008). Survey and behavioral measurements of interpersonal trust. Journal of Research in Personality, 42, 1585-1593. doi:10.1016/j.jrp.2008.07.011

Fehr, E. (2009). On the economics and biology of trust. Journal of the European Economic Association, 7, 235-266. doi:10.1162/JEEA.2009.7.2-3.236

Garner, H. C. (2009). Empathy: A true leader skill. Military Review, 89(6), 84-92. Retrieved from http://www.dtic.mil/dtic/aulimp/citations/gsa/2009_152754/164565.html

George, B. (2007). True north: Discover your authentic leadership. San Francisco, CA: JosseyBass.

Gill, R. (2011). Theory and practice of leadership. Thousand Oaks, CA: Sage.

Gill, H., Boies, K., Finegan, J. E., \& McNally, J. (2005). Antecedents of trust: Establishing a boundary condition for the relation between propensity to trust and intention to trust. Journal of Business and Psychology, 19, 287-302. doi:10.1007/s10869-004-2229-8

Gillespie, N. (2003). Measuring trust in work relationships: The Behavioural Trust Inventory. Paper presented at the Academy of Management Conference, Seattle, WA. 
Gillespie, N. (2012). Measuring trust in organizational context: An overview of survey-based measures. In F. Lyon, G. Mollering, \& N. K. Saunders (Eds.), Handbook of research methods on trust (pp. 175-187). Newhampton, MA: Edward Elgar Publishing.

Gillespie, N. (2015). Survey measures of trust in organizational contexts: An overview. In F. Lyon, G. Mollering, \& N. K. Saunders (Eds.), Handbook of trust methodology (2nd ed., pp 225-239). Cheltenham, England: Edward Elgar Publishing.

Glanville, J. L., \& Paxton, P. (2007). How do we learn to trust? A confirmatory tetrad of the sources of generalized trust. Social Psychology Quarterly, 70, 230-242. doi:10.1177/019027250707000303

Glaser, E. L. Laibson, D., Scheinkman, J., \& Souter, C. L. (2000). Measuring trust. Quarterly Journal of Economics, 115, 811-846. doi:10.1162/003355300554926

Godfrey, P. C. (2005). The relationship between corporate philanthropy and shareholder wealth: A risk management perspective. Academy of Management Review, 30, 777-798. doi:10.5465/AMR.2005.18378878

Goleman, D. (2000). Leadership that gets results. Harvard Business Review, 78, 78-90. Retrieved from https://hbr.org/2000/03/leadership-that-gets-results

Guerrero, L. K., \& Andersen, P. A. (1998). The dark side of jealousy and envy: Desire, delusion, desperation \& destructive communication. In H. H. Spitzberg \& W. R. Cupach (Eds.), The dark side of close relationships (pp. 33-70). Mahwah, NJ: Lawrence Erlbaum Associates.

Gurdjain, P., Halbeisen, T., \& Lane, K. (2014). Why leadership-development programs fail. McKinsey Quarterly, 1, 121-126. Retrieved from http://www.mckinsey.com/featuredinsights/leadership/why-leadership-development-programs-fail 
Hackman J. R. (2002). Why teams don’t work. In R. S. Tindale, L. Heath, J. Edwards, E. J. Posavac, F. B. Bryant, Y. Suarez-Balcazar, ... J. Myers (Eds.), Theory and research on small groups. Social psychological applications to social issues (pp. 245-267). Boston, MA: Springer.

Handfield, R. B., \& Bechtel, C. (2002). The role of trust and relationship structure in improving supply chain. Industrial Marketing Management, 31, 367-382. doi:10.1016/S00198501(01)00169-9

Hardin, R. (2002). Trust and trustworthiness. New York, NY: Russell Sage Foundation.

Haselhuhn, M., Scheitzer, M., Kray, L., \& Kennedy, J. (2017). Perceptions of high integrity can persist after deception: How implicit beliefs moderate trust erosion. Journal of Business Ethics, 145, 215-225. doi:10.1007/s 10551-017-3649-5

Heap, S. (1998). NGOs and the private sector. Potential for partnerships? (INTRAC Occasional Papers Series No. 27). Oxford, United Kingdom: INTRAC.

Heyns, M., \& Rothmann, S. (2015). Dimensionality of trust: An analysis of the relations between propensity, trustworthiness and trust. SA Journal of Industrial Psychology, 41(1). doi:10.4102/sajip.v41i1.1263

Hill, C. A., \& O'Hara, E. A. (2006). A cognitive theory of trust. Washington University Law Review, 84, 1717-1796. Retrieved from https://openscholarship.wustl.edu/law_lawreview/vol84/iss7/4

Huang, Y., \& Wilkinson, I. F. (2013). The dynamics and evolution of trust in business relationships. Industrial Marketing Management, 42, 455-465. doi:10.1016/j.indmarman.2013.02.016 
Ilies, R., Morgenson, F. P., \& Nahrgang, J. D. (2005). Authentic leadership and eudaemonic well-being: Understanding leader-follower outcomes. The Leadership Quarterly, 16, 373394. doi:10.1016/j.leaqua.2005.03.002

Jackson, K. T. (2005). Towards authenticity: A Sartrean perspective on business ethics. Journal of Business Ethics, 58, 307-325. doi:10.1007/s10551-005-1178-0

Jacobs, G., \& Keegan, A. (2018). Ethical considerations and change recipient's reactions: “It's not about me.” Journal of Business Ethics, 152, 73-90. doi:10.1007/s10551-016-3311-7

Jacobson, N. S., \& Truax, P. (1991). Clinical significance: A statistical approach to defining meaningful change in psychotherapy research. Journal of Consulting and Clinical Psychology, 59, 12-19. doi:10.1037/0022006x.59.1.12

Johnson, D., \& Grayson, K. (2005). Cognitive and affective trust in service relationships. Journal of Business Research, 58, 500-507. doi:10.1016/S0148-2963(03)00140-1

Johnson, R. B., \& Onwuegbuzie, A. J. (2004). Mixed methods research: A research paradigm whose time has come. Educational Researcher, 33(7), 14-26. doi:10.3102/0013189x033007014

Jones, G. R., \& George, J. M. (1998). The experience of evolution of trust: Implications for cooperation and teamwork. Academy of Management Review, 23, 531-546. doi:10.5465/amr.1998.926625

Kanter, R. M. (2009). What would Peter say? Harvard Business Review, 87(11), 64-70. Retrieved from https://hbr.org/2009/11/what-would-peter-say

Katzenbach, J. R., \& Smith, D. K. (1992). Why teams matter. McKinsey Quarterly, 3, 3-27. Retrieved from http://go.gale.com 
Keltner, D., Van Kleef, G. A., Chen, S., \& Kraus, M. W. (2008). A reciprocal influence model of social power: Emerging principles and lines of inquire. Advances in Experimental Social Psychology, 40, 151-192. doi:10.1016/S0065-2601(07)00003-2

Kellogg, K. C. (2019). How to orchestrate change from the bottom up. Harvard Business Review Digital Articles, 2-5. Retrieved from https://hbr.org/2019/02/how-to-orchestrate-changefrom-the-bottom-up

Kernis, M. H. (2003). Toward a conceptualization of optimal self-esteem. Psychological Inquiry, 14, 1-26. doi:10.2075/S15327965PLI1401_01

Kirk, R. E. (1996). Practical significance: A concept whose time has come. Educational and Psychological Measurement, 56, 746-759. doi:10.1177/0013164496056005002

Kirkpatrick, J. D., \& Kirkpatrick, W. K. (2016). Kirkpatrick's four levels of training evaluation. Alexandria, VA: ATD Press

Koh, A. W. L., Lee, S. C., \& Lim, S. W. H. (2018). The learning benefits of teaching: A retrieval practice hypothesis. Applied Cognitive Psychology, 32, 401-410. doi:10.1002/acp.3410

Kramer, R. M. (1999). Trust and distrust in organizations: Emerging perspectives, enduring questions. Annual Review of Psychology, 50, 569-598.

doi:10.1146/annurev.psych.50.1.569

Krueger, R. A., \& Casey, M. A. (2015). Focus groups: A practical guide for applied research. Thousand Oaks, CA: Sage.

Legg, C., \& Hookway, C. (2019). Pragmatism. The Stanford Encyclopedia of Philosophy. Retrieved from https://plato.stanford.edu/archives/spr2019/entries/pragmatism/ 
Lewicki, R. J. (2006). Trust, trust development, and trust repair. In M. Deutsch, P. T. Coleman, \& E. C. Marcus (Eds.), The handbook of conflict resolution: Theory and practice (pp. 92119). San Francisco, CA: Jossey-Bass.

Lewicki, R. J., McAllister, D. J., \& Bies, R. J. (1998). Trust and distrust: New relationships and realities. Academy of Management Review, 23, 438-458. doi:10.5465/amr.1998.926620

Love, J. H., \& Roper, S. (2009). Organizing innovation: Complementarities between crossfunctional teams. Technovation, 29, 192-203. doi:10.1016/j.technovation.2008.07.008

Luft, S. (2004). Husserl's theory of phenomenological reduction: Between life-world and Cartesianism. Research in Phenomenology, 34, 198-234. doi:10.1163/1569164042404518

Mayer, R. C., Davis, J. H., \& Schoorman, F. D. (1995). An integrative model of organizational trust. Academy of Management Review, 20, 709-734. doi:10.5465/amr.1995.9508080335

McAllister, D. J. (1995). Affect- and cognition-based trust as foundations for interpersonal cooperation in organizations. Academy of Management Journal, 38, 24-59. doi: $10.5465 / 256727$

McEvily, B., \& Tortolenni, M. (2011). Measuring trust in organizational research: Review and recommendations. Journal of Trust Research, 1, 23-63. doi:10.1080/21515581.2011.552424

McMahon, K., Ruggeri, A., Kammer, J., \& Katsikopoulos, V. K. (2016). Beyond idea generation: The power of groups in developing ideas. Creativity Research Journal, 28, 247-257. doi:10.1080/104004119.2016.1195637

Merriam, S. B., \& Associates (2002). Qualitative research in practice. San Francisco, CA: Jossey-Bass. 
Mertens, D. M., \& Hesse-Biber, S. (2012). Triangulation and mixed methods research:

Provocative positions. Journal of Mixed Methods Research, 6, 75-79. doi:10.1177.1558689812437100

Meuser, J. D., Gardner, W. L., Dinh, J. E., Hu, J., Liden, R. C., \& Lord, R. G. (2016). A network analysis of leadership theory: The infancy of integration. Journal of Management, 42, 1374-1403. doi:10.11770/0149206316647099.

Myers, S. A., \& Anderson, C. M. (2008). The fundamentals of small group communications. Thousand Oaks, CA: Sage

Meyerson, D., Weick, K. E., \& Kramer, R. M. (1996). Swift trust in temporary groups. In R. M. Kramer \& T. R. Tyler (Eds.), Trust in organizations: Frontiers of theory and research (pp. 166-195). Thousand Oaks, CA: Sage.

Miller, S. A. (2014). John Dewey is a tool: Lessons from Rorty and Brandom on the history of pragmatism. Transactions of the Charles. S. Pierce Society, 50, 246-264. doi:10.2979/tranchcharperirsoc.50.2.246

Molm, L. D., Takahashi, N., \& Peterson, G. (2000). Risk and trust in social exchange: An experimental test of classical proposition. American Journal of Sociology, 105, 13961427. doi:10.1086/210434

Mueller, P. A., \& Oppenheimer, D. M. (2014). The pen is mightier that the keyboard: Advantages of longhand over laptop note taking. Psychological Science, 25, 1159-1168. doi:10.1177/0956797614524581

Muijs, D. (2011). Doing quantitative research in education with SPSS. Thousand Oaks, CA: Sage. 
Nielsen, R., Marrone, J. A., \& Slay, H. S. (2010). A new look at humility: Exploring the humility concept and its role in socialized charismatic leadership. Journal of Leadership \& Organizational Studies, 17, 33-43. doi:10.1177/1548051809350892

Nienaber, A. M., Hofeditz, M., \& Romeike, P. D. (2015). Vulnerability and trust in leaderfollower relationships. Personnel Review, 44, 567-591. doi:10.1108/PR-09-2013-0162

Novicevic, M. M., Harvey, M. G., Buckley, M. R., Brown, J. A., \& Evans, R. (2006). Authentic leadership: A historical perspective. Journal of Leadership and Organizational Studies, 13, 64-76. doi:10.1177/10717919070130010901

O’Neil, T. A., \& Salas, E. (2018). Creating high performance teamwork in organizations, Human Resource Management Review, 28, 325-331. doi:10.1016/j.hrmr.2017.09.001

Osterman, P. (1994). How common is workplace transformation and who adopts it? ILR Review, 47, 173-188. doi:10.1177/001979399404700202

Parker, A., \& Tritter, J. (2006). Focus group methodology: Current practice and recent debate. International Journal of Research \& Methodology in Education, 29, 23-37. doi:10.1080/01406720500537304

Patterson, K., Grenny, J., McMillan, R., \& Switzler, A. (2012). Crucial conversations: Tools for talking when stakes are high. New York, NY: McGraw Hill.

Patton, M. Q. (1997). Using focused evaluation: The next century text. Thousand Oaks, CA: Sage.

Pfeffer, J. (2008). What ever happened to pragmatism? Journal of Management Inquiry, 17, 5760. doi: $10.1177 / 1056492607312770$ 
Rahman, U. U., Rehman, C. A., Imran, M. K., \& Aslam, U. (2017). Does team orientation matter? Linking work engagement and relational psychological contract with performance. Journal of Management Development, 36, 1102-1113. doi:10.1108/jmd-102016-2204

Rotter, J. B. (1980). Interpersonal trust, trustworthiness, and gullibility. American Psychologist, 35(1), 1-7. doi:10.1037/0005-066X.35.1.1

Rousseau, D. M., Sitkin, S. B., Burt, R. S., \& Camerer, C. (1998). Not so different after all: A cross-discipline view of trust. Academy of Management Review, 23, 393-404. doi:10.5465/amr.1998.926617

Rowatt, W. C., Ottenbreit, A., Nesselroade, K. P., Jr., \& Cunningham, P. A. (2002). On being holier-than-thou or humbler-than-thee: A social-psychological perspective on religiousness and humility. Journal for the Scientific Study of Religion, 41, 227-237. doi:10.1111/1468-5906.00113

Ryan, R. M., \& Deci, E. L. (2001). On happiness and human potential: A review of the hedonic and eudainomic well-being. Annual Review of Psychology, 52, 141-166. doi:10.1146/annurev.psych.52.1.141

Salas, E., Sims, D. E., \& Burke, S. (2005). Is there a "big five" in teamwork? Small Group Research, 36, 555-599. doi:10.1177/1046496405277134

Salkind, N. J. (Ed.) (2010). Triangulation. Encyclopedia of research design. Thousand Oaks, CA: Sage.

Salovey, P., \& Mayer, J. D. (1990). Emotional intelligence. Imagination, Cognition and Personality, 9, 185-211. doi:10.2190/DUGG-P24E-52WK-6CDG 
Sangeetha, P., \& Kumaran, S. (2018). Impact of shared leadership on cross functional team effectiveness and performance with respect to manufacturing companies. Journal of Management Research, 18, 44-55. Retrieved from http://www.indianjournals.com

Sechrest, L., \& Sidani, S. (1995). Quantitative and qualitative methods: Is there an alternative? Evaluation and Program Planning, 18, 77-87. doi:10.1016/0149-7189(94)00051-X

Schaubroeck, J. M., Lam, S. S. K., \& Peng, A. C. (2011). Cognition-based and affect-based trust as mediators or leader behavior influence on team performance. Journal of Applied Psychology, 96, 863-871. doi:10.1037/a0022625

Schein, E. (2013). Humble inquiry: The gentle art of asking instead of telling. Oakland, CA: Berrett-Koehler.

Schoorman, F. D., Mayer, R. C., \& Davis, J. H. (2007). An integrative model of organizational trust: Past, present, and future. Academy of Management Review, 32, 344-354. doi:10.5465/amr.2007.24348410

Simpson, T. W. (2013). Trustworthiness and moral character. Ethical Theory and Moral Practice, 16, 543-557. doi:10.1007/s10677-012-9373-4

Stack, L. C. (1978). Trust in dimensions of personality. In H. London \& J. E. Exner (Eds.), Dimensionality of personality (pp. 561-599). New York, NY: Wiley \& Sons.

Stathakas, C. (2013). What is gestalt and why you need to know it. Retrieved from https://www.stathakis.com/blog/leadership/bid/320702/what-is-gestalt-and-why-youneed-to-know-it

Sullivan, G. M., \& Feinn, R. (2012). Using effect size - Or why the $p$ value is not enough. Journal of Graduate Medical Education, 4, 279-282. doi:10.4300/JGME-D-12-00156.1 
Tashakkori, A., \& Creswell, J. W. (2007). Editorial: The new era of mixed methods. Journal of Mixed Methods Research, 1(1), 3-7. doi:10.1177/2345678906293042

Tatham, P., \& Kovacs, G. (2010). The application of "swift trust" to humanitarian logistics. International Journal of Production Economics, 12(6), 35-45. doi:10.1016/j.ijpe.2009.10.006

Thielmann, I., \& Hilbig, B. E. (2014). Trust in me, trust in you: A social projection account of the link between personality, cooperativeness, and trustworthiness expectations. Journal of Research in Personality, 50, 61-65. doi:10.1016/j.jrp.2014.03.006

Thomas, G. F., Zolin, R., \& Hartman, J. L. (2009). The central role of communication in developing trust and its effect on employee involvement. Journal of Business Communication, 46, 287-310. doi:10.1177/0021943609333522

U.S. Code of Federal Regulations, Department of Health and Human Services (2009). Title 45, Part 46: Protection of human subjects. Retrieved from https://www.hhs.gov/ohrp/regulations-and-policy/guidance/faq/45-cfr-46/index.html

U.S. Department of Health and Human Services, Office for Human Research Protections. (2018). The Belmont report: Ethical principles and guidelines for the protection of human subjects of research. Retrieved from https://www.hhs.gov/ohrp/regulations-andpolicy/belmont-report/read-the-belmont-report/index.html

U.S. Small Business Administration. (2019). SBA's size standards methodology. Retrieved from https://www.sba.gov/document/support--size-standards-methodology-white-paper

Urdan, T. C. (2010). Statistics in plain English. New York, NY: Routledge.

Uslaner, E. M. (1999). Democracy and social capital. In M. E. Warren (Ed.), Democracy and trust (pp. 121-150). Cambridge University Press. 
Vangen, S., \& Huxham, C. (2003). Nurturing collaborative relations: Building trust in interorganizational collaboration. Journal of Behavioral Science, 39, 5-31. doi:10.1177/0021886303039001001

Vera, D., \& Rodriguez-Lopez, A. (2004). Humility as a source of competitive advantage. Organizational Dynamics, 33, 393-204. doi:10.1016/j.orgdyn.2004.09.006

Watson, W. D. (2011). Trust but verify: Regan, Gorbachev, and the INF treaty. The Hilltop Review, 5(1), 21-39. Retrieved from https://scholarworks.wmich.edu/hilltopreview/vol5/iss1/5

Webber, S. S. (2008). Development of cognitive and affective trust in teams. Small Group Research, 39, 746-769. doi:10.1177/1046496408323569

Weber, J. M., Malhotra, D., \& Murnigham, J. K. (2004). Normal acts of irrational trust: Motivated attributions and the trust development process. Research in Organizational Behavior, 26, 75-101. doi:10.1016/S0191-3085(04)26003-8

Western, S. (2013). Leadership: A critical text. Los Angeles, CA: Sage.

Wilmot, W. W., \& Hocker, J. L. (2001). Interpersonal conflict (6th ed.). Boston, MA: McGrawHill.

Wolf, S. (2002). Getting to "groupaha": Provoking creative processes in group tasks. In L. R. Frey (Ed.), New directions in group communication (pp. 203-217). Thousand Oaks, CA: Sage.

Young, C. B., \& Henquinet, J. A. (2000). A conceptual framework for designing group projects. Journal of Education for Business, 76, 56-60. doi:10.1080/08832320009599051 
Young-Hyman, T. (2017). Cooperating without co-laboring: How formal organizational power moderates cross-functional interaction in project teams. Administrative Science Quarterly, 62, 179-214. doi:10.1177/0001839216655090

Yuan, X., Olfman, L., \& Yi, J. (2016). How do institution-based trust in interpersonal trust affect interdepartmental knowledge sharing? Information Resources Management Journal, 29, 15-38. doi:10.4018/IRMJ.2016010102

Zahara, D., \& Hedge, C. (2010). The reliable change index: Why isn't it more popular in academic psychology? Psychology Postgraduate Affairs Group Quarterly, 76, 14-20. doi:10.1.1.667.6093

Zak, P. (2017). Trust factor: The science of creating high-performance companies. New York, NY: Amacom. 


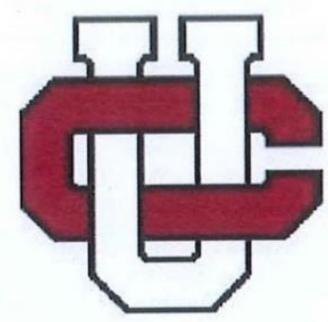

\section{APPENDICES}

\section{Appendix A: Call for Volunteers}

\section{VCHAPMAN $\left.\right|_{\text {IRB-19.228 }}$ \\ $\begin{array}{lll}\text { AUNIVERSITY } & \text { IRp-19-228 } \\ \text { Aproved on } 7-9-2019\end{array}$ \\ INSTITUTIONAL REVIEW BOARD \\ VOLUNTEERS NEEDED FOR RESEARCH STUDY}

\section{Developing Trust in a Cross-FunctionalWorkgroup}

- Attalah College of Educational Studies is conducting research to find out if an intervention based on improving communication techniques will have an effect on the amount of trust developed in a cross functional workgroup.

- Criteria for acceptance is as follows:

○ Must be between the ages of 18 and 65 years old.

- Employed by the subject organization

- of Supervisor, Manager or Director

- At least 4 functional operating groups

- No more than two individuals from the same department

○ You will be asked to participate in 1390 -minute classroom sessions, as well as a 2

○ hour focus group interview approximately 2 weeks after the course work is completed. Some participants may be asked to participate in a 1-hour follow-up individual interview with the researcher.

Participation will take place in the company conference room during normal work hours. There minimal risks involved in this research. These risks potentially include exposure of your thoughts and ideas in a group setting. In addition, the researcher does have a personal or business relationship with executive management within the company

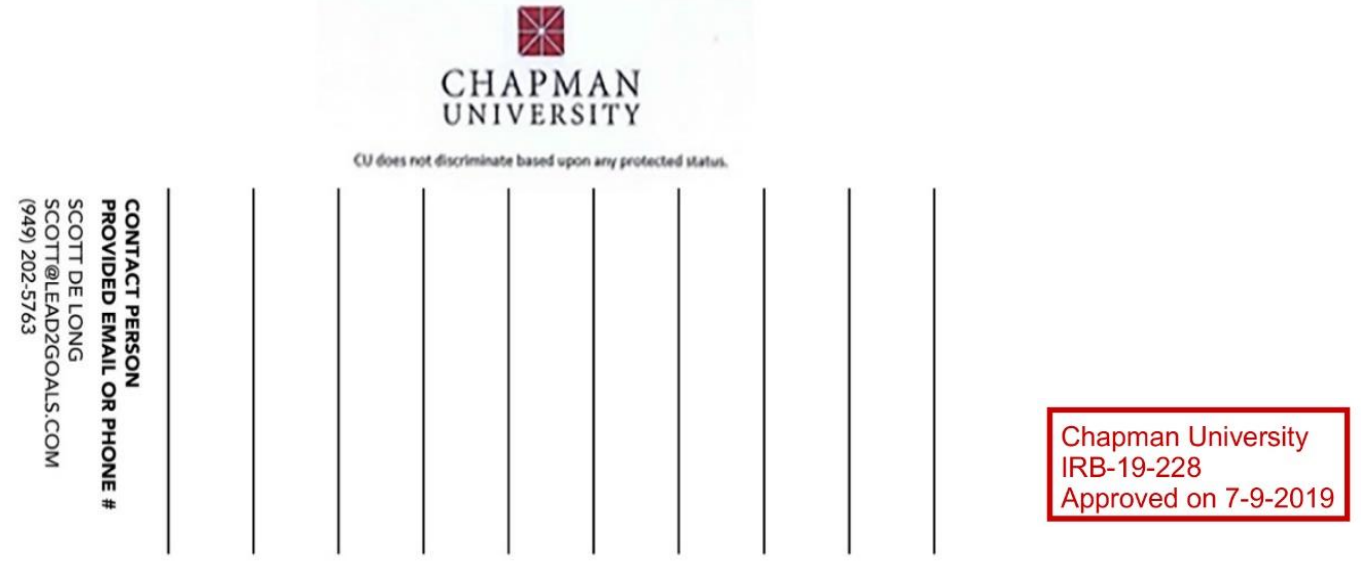




\section{Appendix B: Informed Consent Form}

\section{ADULT INFORMED CONSENT TO PARTICIPATE IN RESEARCH}

\section{Title of Study}

Developing Trust in a Cross-Functional Workgroup

\section{Members of the Research Team}

Student Researcher: R. Scott De Long

Lead Researcher: Whitney McIntyre Miller, $\mathrm{PhD}$

Office: (949) 292-2664

Office: (714) 744-2134

\section{Key Information}

You are being asked to take part in a research study. Research studies include only people who choose to take part. A member of the research team will explain the study to you and will answer any questions you might have. You should take your time in deciding whether or not you want to participate.

If you agree to participate in this study, the project will involve:

- Midlevel managers with times of supervisor, manager or director

- Procedures will include 13 week 90 minute course delivered during normal working hours at your place of business, plus a focus group interview lasting approximately 120 minutes and potentially individual interview lasting approximately 60 minutes

- There are 14 number of visits

- These visits will take 22 hours total

- There are not any risks associated with this study that exceed what would typically be encountered in daily life

- You will not be paid for your participation, however your firm will provide you the time away from your normal tasks to complete the study

- You will be provided a copy of this consent form

\section{Invitation}

You are invited to take part in this research study. The information in this form is meant to help you decide whether or not to participate. If you have any questions, please ask.

\section{Why are you being asked to be in this research study?}

You are being asked to be in this study because you are either, a supervisor, manager or director who may potentially work in cross-functional work groups in your normal course of business. You must be 18 years of age or older to participate.

\section{What is the reason for doing this research study?}

Cross-functional work groups aid a company in many organizational processes and change management. Creating a functional team from a group of people with differing motivations based on their departmental needs requires the group aligns on a unifying mission and that they develop trust. This communication program is designed to assist the group in developing trust through better communication. This research is designed to (1) determine if the intervention does assist participants in developing trust within the group (2) understand the effectiveness of the components taught during the intervention. 


\section{What will be done during this research study?}

You will be asked to attend and participate in group activities once a week for 13 consecutive weeks, these activities will last approximately 90 minutes. You will be provided reading and writing assignments each week that will be expected to be completed after class, this work should take the average participant 45-60 minutes per week. There will be a short pretest administered on the first day of course work, and a corresponding posttest on the final day. In addition, you will be asked to participate in a 2 hour focus group approximately two weeks after the last class, this will be conducted during your normal business hours. You may be asked for a follow up interview, which will last no more than 60 minutes within a week after the focus group is concluded.

\section{How will my data be used?}

Your data will be collected by the researcher, and held in confidence. While personally identifiable information will be collected, it will be stored safely in the researcher's code book. You will be assigned a number to identify you but the final report will use pseudonyms in place of real names. Nobody but the researcher will have access to the data, and your identifiable information.

What are the possible risks of being in this research study?

As with any study involving collection of data, there is the possibility of breach of confidentiality of data. Other risks in this research include possible emotional and/or psychological distress because the surveys involve sensitive questions about your relationships with co-workers. It is possible that other rare side effects could occur that are not described in this consent form. It is also possible that you could have a side effect that has not occurred before.

\section{What are the possible benefits to you?}

The intervention is designed to improve communication skills. These skills can provide tremendous benefits in the workplace, but can also be advantageous at home and in nonwork relationships. You will learn conflict resolution skills as well as other communication skills. However, you may not get any benefit from being in this research study.

\section{What are the possible benefits to other people?}

The benefits to science and/or society may include better understanding of how to better communicate, and build trust.

\section{What are the alternatives to being in this research study?}

Instead of being in this research study you can choose not to participate. This is a voluntary program and there will not be any reporting to management if you choose not to participate.

\section{What will participating in this research study cost you?}

There is no cost to you to be in this research study.

\section{Will you be compensated for being in this research study?}

You will not be compensated for your participation in this research study.

\section{What should you do if you have a problem during this research study?}

Your welfare is the major concern of every member of the research team. If you have a problem as a direct result of being in this study, you should immediately contact one of the people listed at the beginning of this consent form.

\section{How will information about you be protected?}

Reasonable steps will be taken to protect your privacy and the confidentiality of your study data. 
The data will be stored in a locked cabinet in the investigator's office and will only be seen by the research team during the study and for 3 years after the study is complete.

The data will be stored electronically through a secure server and will only be seen by the research team during the study and for 3 years after the study is complete.

The only people who will have access to your research records are the members of the research team, the Institutional Review Board (IRB), and any other person, agency, or sponsor as required by law.

Information from this study may be published in scientific journals or presented at scientific meetings but the data will be reported as group or summarized data and your identity will be kept strictly confidential.

\section{What are your rights as a research subject?}

You may ask any questions about this research and have those questions answered before agreeing to participate in the study or during the study.

For study related questions, please contact the investigator(s) listed at the beginning of this form.

For questions concerning your rights or complaints about the research, contact the Institutional Review Board (IRB) at (714) 628-2833 or irb@ chapman.edu.

\section{What will happen if you decide not to be in this research study or decide to stop participating once you start?}

You can decide not to be in this research study, or you can stop being in this research study (i.e., "withdraw") at any time before, during, or after the research begins for any reason. Deciding not to be in this research study or deciding to withdraw will not affect your relationship with the investigator or with Chapman University or your employer. You will not lose any benefits to which you are entitled.

\section{Documentation of informed consent}

You are voluntarily deciding whether to be in this research study. Signing this form means that (1) you have read and understood this consent form, (2) you have had the consent form explained to you, (3) you have had your questions answered, and (4) you have decided to be in the research study. You will be given a copy of this consent form to keep.

Printed Name of Participant

Signature of Participant

Date 


AUDIO RECORDING:
I have received an adequate description of the purpose and procedures for audio recording sessions
during the course of the proposed research. I give my consent to allow myself to be audio recorded
during participation in this study, and for those records to be reviewed by persons involved in the
study, as well as for other professional purposes as described to me.
Yes, I agree to allow the research team to audio record my interview(s).
Signature of Participant or Legal Guardian not wish to have my interview(s) audio recorded.

\section{Investigator certification:}

My signature certifies that all elements of informed consent described on this consent form have been explained fully to the subject. In my judgment, the participant possesses the capacity to give informed consent to participate in this research and is voluntarily and knowingly giving informed consent to participate.

Signature of Person Obtaining Consent

Date 


\section{Appendix C: Lesson Plans}

\section{Week 1 Lesson Plan}

Introductions

Name, department, and position

Syllabus-Purpose of the course-Purpose of the study

Ground Rules

What is said here, stays here, Show-up, do pre-work, be present

Informed Consent

Questions?

BTI pretest

Elements of a TEAM

Unifying purpose, Trust

What is your superpower, the one thing either personal or professional that you excel at, and makes you who you are?

Circle of Trust

Handout the textbook and the Concept Matrix

\section{Assignment for Week 2}

Read Chapter 1 in Crucial Conversations

Fill out the Concept Matrix

\section{Quote of the week:}

When entire companies embrace a growth mindset, their employees report feeling far more empowered and committed; they also receive far greater organizational support for collaboration and innovation. Mindset: Carol S. Dweck 


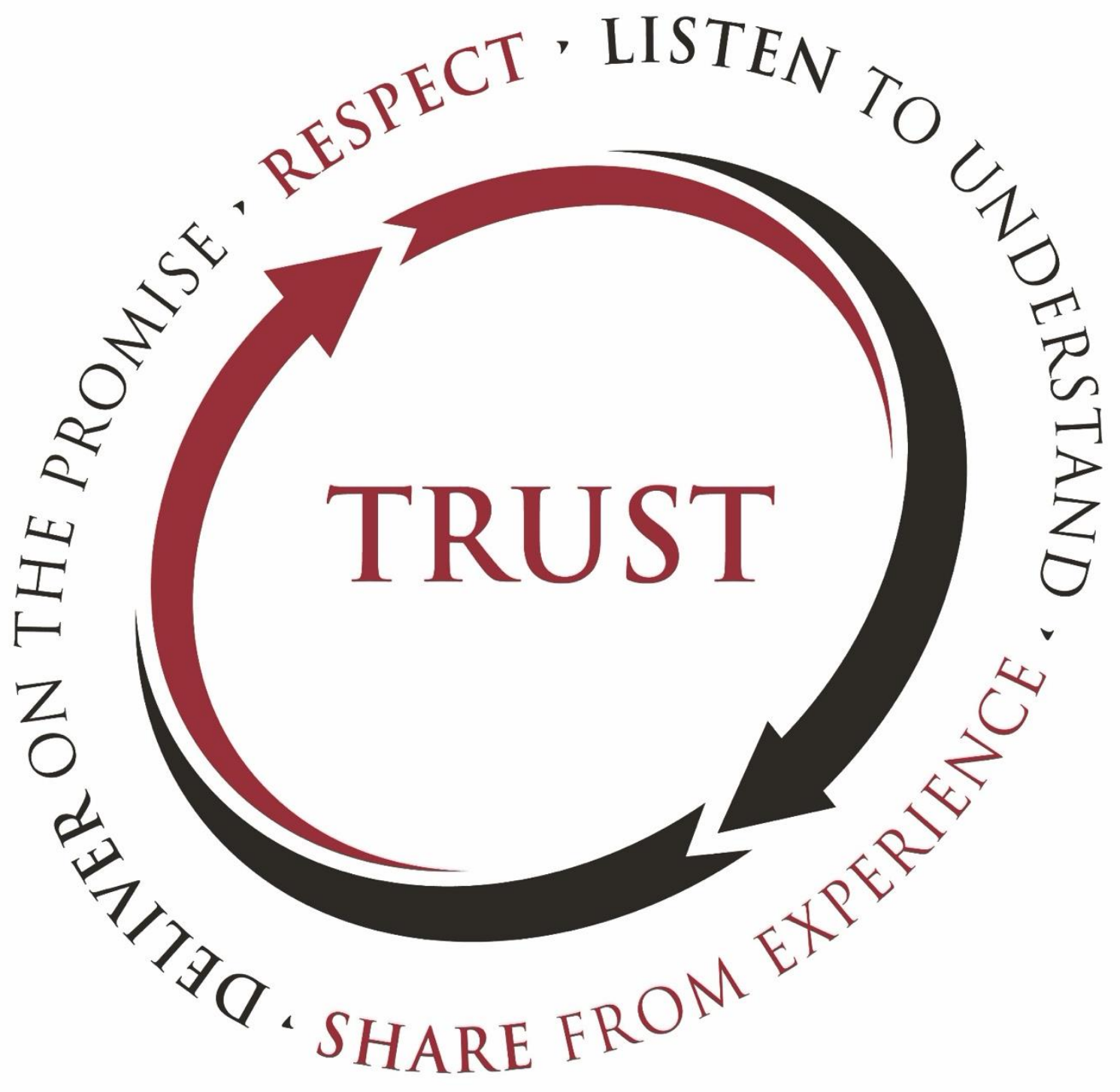




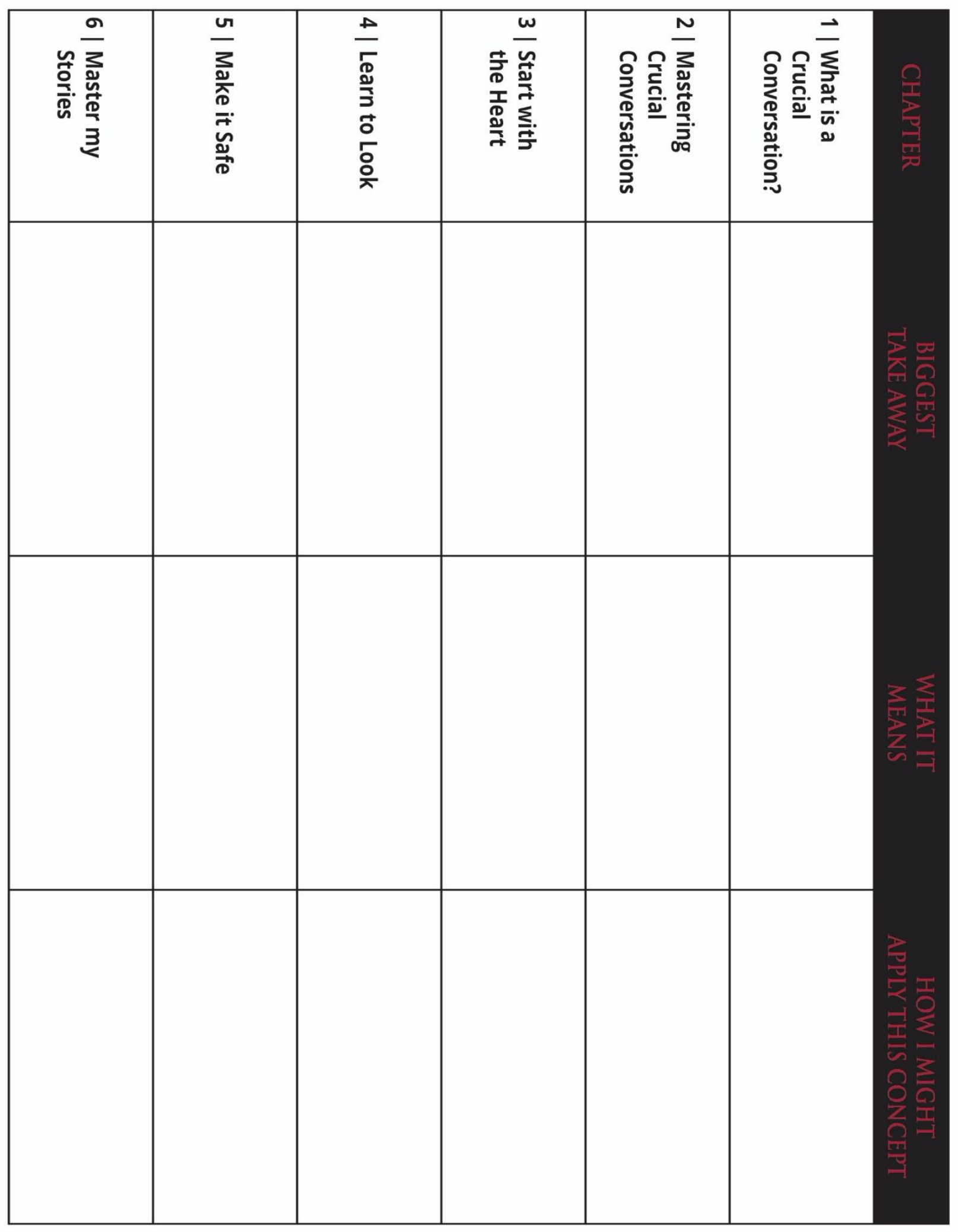




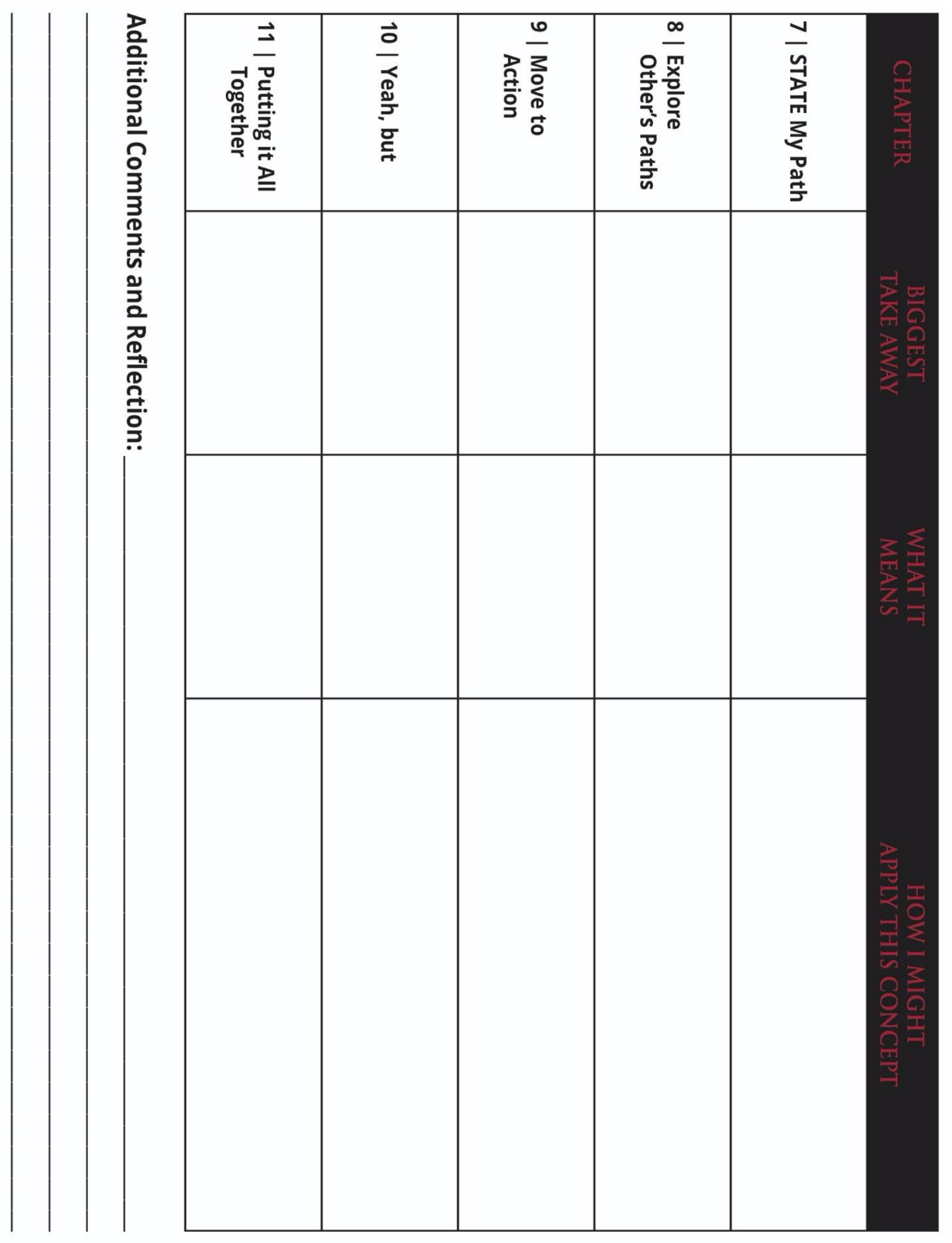




\section{Week 2 Lesson Plan}

Chapter 1-What is a Crucial Conversation? And who cares?

Define a Crucial Conversation-(Stakes are high-Opinions Vary-Emotions strong)

What were the critical take-a-ways for you from the chapter?

What does that concept mean?

How might you apply that concept in your life?

(How we typically handle CC; when it matters most, we do our worst; Kickstart your career; improve your organization; Improve your relationships; improve your personal health)

Nobody likes being told what to do (or how to do it)

How to get consensus: Identify a problem, describe a POTENTIAL solution, and ask, what do you think?

How to assign work: Here is what we need, from who, by when

\section{Assignment for Week 3}

In the coming week, look for a crucial conversation (that does not involve you, or work) one that you believe would be in the best interest of the parties and describe the situation without telling who these folks are. What are the factors that make this a crucial conversation? Why is it important? What do you think stops these people from having the conversation? Provide a potential solution (if you were one of the participants, how might you start this conversation).

Consensus-different dictionaries give slightly different meanings, in general, it comes from the Latin term of the same name to mean agreement. The difference is, do all have to agree on the same thing, or is a consensus the group deciding on what is in the best interest of the group/organization? The consensus is a process by which to make decisions. It is one in which we can all support the outcome. It is participatory, it is collaborative, it is cooperative, yet dissenters are to be heard and an alternate position to be presented and discussed.

Rewards include better decisions, easier implementation, and better relationships. Risks include the time it takes to reach consensus (allowing others to be heard) and the potential of stagnation.

Quote of the Week: Coming together is a beginning, staying together is progress, and working together is success. Henry Ford 


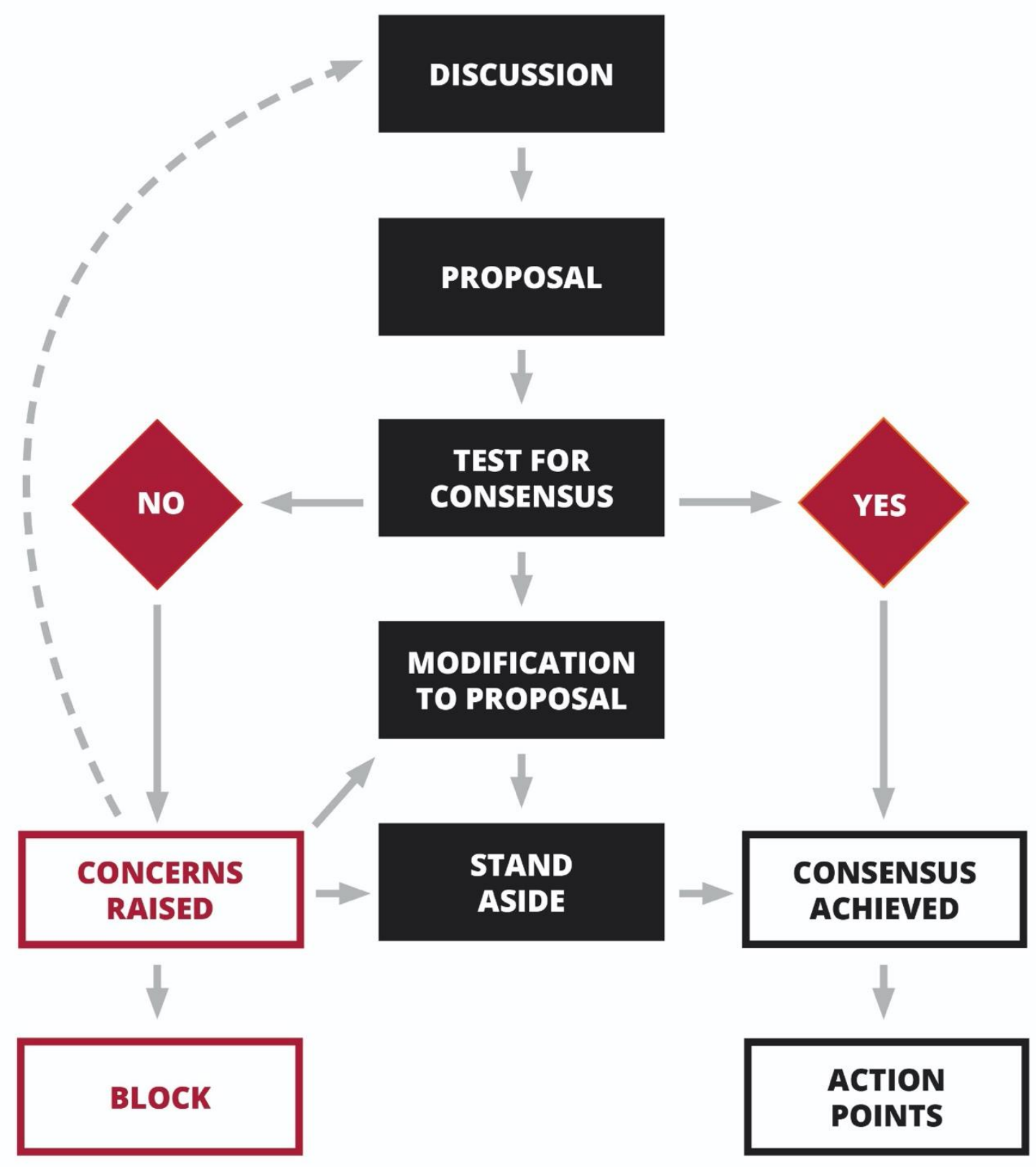




\section{Week 3 Lesson Plan}

Review and Issues from Week 2?

Define the Fool's Choice- (when we feel we need to make a decision based on binary choices)

Chapter 2-Mastering Crucial Conversations-The power of dialogue

What were the key take-a-ways for you from the chapter?

What does that concept mean?

How might you apply that concept in your life?

The pool of shared meaning-what does it mean? Why might it be important? (the pool of shared meaning is the birthplace of synergy)

What was unique about Kevin? Are there any Kevin's in the organization today? What makes them so?

\section{This week's assignment}

In the coming week, look for a crucial conversation (that does not involve you, or work) one that you believe would be in the best interest of the parties and describe the situation without telling who these folks are. What are the factors that make this a crucial conversation? Why is it important? What do you think stops these people from having the conversation? Provide a potential solution (if you were one of the participants, how might you start this conversation).

Consensus Rewards include better decisions, easier implementation, and better relationships.

Risks include the time it takes to reach consensus (allowing others to be heard) and the potential of stagnation, Group Think and anchoring.

\section{Assignment for Week 4}

Chapter 3 and Concept Matrix

Look inside the company for Kevin, bring an example where somebody did not take the fool's choice, brought additional information in the pool of shared meaning, and tactfully challenged power.

Inspiration-power of moving intellect or emotions, (internal)

Motivation-an external force that elicits action, (external)

Quote of the week: There's always the motivation of wanting to win. Everybody has that. But a champion needs, in his attitude, a motivation above and beyond winning. Pat Riley 


\section{Week 4 Lesson Plan}

Issues from Week 3 ?

The pool of shared meaning-what does it mean, why might it be important? (the pool of shared meaning is the birthplace of synergy) The Fool's Choice-Binary decisions, right wrong, fight or flight

Chapter 3-Start with the Heart-How to stay focused on what you really want

How might you apply that concept in your life?

Start with the Heart

Work on me first and us next (What is my part in this?)

1. What is it I really want?

2. What do I want for others?

3. What do I want for the relationship?

4. Bonus Question: Is how I am acting going to allow me to get what I want for the 3 questions above?

\section{Last week's assignment}

Look inside the company for Kevin, bring an example where somebody did not take the fool's choice, brought additional information in the pool of shared meaning, and tactfully challenged power.

\section{This week's assignment}

Assignment for Week 5: Chapter 4 and Concept Matrix

Look for a situation in your own life where conflict was present; describe the situation and the results, including the situational results as well as the relationship results. You may have to step out of your body and look from above to see the real relational results. Now go back and answer the three questions above and a potential alternative for the bonus question.

Humility-as the antithesis of Pride, is humility an honorable trait? What makes it so? If humility is the absence of Pride, is Pride a bad thing? How to practice Humility-talk less listen more, practice mindfulness, express gratitude, look inward-what is my part in this?

Quote of the week: Humility, I have learned, must never be confused with meekness. Humility is being open to the ideas of others. Simon Sinek

\section{Week 5 Lesson Plan}

Issues from Week 4? Review of Week 4

Start with the Heart review (what I want, what I want for others, for the relationship)

Yes, AND. Not but 
Chapter 4 Learn to Look-How to notice when safety is at risk

Content AND Conditions

Physical symptoms; Emotional symptoms in self, what do you notice, what do you think others notice?

"When it is safe, you can say anything" explain this concept.

\section{Last week's assignment discussion}

Look for a situation in your own life where conflict was present; describe the situation and the results, including the situational results as well as the relationship results. You may have to step out of your body and look from above to see the real relational results. Now go back and answer the three questions above and a potential alternative for the bonus question.

Did you take the quiz? Any realizations or reflection?

\section{Assignment for Week 6: Chapter 5 and Concept Matrix}

Have at least two conversations. One with a member of this team, pick someone you feel comfortable with already and discuss an area you would like to improve on, what that area is, and how you might practice what you are becoming aware of. What did you notice in them, in you?

Next, find someone who is not participating in this program and describe what you are going through, what you are reading, and how you are reflecting through writing and discussion and notice the response. Are they interested or not? What kind of questions are they asking you? What questions would you have liked them to ask?

Empathy- a condition of understanding the feelings of others, in contrast to sympathy, where you share the feelings of others.

Quote of the week: When you show deep empathy toward others, their defensive energy goes down, and positive energy replaces it. That's when you can get more creative in solving problems. Stephen Covey 


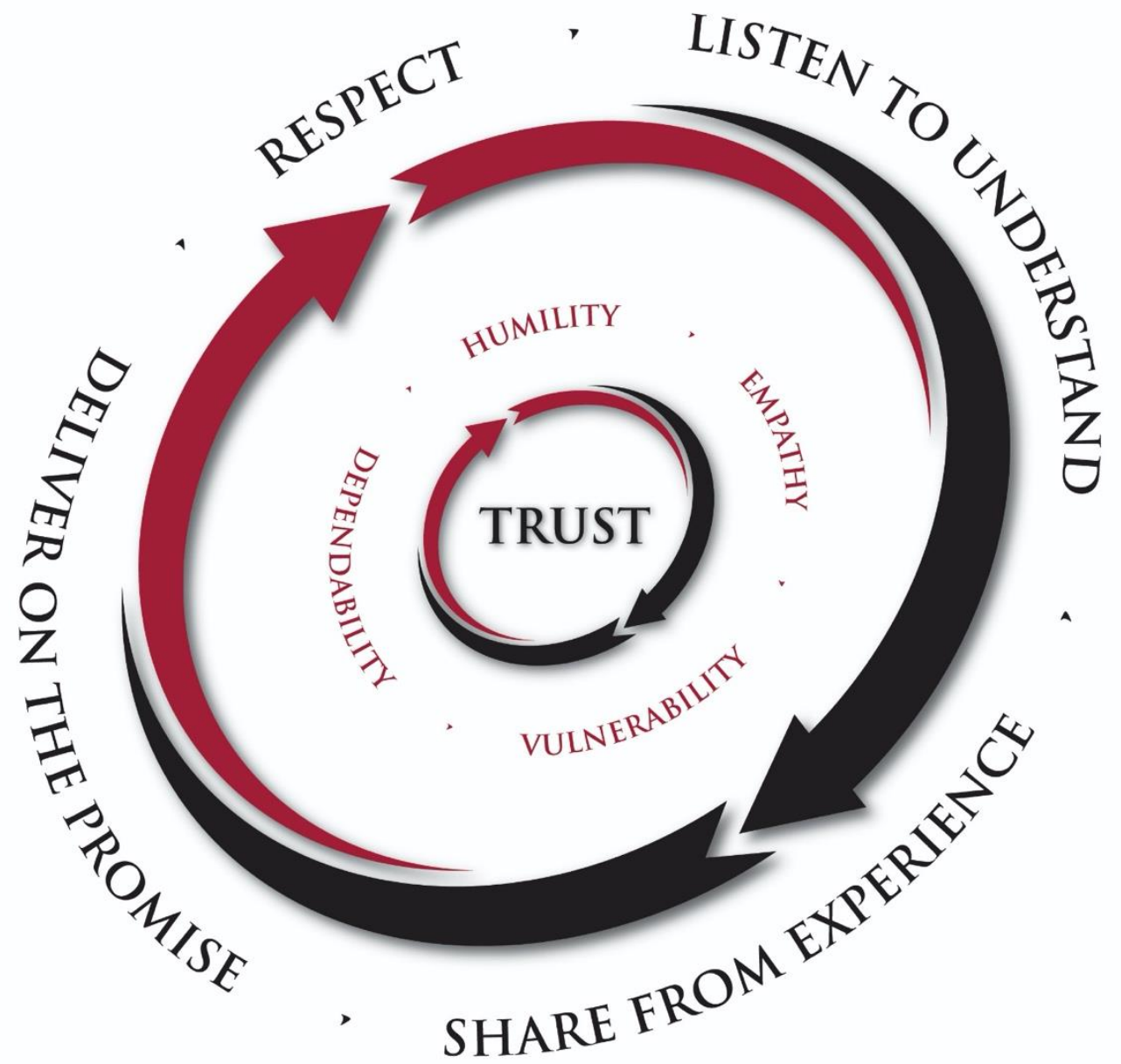

\section{Week 6 Lesson Plan}

Issues from Week 5? Review of week 5 Learn to Look

Content and Conditions

Looking for others using silence or violence

Your personal style under stress

Chapter 5 Make it Safe: How to make it safe to talk to anybody about anything

Step out then step back in

Mutual Purpose-Intentions Mutual Respect (respect is like air) Respecting those who do not respect you. Is this possible? 
Apologize-Contrast-Create Mutual Purpose (CRIB- commit, recognize, invent, brainstorm)

\section{Last week's assignment discussion}

Have at least two conversations. One with a member of this team, pick someone you feel comfortable with already and discuss an area you would like to improve on, what that area is, and how you might practice what you are becoming aware of. What did you notice in them, in you?

Next, find someone who is not participating in this program and describe what you are going through, what you are reading, and how you are reflecting through writing and discussion and notice the response. Are they interested or not? What kind of questions are they asking you? What questions would you have liked them to ask?

\section{Assignment for Week 7:}

\section{Chapter 6 and Concept Matrix}

Look for a conflict that has appeared at work, preferably with someone in the group, but that is not necessary, it could be anybody in the organization and create a strategy surrounding CRIB. Develop your strategy, write it down, then go to the other person and seek agreement to the process, see if we can get common ground on the mutual purpose, AND then brainstorm potential strategies to resolve the conflict around the mutual purpose.

Vulnerability. The state of being exposed to harm, either physically or emotionally. Trust the willingness to be vulnerable to the actions of others based on the expectation of a positive response (Mayer et al. 1995; Rousseau et al., 1998).

Quote of the week: Teamwork begins by building trust. And the only way to do that is to overcome our need for invulnerability. Patrick Lencioni

\section{Week 7 Lesson Plan}

Chapter 6 Master My Stories: How to stay in dialogue when you are angry scared or hurt

Issues from Week 6? Review of Week 6 Make it safe

CRIB (Commit, Recognize, Invent, Brainstorm)

When others misinterpret your INTENT, start with contrasting what I don't want, what I do want Mutual purpose/Mutual Respect APOLOGIZE when appropriate (when is that?)

Concept Matrix discussion on Chapter 6

Fact of story, getting in touch with your feelings, get back to the facts, clever stories (victim, villain, helpless), What is MY part in this?

Can someone make you mad, angry? No, can you feel hurt and express that? Yes. 


\section{Last week's assignment discussion}

Look for a conflict that has appeared at work, preferably with someone in the group, but that is not necessary, it could be anybody in the organization and create a strategy surrounding CRIB. Develop your strategy, write it down, then go to the other person and seek agreement to the process, see if we can get common ground on the mutual purpose, AND then Brainstorm potential strategies to resolve the conflict around the mutual purpose.

\section{Assignment for Week 8}

\section{Chapter 7 and Concept Matrix}

This week's assignment is all about you. Notice any and all conversations where you were triggered this week. What did that look like, what did that feel like, and how did you proceed once you recognized these things. What happened next? Were there differences in the way you reacted with people you

RESPECTED versus those you have to tolerate? Were you able to look at the two different definitions of respect (earned versus humanity) write down your reflections on this process.

Interdependencies- the dependence of two or more people or things on each other. Obvious and important, Manager-subordinate, peers within a department, less obvious and maybe more important to understand cross-functional interdependencies.

Quote of the week: Appearance is something absolute, but reality is not that way - everything is interdependent, not absolute. Dalai Lama

\section{Week 8 Lesson Plan}

Issues from Week 7? Review of chapter 6 Master my Stories

Notice my own behavior-Get in touch with my feelings

Fact or story- what is the story I am telling myself? What is my evidence?

Victim-Villain or Helpless

Chapter 7 State My PATH: How to speak persuasively not abrasively

STATE (Share facts, Tell my story, Ask for other's paths, Talk tentatively, Encourage testing)

To me this chapter is out of sequence, chapter 8 talks about exploring others' paths which I believe should come before telling my story if I want them to feel at ease, and that I am a partner in this discussion.

\section{Last week's assignment discussion}

This week's assignment is all about you. Notice any and all conversations where you were triggered this week. What did that look like, what did that feel like, and how did you proceed once you recognized these things. What happened next? Were there differences in the way you reacted with people you

RESPECTED versus those you have to tolerate? Were you able to look at the two different definitions of respect (earned versus humanity), write down your reflections on this process. 


\section{Assignment for Week 9: Chapter 8 and Concept Matrix}

This week's assignment is to look for other's triggers. Please do not tell who you are noticing. This week is about the awareness of others, particularly in the workforce. Look for body language, including facial cues, tone, inflection, or speed in which they use their voice. Once you recognized a trigger, what did you do?

Communication statistics:

In terms of importance, people allocate $7 \%$ to words, $38 \%$ to the tone of voice, and $55 \%$ to nonverbal behaviors. For effective communication, these aspects have to support one another...nonverbal communication tops words $100 \%$ of the time. Judith Glaser, Conversational Intelligence

Quote of the week: To get to the next level of greatness depends on the quality of our culture, which depends on the quality of our relationships, which depends on the quality of our conversations. Judith E. Glaser Conversational Intelligence

\section{Week 9 Lesson Plan}

Issues from Week 8? Review of Week 8 STATE my path

STATE (Share facts, Tell my story, Ask for other's paths, Talk tentatively, Encourage testing)

Say what I mean just don't say it mean

Chapter 8 Explore other's paths: How to listen when others blow up or clam up

"You will never work through your differences until all parties freely add to the pool of meaning" p.156

"You can't force others to dialogue; you can make it safe for them to do so" p.156

Be Sincere, Curious, Patient-Stay curious It requires Listening!

Creating safety through tone of voice, body language, and remain calm and collected/don't push too hard. Just because I am listening to you does not mean I have to agree with you.

Agree-Build-Compare, your thoughts on this?

\section{Last week's assignment discussion}

Last week's assignment is to look for other's triggers. Please do not tell who you are noticing. This week is about the awareness of others, particularly in the workforce. Look for body language, including facial cues, tone, inflection, or speed in which they use their voice. Once you recognized a trigger, what did you do?

\section{Assignment for Week 10}

Chapter 9 and Concept Matrix 
Find a problem that is happening at work, where someone from another department comes to you or your department and tells you that they have a problem. 1. Ask them what do they think the solution should be? 2. When you do provide your potential solution, ask them for their thoughts on your potential solution. Notice and write about their reactions.

This assignment uses two approaches we have discussed 1. Identify the problem, here is a POTENTIAL solution, then ask, "What do you think?" And 2. If someone brings a problem without a potential solution, they are just bitching, and I don't have time for that

Quote of the week: Humble Inquiry is the skill and art of drawing someone out, of asking questions to which you do not know the answer, of building a relationship based on curiosity and interest in the other person" Edgar H. Schein, Humble Inquiry: The gentle art of asking instead of telling.

\section{Week 10 Lesson Plan}

Issues from Week 9? Review Chapter 8: Exploring other's paths

Ask, Mirror, Paraphrase, Prime

Agree, Build, Compare

Be Curious, Patient, Stay Curious, it is all about listening!

Chapter 9 Move to action: How to turn crucial conversations into action and results

Decide how to decide-Up front; this causes harm when a leader makes a decision others believe should have been a vote. Command- Consult-Vote-Consensus

Here is what we/I need from who and by when solves a myriad of problems. What does follow up look like?

\section{Last week's assignment discussion}

Find a problem that is happening at work, where someone from another department comes to you or your department and tells you that they have a problem. 1. Ask them what do they think the solution should be? 2. When you do provide your potential solution, ask them for their thoughts on your potential solution. Notice and write about their reactions.

This assignment uses two approaches we have discussed 1. Identify the problem, here is a POTENTIAL solution, then ask "What do you think?" And 2. If someone brings a problem without a potential solution they are just complaining, I don't have time for that!

\section{Assignment for Week 11}

Chapter 10 and Concept Matrix

This is a Repeat assignment from Week 9 
Find a problem that is happening at work, where someone from another department comes to you or your department and tells you that they have a problem. 1. Ask them what do they think the solution should be? 2. When you do provide your potential solution, ask them for their thoughts on your potential solution. Notice and write about their reactions.

\section{Quotes of the week:}

It is the long history of humankind (and animal kind, too) that those who learned to collaborate and improvise most effectively have prevailed. Charles Darwin

It is not necessary to change. Survival is not mandatory. W. Edwards Deming

\section{Week 11 Lesson Plan}

Issues from Week 10? Review Chapter 9: Exploring other's paths

Decide how to decide-Up front this causes harm when a leader makes a decision others believe should have been a vote.

\section{Command- Consult-Vote-Consensus}

Here is what we/I need from who and by when solves a myriad of problems. What does follow up look like?

Chapter 10 Yeah, but: Advice for tough cases

Start with the Heart-what are my outcomes I am looking for

Learn to look

Make it safe

Master my stories

State my path

Explore other's paths

Move to action

\section{Last week's assignment discussion}

Find a problem that is happening at work, where someone from another department comes to you or your department and tells you they have a problem. 1. Ask them what do they think the solution should be? 2. When you do provide your potential solution, ask them for their thoughts on your potential solution. Notice and write about their reactions.

\section{Assignment for Week 12}

Chapter 11 and Concept Matrix

Find one of your Ya, Buts and write it out, what are the issues that are too difficult to face. Write out a potential solution to your individual situation. Answer what are the outcomes you are looking for, what are the barriers, and which techniques could you apply to overcome the barriers. Then try it out. What 
emotions came up for you, what did you notice in the other person. Did you have to step back, if so did you step back in, what did you do in the meantime to get back on track. How did it turn out.

Quote of the week: We know only too well that what we are doing is nothing more than a drop in the ocean. But if the drop were not there, the ocean would be missing something. Mother Teresa

\section{Week 12 Lesson Plan}

Issues from Week 11? Review Chapter 10: Tough Cases

Go through the process-Start with the Heart, Learn to look, Make it Safe, Master my Stories, State my path, Explore others path's and Move to action

Chapter 11 Putting it all together

Learn to Look-at others, at self-do you have a coach? (someone here)" I think we have moved from dialogue" (what are your triggers, and what do you do when you recognize them?)

Make it safe for the other-Listen to Understand "comfort in I understand-similar to the nurse's touch."

Use the table on pages 214-216 in Crucial Conversations as a refresher

\section{Last week's assignment discussion}

Find one of your Ya, Buts and write it out, what are the issues that are too difficult to face. Write out a potential solution to your situation. Answer what the outcomes you are looking for, what the barriers are, and which techniques you could apply to overcome the obstacles are. Then try it out. What emotions came up for you, what did you notice in the other person. Did you have to step back, if so did you step back in, what did you do in the meantime to get back on track. How did it turn out?

\section{Assignment for next week, our last week together.}

This week's exercise may be the most time-consuming. I am asking you to write a blog article, 600 to 800 words, about one piece of this experience. To do this, you may want to look at a few other blogs on that topic and synthesize your learning. The goal of the blog is to encourage or better yet inspire others to want to dive deeper into the subject you are describing. See the attached sign-up sheet for topics. Your article needs to reference three other pieces of work, they could be Crucial conversations, a video, another blog, and create a hyperlink to that article use hyperlinks to reference the other places you can send your readers.

https://www.vitalsmarts.com/resource/crucial-conversations-book/

https://lead2goals.com/blog/

https://www.ted.com/talks/brene_brown_on_vulnerability?language=en

Quote of the week: The more that you READ, the more things you know, the more you LEARN, the more places you'll GO. Dr. Suess 


\section{The Blog Sign-Up Sheet for Week 13}

Intention

Sincerity

Respect

Trust

Vulnerability

Empathy

Humility

Listen to Understand

Share from Experience

Deliver on the promise

Cross Functional Work Groups 

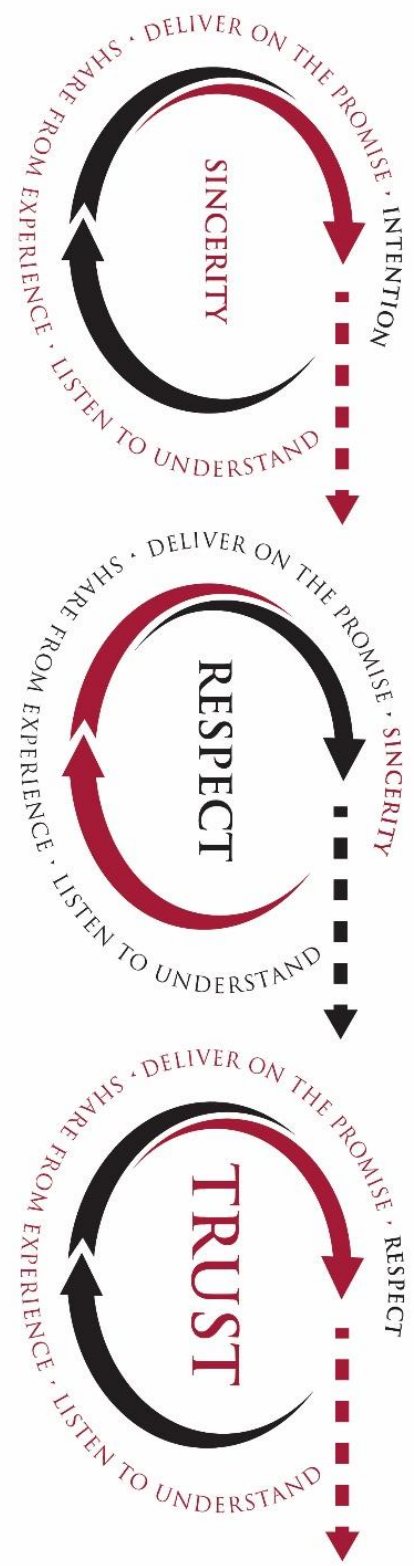

$$
\text { 疋 }
$$




\section{Week 13 Lesson Plan}

Issues from Week 12? Review Chapter 11: Tough Cases

Go through the process-Start with the Heart, Learn to look, Make it Safe, Master my Stories, State my path, Explore others path's and Move to action

Chapter 11 Putting it all together

\section{Last week's assignment discussion}

Write a blog article, 600 to 800 words Assignment in preparation for the focus group.

Read each Blog Article (for those willing)

Preparation for the focus Group

Re-read your concept matrix and any notes you took when others were speaking. Think about the stories we told during the course. Talk to your cohort about what struck you about the benefits of the course. Think about what you liked and what you thought could have been done better. Did this course make you Respect, Trust the group? Did the stories inspire you to want to know more about this group?

\section{Assignment to make this program really set in:}

Re-read the book (or listen to it). Talk to the people in your department and INSPIRE them with your style, do not push anybody to read; they will want to if they are inspired. Become the teacher without being the preacher.

Post Test

Final Reflections on the course

Quote of the week: Find a group of people who challenge and inspire you, spend a lot of time with them, and it will change your life. Amy Poehler 


\section{Appendix D: Course Syllabus}

\section{Course Description}

In a world where we attempt to balance the demands of our professional life, and those of our personal lives, many of us have forgotten the lessons we learned on the playground. If you remember back to your childhood, you may recall that by making friends, our lives became a little easier, and a whole lot more fun. In our adult world, the stress and pressures we all deal with daily have gotten us out of the simple concepts we learned in the sandbox. Treat each other with respect, listen, and emphasize with their story, share your story with others, and always do what you say you are going to do. Can we do that in the workplace? Would those elements allow us to be more productive and have a little fun?

This course is designed to walk through the lessons we learned as children, and relearn the techniques through our adult lens. Critical to the learning is the desire to take a look at our own behaviors, understand how others may view them, and do some hard work. This course combines adult learning and leadership theories with practice implementing concepts and techniques that will allow you to become a better communicator.

\section{Program Learning Outcomes}

- Identify when a topic becomes a crucial conversation;

- Understand the value of listening to understand;

- Develop the skills to share information with others without eliciting confrontation; and

- Discover how to mitigate conflict, encourage dialogue, and create synergistic resolutions.

\section{Course Objectives}

- Articulate the theory behind the Circle of Trust and what parts communication plays in theory.

- Develop the communication skills to turn a group into a team.

- Apply the theories into practice in your work and home life.

\section{Required Text}

Patterson, K., Grenny, J., McMillan, R., \& Switzler, A. (2012). Crucial conversations: Tools for talking when stakes are high. New York, NY: McGraw Hill

\section{Supplemental Reading}

Schein, E. (2013). Humble inquiry: The gentle art of asking instead of telling. Oakland, CA: BerrettKoehler. 


\section{Time commitment and Expectations}

Each week for 13 consecutive weeks, the group will meet for 90 minutes at the same time on the same day and in your company's conference room. Also, you will be required to read one chapter per week of crucial conversations, which takes approximately 30 minutes. You are also required to write a summary of the reading in the concept matrix, which may take an additional 15 minutes.

The expectations are for each participant to be at every session, have read the assigned chapter, and completed the concept matrix for that chapter. We do understand that there may be circumstances that prevent a participant from being present each week. However, the expectations are that even if you cannot attend the class, that you read the chapter and complete all assignments. If a participant misses more than three classes, they will be excused from the course.

\section{Class process}

The classroom portion of the course will follow a general pattern, which includes a brief introduction to the week's topic. Then we go to each participant and read from their concept matrix the first two categories, what was the biggest takeaway, and what does that mean. When this is finished, we will find the themes and dive deeper with those who wish to describe the third section of the concept matrix, how might I apply this concept? We will finish the class with an introduction to the next section, and preparation for the following week.

Week $1 \quad$ Introductions, Expectations, Pretest, Circle of Trust, Week 2 assignment

Week 2 Chapter 1, Crucial Conversation Round Table, Week 3 assignment

Week $3 \quad$ Chapter 2, The Power of Dialogue, Round Table, Week 4 assignment

Week $4 \quad$ Chapter 3, Start with the Heart, Round Table, Week 5 assignment

Week 5 Chapter 4, Learn to Look for Safety, Round Table, Week 6 assignment

Week $6 \quad$ Chapter 5, Make it Safe, Round Table, Week 7 assignment

Week 7 Chapter 6, Master my Stories, Round Table, Week 8 assignment

Week $8 \quad$ Chapter 7, State my Path, Round Table, Week 9 assignment

Week 9

Week 10

Week 11

Week 12

Week 13

Chapter 8, Explore other's Paths, Round Table, Week 10 assignment

Chapter 9, Move to Action, Round Table, Week 11 assignment

Chapter 10, Advice for tough cases, Round Table, Week 12 assignment

Chapter 11, Putting it all together, Round Table, the final assignment

Round Table, Lessons learned, what we will take away \& Posttest 


\section{Appendix E: The Behavioural Trust Inventory (Team Version)}

Please indicate how willing you are to engage in each of the following behaviours with your team, by circling a number from 1 to 7 .

How willing are you to do the following with your team?

1. Rely on your team's collective task related skills and abilities.

\begin{tabular}{ccccccc}
\multicolumn{2}{c}{$\begin{array}{l}\text { Not at all } \\
\text { willing }\end{array}$} & \multicolumn{3}{c}{$\begin{array}{c}\text { Completely } \\
\text { willing }\end{array}$} \\
\hline 1 & 2 & 3 & 4 & 5 & 6 & 7 \\
1 & 2 & 3 & 4 & 5 & 6 & 7 \\
1 & 2 & 3 & 4 & 5 & 6 & 7 \\
1 & 2 & 3 & 4 & 5 & 6 & 7 \\
1 & 2 & 3 & 4 & 5 & 6 & 7 \\
1 & 2 & 3 & 4 & 5 & 6 & 7 \\
1 & 2 & 3 & 4 & 5 & 6 & 7 \\
1 & 2 & 3 & 4 & 5 & 6 & 7 \\
1 & 2 & 3 & 4 & 5 & 6 & 7 \\
1 & 2 & 3 & 4 & 5 & 6 & 7
\end{tabular}

The Behavioural Trust Inventory is being used with the permission of Dr. Nicole Gillespie.

Personal Identifiable Information to be kept Anonymous, the following is for statistical analysis

Name:

Title:

Department:

Gender:

Circle one: Age:18-35, 36-50, 50-65

Circle one: Education: HS, AA. BA/BS, MA/MS, JD/PhD 


\section{Appendix F: The Behavioural Trust Inventory (Team Version) Posttest}

Please indicate how willing you are to engage in each of the following behaviours with your team, by circling a number from 1 to 7 .

How willing are you to do the following with your team?

1. Rely on your team's collective task related skills and

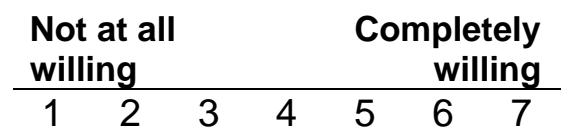
abilities.

2. Depend on your team to handle an important issue on your behalf.

3. Rely on your team to represent your work accurately to others.

4. Depend on your team to back you up in difficult situations.

5. Rely on your team's collective work-related judgements.

6. Share your personal feelings with your team.

7. Discuss work-related problems or difficulties with your team that could potentially be used to disadvantage you.

8. Confide in your team about personal issues that are affecting your work.

9. Discuss how you honestly feel about your work, even negative feelings and frustration.

10. Share your personal beliefs with your team.

$\begin{array}{lllllll}1 & 2 & 3 & 4 & 5 & 6 & 7 \\ 1 & 2 & 3 & 4 & 5 & 6 & 7 \\ 1 & 2 & 3 & 4 & 5 & 6 & 7\end{array}$

The Behavioural Trust Inventory is being used with the permission of Dr. Nicole Gillespie.

Personal Identifiable Information to be kept Anonymous, the following if for statistical analysis

Name: 


\section{Appendix G: Observer's Role and Responsibility}

\section{Observer's name: Lisa Boskovich}

This document is to capture the role and responsibilities of the observer for the intervention portion of the dissertation study of R. Scott De Long. The observer will be present in at least two of the classes for each participant group. These appearances will be during Week 1 and Week 7 for each group. The purpose of multiple appearances is to (a) Ensure the groups have exposure to the observer prior to the focus group, and (b) Provide a source of inter-rater reliability for the study.

1. The role of the observer is to document in the form of field notes the following:

a. The facilitator has complied with the procedures set for the study

i. Informed consent documentation and explanation

ii. A consistent approach in teaching the course

b. The application of a consistent demeanor/approach by the facilitator

c. Documentation of participant's demeanor/participation during course work

d. Any additional notes or observations noted during the course work.

2. The observer will be present during the focus group session for each participant group. The role of the observer for the focus group is to:

a. Ensure the facilitator is adhering to the semi-structured questioner approved by IRB.

b. Note any discrepancies or differences in the approach of the facilitator between participant groups.

c. Documentation of participant's demeanor/participation during the focus group.

3. The observer and facilitator will meet within 30 minutes of each scheduled session the observer participates in and share their observations and notes. In addition, the observer will use a rubric established for each session, document their observations, and submit the rubric to the facilitator for inclusion in the study.

The observer shall be paid a fee of $\$ 250$ for her time and expertise.

Offered by:

R. Scott De Long-Facilitator
Accepted by: Lisa Boskovich

Lisa Boskovich-Observer 


\section{Appendix H: Semi-Structured Focus Group Question Guide}

After a brief introduction of the process, and thank the participants for their involvement, I will start the session with

Opening Questions (designed to allow the participant to feel at ease and get each of them talking early in the process)

Please remember back to the first day of this course and tell us in your own words why you remember saying when I asked, "Tell me why you are here, why you volunteered and what it is that you are expecting out of this course?"

Transition Questions (designed to get the participants prepared to be thinking of the program and what they have learned)

These will come from the opening questions, and will specifically ask how the course work related to their expectations. If the course was not what they thought it would be, can they describe what they now believe it to be about?

For those who seemed to have expectations aligned with the coursework. "were your expectations met or not, can you describe why or why not? If a general statement is made on why, I will dig down and ask specifically, what were some of the issues that either led or failed to meet your expectations?

Key Questions (these get to the heart of the research questions)

Can you define empathic listening?

What role did empathic listening play in the development of trust within this group?

What issues presented themselves (if any) that blocked empathic listening from being used?

Can you describe the Gestalt language protocol?

What role does GLP play in the development of trust?

What issues presented themselves (if any) that blocked this protocol from being used?

What were some of the most impactful lessons you learned during the sessions?

What lessons or exercises could have been done better? How would you redo those?

Closing Questions (after thanking them again for their participation and honesty)

Is there anything else you would like to say about the program, the process, or your team we did not discuss yet? 
Appendix I

Please mark each of the following questions from 1 to 5.

$1=$ strongly disagree, $2=$ disagree, $3=$ neither disagree or agree, $4=$ agree, $5=$ strongly

agree

The course was successful in delivering the stated Program Learning Outcomes

Identify when a topic becomes a crucial conversation;

Understand the value of listening to understand;

Develop the skills to share information with others without eliciting confrontation; and

Discover how to mitigate conflict, encourage dialogue, and create synergistic resolutions.

\section{The course was successful in delivering on the stated Course Objectives}

Articulate the theory behind the Circle of Trust and what parts communication plays in the theory.

Develop the communication skills to turn a group into a team.

Apply the theories into practice in your work and home life.

\section{Course Tools}

The textbook chosen was appropriate for the learning outcomes

The concept matrix was a useful guide to assist my understanding of the content

The homework assignments added to my understanding of the content

\section{Facilitator}

The facilitator was knowledgeable and well prepared

The facilitator treated me with respect

The facilitator provided useful guidance

\section{Content}

The skills learned aided with relationships inside the workplace

The skills learned aided with relationships outside the work place

\section{Professional development}

The skills learned are relevant in my current work position

The skills learned will aid in my future performance evaluations 
Appendix I

Please mark each of the following questions from 1 to 5.

$1=$ strongly disagree, $2=$ disagree, $3=$ neither disagree or agree, $4=$ agree, $5=$ strongly

agree

The course was successful in delivering the stated Program Learning Outcomes

Identify when a topic becomes a crucial conversation;

Understand the value of listening to understand;

Develop the skills to share information with others without eliciting confrontation; and

Discover how to mitigate conflict, encourage dialogue, and create synergistic resolutions.

\section{The course was successful in delivering on the stated Course Objectives}

Articulate the theory behind the Circle of Trust and what parts communication plays in the theory.

Develop the communication skills to turn a group into a team.

Apply the theories into practice in your work and home life.

\section{Course Tools}

The textbook chosen was appropriate for the learning outcomes

The concept matrix was a useful guide to assist my understanding of the content

The homework assignments added to my understanding of the content

\section{Facilitator}

The facilitator was knowledgeable and well prepared

The facilitator treated me with respect

The facilitator provided useful guidance

\section{Content}

The skills learned aided with relationships inside the workplace

The skills learned aided with relationships outside the work place

\section{Professional development}

The skills learned are relevant in my current work position

The skills learned will aid in my future performance evaluations 
What about the class did you find most useful?

What about the class did you find least useful?

In what ways could we improve this training to make it more relevant to your current position?

Additional Comments:

Date:

Name (optional): 